JULIANA ELSTON GOLDMAN

\title{
AVALIAÇÃO LONGITUDINAL DA ADESÃO À DENTINA IRRADIADA PELO LASER DE Er,Cr:YSGG
}




\section{Juliana Elston Goldman}

Avaliação longitudinal da adesão à dentina irradiada pelo laser Er,Cr:YSGG

Dissertação apresentada à Faculdade de Odontologia da Universidade de São Paulo, para obter o título de Mestre, pelo programa de Pós-Graduação em Odontologia.

Área de Concentração: Dentística

Orientadora: Profa. Dra. Ana Cecília Corrêa Aranha

São Paulo 
Catalogação-na-Publicação

Serviço de Documentação Odontológica

Faculdade de Odontologia da Universidade de São Paulo

\section{Goldman, Juliana Elston}

Avaliação longitudinal da adesão à dentina irradiada pelo laser Er,Cr:YSGG / Juliana Elston Goldman; orientador Ana Cecília Corrêa Aranha. -- São Paulo, 2009.

98p. : tab., fig.; $30 \mathrm{~cm}$.

Dissertação (Mestrado - Programa de Pós-Graduação em Odontologia. Área de Concentração: Dentística) -- Faculdade de Odontologia da Universidade de São Paulo.

1. Dentina - Resistência de união (Odontologia) - Laser 2. Dentística

\section{AUTORIZO A REPRODUÇÃO E DIVULGAÇÃO TOTAL OU PARCIAL DESTE TRABALHO, POR QUALQUER MEIO CONVENCIONAL OU ELETRÔNICO, PARA FINS DE ESTUDO E PESQUISA, DESDE QUE CITADA A FONTE E COMUNICADA AO AUTOR A REFERÊNCIA DA CITAÇÃO.}

São Paulo,

Assinatura:

E-mail: 


\section{FOLHA DE APROVAÇÃO}

Goldman JE. Avaliação longitudinal da adesão à dentina irradiada pelo laser Er,Cr:YSGG [Dissertação de Mestrado]. São Paulo: Faculdade de Odontologia da USP; 2009.

São Paulo, / / 2009

\section{Banca Examinadora}

1) $\operatorname{Prof}(\mathrm{a}) . \operatorname{Dr}(\mathrm{a})$.

Titulação:

Julgamento:

Assinatura:

2) $\operatorname{Prof}(a) . \operatorname{Dr}(a)$

Titulação:

Julgamento:

Assinatura:

3) $\operatorname{Prof}(a) \cdot \operatorname{Dr}(a)$.

Titulação:

Julgamento:

Assinatura: 


\section{DEDICATÓRIA}

Aos meus pais, Marisa e Bernardo, meus exemplos na profissão. Dedico a eles, que dedicam sua vida e seu amor à mim e à minha irmã, todas as minhas conquistas. Agradeço todo o seu empenho em criar um ambiente próprio para que eu pudesse me dedicar aos estudos. Meu amor por vocês cresce a cada instante.

À minha irmã Fernanda, minha melhor amiga e companheira. Obrigada pelo grande valor que sempre deu a todas as minhas realizações. Estaremos sempre juntas.

Ao meu querido Rodolfo, meu grande companheiro por toda a vida. Muito obrigada por sempre acreditar em mim e me incentivar a buscar o melhor. Seu carinho e compreensão tiveram grande importância neste projeto. 


\section{AGRADECIMENTOS}

À minha orientadora, Profa. Dra. Ana Cecília Corrêa Aranha, que sempre terei como exemplo de competência, tanto na vida profissional como pessoal. Muito obrigada pela orientação no trabalho e por acreditar e mim. Serei sempre grata pela oportunidade de trabalhar com você.

Ao Prof. Dr. Glauco Fioraneli Vieira, meu orientador na Iniciação Científica, que me proporcionou a primeira oportunidade de trabalhar no Departamento de Dentística. Meus sinceros agradecimentos por sua amizade e por estar sempre por perto, me ajudando de todas as formas.

À Profa. Dra. Patrícia Moreira de Freitas, por sua disponibilidade em ajudar e pela sua amizade.

Ao Prof. Dr. Marcelo Oliveira, que foi uma referência durante o período de elaboração desta pesquisa.

À Profa. Dra. Adriana Bona Matos, pelos ensinamentos durante a graduação e pós graduação.

Ao Prof. Dr. José Augusto Rodrigues e à Profa. Dra. Giselle Maria Marchi Baron, por terem gentilmente aceitado o convite de participar da banca examinadora.

Ao Prof. Dr. Washington Steagall Jr., pela fundamental ajuda na análise estatística deste trabalho e pela amizade de longa data.

A todos os professores do Departamento de Dentística, pelos conhecimentos transmitidos e exemplos profissionais.

Aos meu avós maternos, Neyde e Julio, paternos, Bernardo e Lourdinha e tios, tias e primos pelo amor incondicional e presença em minha vida.

Ao meu avô Bernardo Goldman, por dedicar sua carreira jurídica à causa científica, exercendo um papel relevante na criação da carreira de Pesquisador Científico.

Aos meus sogros Leonice e Seiki, pelo carinho e dedicação em oferecer todo o conforto possível.

Às minhas amigas de graduação e pós-graduação Amanda, Bruna, Camila e Débora, pelo inabalável companheirismo em momentos importantes.

A todos os meus colegas de Pós-Graduação. Seus conhecimentos e companhia foram de fundamental importância para superar os desafios do curso. 
Às minhas amigas do Dante, presença constante em minha vida desde a infância. Muito obrigada por fazerem parte de mim.

À colega de pós-graduação Simone Moretto, pelas informações oferecidas em todas as etapas da pesquisa e pela disposição em ajudar.

À Dra. Gabriela Boraks e à Esther, por terem viabilizado a realização deste trabalho através de doações ao Banco de Dentes.

Ao Laboratório de Papel e Celulose do IPT, pelo auxílio com os ensaios de microtração.

À equipe do LELO, pela maneira tão atenciosa como fui atendida sempre que estive lá.

Aos funcionários da biblioteca da FOUSP, pelo grande auxílio prestado durante todo o curso, tanto para a obtenção das referências bibliográficas como na orientação sobre as normas de escrita.

À Faculdade de Odontologia da Universidade de São Paulo, representada pelo seu diretor Prof. Dr. Carlos de Paula Eduardo.

À Universidade de São Paulo, representada pela Magnífica Reitora Profa. Dra. Suely Vilela.

A todos os funcionários da FOUSP, por sua atenção e apoio durante todos os anos de estudo.

Ao $C N P Q$, pela concessão da bolsa de estudos. 
Há um tempo em que é preciso abandonar as roupas usadas, que já tem a forma do nosso corpo, e esquecer os nossos caminhos, que nos levam sempre aos mesmos lugares. É o tempo da travessia: e, se não ousarmos fazê-la, teremos ficado, para sempre, à margem de nós mesmos. 
Goldman JE. Avaliação longitudinal da adesão à dentina irradiada pelo laser Er,Cr:YSGG [Dissertação de Mestrado]. São Paulo: Faculdade de Odontologia da USP; 2009.

\section{RESUMO}

O laser de Er,Cr:YSGG se apresenta como um aliado aos procedimentos minimamente invasivos. Porém, pouco se sabe sobre a longevidade da resistência de união à dentina irradiada por este equipamento. Dessa forma, o objetivo deste estudo foi avaliar a resistência de união à dentina irradiada após 90 dias de armazenamento. Para tanto, foram utilizados 64 molares humanos hígidos, que tiveram as superfícies oclusais desgastadas até a exposição de uma superfície de dentina. Esta superfície foi tratada com: abrasão com lixa SiC 600\# (controle) e irradiação com o laser de Er,Cr:YSGG em $2 \mathrm{~W}\left(90,9 \mathrm{~J} / \mathrm{cm}^{2}\right)$ ou $4 \mathrm{~W}\left(181,8 \mathrm{~J} / \mathrm{cm}^{2}\right)$. Foram utilizados os seguintes sistemas adesivos: Adper Single Bond (3MESPE), Clearfil SE (Kuraray) ou Clearfil S3 (Kuraray), e a confecção de um bloco de resina composta Z250-3MESPE. Os dentes foram seccionados para a obtenção de palitos para o teste de microtração. Metade dos palitos foi ensaiada imediatamente, e a outra metade após 90 dias de armazenamento em água destilada. Os resultados mostraram que em todos os grupos em que foi utilizado o laser Er,Cr:YSGG apresentaram os menores valores de resistência adesiva. Com exceção do grupo controle/Clearfil S3, todos os grupos apresentaram decréscimo nos valores de resistência adesiva após os 90 dias de armazenamento. Entre os sistemas adesivos utilizados, o Single Bond apresentou os melhores valores de resistência adesiva, demonstrando maior estabilidade frente aos 90 dias de desafio/armazenamento.

Palavraschave: Laser de Er,Cr:YSGG, microtração, longevidade, interface adesiva 
Goldman JE. Avaliação longitudinal da adesão à dentina irradiada pelo laser Er,Cr:YSGG. [Dissertação de Mestrado]. São Paulo: Faculdade de Odontologia da USP; 2009.

\begin{abstract}
In the minimally invasive dentistry, the Er,Cr:YSGG laser has been considered as an efficient equipment. However, little is known about the longevity of the bond strength to irradiated dentin. So, the objective of this study was to evaluate the bond strength values to laser irradiated dentin after 90 days storage. Sixty-four sound human molars were used. A flat coronal dentin surface was obtained by removing the oclusal enamel with a slow speed diamond saw. Dentin surfaces were treated with: abrasion with SiC 600\# (control group) and laser irradiation with Er,Cr:YSGG in 2W or 4W. Subsequently, adhesive systems were used: Adper Single Bond (3MESPE), Clearfil SE (Kuraray) or ClearfilS3 (Kuraray). After adhesive procedures, a block of Z250-3MESPE composite resin was build up on each tooth. The teeth were sectioned in order to obtain samples for the microtensile bond strength test. Half of the samples was tested immediately, and the other half were stored for 90 days in distilled water. The results showed that all the groups in which laser was used presenter lower bond strength values. With the exception of Clearfil S3/control group, all groups showed weaker bond strength after 90 days of storage. Among all the adhesives systems used, Single Bond presented the best results, showing more stability after 90 days of storage.
\end{abstract}

Keywords: Er,Cr:YSGG laser, microtensile, longevity, adhesive interface 


\section{SUMÁRIO}

p.

1 INTRODUÇÃO...................................................................................... 9

2 REVISÃO DE LITERATURA................................................................... 12

2.1 - Utilização do laser na estrutura dental............................................ 12

2.2 Morfologia da dentina irradiada pelos lasers de érbio............................. 15

2.3 Adesão à dentina irradiada.......................................................... 18

3 PROPOSIÇÃO.............................................................................. 27

4 MATERIAIS E MÉTODOS....................................................................... 28

5 RESULTADOS........................................................................................... 43

6 DISCUSSÃO........................................................................................ 55

7 CONCLUSÕES........................................................................................... 68

REFERÊNCIAS................................................................................... 69

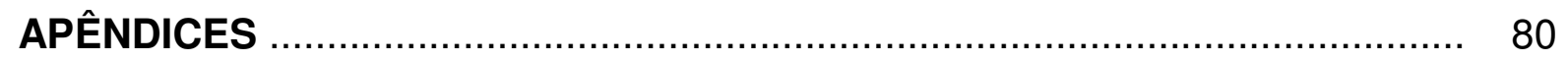

ANEXO..................................................................................................... 96 


\section{1 - INTRODUÇÃ O}

A Odontologia moderna vem se baseando na filosofia dos tratamentos minimamente invasivos. A máxima preservação do substrato dental sadio é hoje objetivo em todos os procedimentos (TYAS et al., 2000).

Incorporada a essa filosofia, está a busca em oferecer ao paciente um tratamento mais agradável evitando danos à estrutura dental remanescente (OLIVEIRA, 2005; GERALDO-MARTINS, 2007).

A partir disso, foram desenvolvidas algumas tecnologias de preparo cavitário, alternativas aos instrumentos rotatórios em alta e baixa rotação (OLIVEIRA, 2005) como o jato de óxido de alumínio, tecnologia esta que permite rápida remoção de esmalte, dentina, tecido cariado e restaurações insatisfatórias através de uma corrente de ar pressurizado contendo partículas abrasivas microscópicas (SAZAK; TURKMEN; GÜNDAY, 2001); o Carisolv®, método químico-mecânico que denatura o colágeno da dentina cariada, permitindo sua remoção com a utilização de curetas especiais (CEDERLUND et al., 1999); as pontas diamantadas CVD em ultra-som, que produzem desgastes devido ao movimento oscilatório (HUGO; STASSINAKIS, 1998); e finalmente, os lasers de alta potência com comprimentos de onda específicos (lasers de Er:YAG e Er,Cr:YSGG), que permitem a remoção de esmalte, dentina e tecido cariado devido a sua interação com a água e a hidroxiapatita presentes nestes tecidos (ARANHA et al., 2007).

Os lasers de Er:YAG e Er,Cr:YSGG são descritos na literatura como seguros para os procedimentos em dentística restauradora quando os relacionamos com o 
aumento de temperatura pulpar (LEE et al., 2006; HOSSAIN et al., 2003a). O laser de Er,Cr:YSGG utiliza um sistema pulsado, conduzido por uma fibra e uma ponta de safira em volta por uma mistura de água e vapor. A combinação de energia laser e água são chamadas de "Hydrokinetic", tecnologia desenvolvida e patenteada por engenheiros da Biolase, Estados Unidos. O equipamento trabalha de modo pulsado, com duração de 140 a $200 \mu$ s e uma taxa de repetição fixa de $20 \mathrm{~Hz}$. A sua potência pode variar de 0 até 6 watts. Este equipamento, possui comprimento de onda de 2,98 $\mu \mathrm{m}$ que está muito próximo do pico de absorção da água $(3 \mu \mathrm{m})$. Assim, podemos concluir que há uma grande afinidade pelos componentes presentes no substrato dentinário, água e hidroxiapatita (ISHIZAKI et al., 2004; CEBALLOS et al., 2001). Dessa forma, sob irrigação abundante, o laser remove eficazmente os tecidos dentais duros com ausência de danos à polpa dental (SECILMIS et al., 2007, HARASHIMA et al., 2005) em um processo denominado de ablação (USUMEZ; AYKENT, 2003, CEBALLOS et al., 2001, LEE et al, 2007).

As superfícies tratadas com o laser de Er,Cr:YSGG apresentam-se irregulares, com túbulos dentinários abertos, livres de smear layer (EKWORAPOJ; SIDHU; MCCABE, 2007; HOSSAIN et al., 2003; GERALDO-MARTINS, 2007) e descontaminadas (ESTEVES-OLIVEIRA et al.; 2007; LEE et al.,2006). Essas características seriam consideradas favoráveis para a união substrato - material resinoso (ESTEVES-OLIVEIRA et al., 2006; GERALDO-MARTINS, 2007), entretanto, a literatura tem mostrado resultados controversos com relação aos valores de resistência de união à dentina (ARANHA et al., 2007; JORDEHI et al., 2007; LEE 2007).

Muitos são os questionamentos referentes à adesão de materiais restauradores estéticos adesivos aos tecidos irradiados. Protocolos adequados 
foram estudados, estudos delineados com relação à força de resistência à união utilizando diversos parâmetros foram realizados, porém, são poucos os estudos longitudinais descritos na literatura.

Sabe-se que em condições ideais, a formação da camada híbrida é necessária para se obter resultados satisfatórios de união à dentina (AL-NAHEDH; ATEYAH, 2006; GWINNETT, 1993). Atualmente, a evolução dos sistemas adesivos busca simplificar o procedimento restaurador e aumentar a resistência de união (SUNICO et al., 2002; ESTEVES-OLIVEIRA et al., 2007).

Essa união pode ser realizada através de diferentes estratégias de união à da superfície dental (SAY et al., 2006) técnica do condicionamento ácido prévio, aplicação de primers autocondicionantes e mais atualmente, os sistemas all-in-one, na qual aplicação de primer e do adesivo estão integrados em um único passo (ELARABY; TALIC, 2007).

Todos estes sistemas adesivos, independente do seu modo de ação devem permear a dentina intertubular (YOSHIYAMA et al., 1995) para a obtenção de uma camada híbrida consistente (GWINNETT, 1993). Porém, pouco se sabe sobre os efeitos destes três tipos distintos de sistemas adesivos em superfícies dentinárias irradiadas com o laser de Er,Cr:YSGG, ao longo do tempo.

Dessa forma, este trabalho in vitro tem como objetivo avaliar longitudinalmente, através do teste de microtração, a estabilidade de restaurações adesivas após a irradiação com o laser de Er,Cr:YSGG, utilizando diferentes parâmetros e sistemas adesivos. 


\section{REVISÃO DA LITERATURA}

\section{1 - Utilização do laser na estrutura dental}

As primeiras utilizações do laser de Rubi em Odontologia foram realizadas in vitro por Goldman et al. (1964), Kinersly et al. (1965), Stern e Sognnaes (1964) e Gordon (1966). Estes estudos observaram a formação de cavidades em esmalte, formação de áreas de fusão e vitrificação e uma maior absorção do laser por tecidos cariados.

Goldman et al. (1965) irradiaram pela primeira vez a estrutura dental in vivo, com o laser de rubi. Foi observada a formação de uma pequena cavidade em esmalte, com áreas de fusão e vitrificação. O voluntário não relatou dor ou sensação de calor, assim como não sofreu injúrias nos tecidos moles adjacentes ao tecido irradiado.

No mesmo ano, Taylor, Shklar e Roeber (1965) irradiaram dentes e mucosa oral de um grupo de animais experimentais com laser de rubi em diversas intensidades de energia. As superfícies de esmalte irradiadas apresentaram a formação de uma depressão no local atingido e alterações na área circundante. Foram observadas alterações patológicas na mucosa oral e na polpa dental compatíveis com aumento de temperatura. A polpa dental apresentou áreas de necrose, com coagulação dos odontoblastos. Os dentes vizinhos aos incisivos irradiados também foram afetados. 
Após estudos que tentaram encontrar o comprimento de onda mais adequado para interagir com os tecidos duros dentais, a especificidade do laser de Er:YAG (érbio:ítrio, alumínio, granada) foi demonstrada por Hibst e Keller (1989). Este laser possui comprimento de onda de 2,94 $\mu$ m, que coincide com o pico de absorção da água e dos radicais hidroxila presentes na hidroxiapatita. Quando a radiação incidente é absorvida pelas moléculas de água presentes no tecido alvo, há aquecimento e evaporação da água. A pressão de vaporização leva à ocorrência de sucessivas microexplosões, com a conseqüente ejeção do tecido irradiado $A$ este processo dá-se o nome de ablação (EVERSOLE; RIZOIU, 1995).

Segundo o estudo de Zach e Cohen (1965), realizado em macacos Rhesus, qualquer elevação da temperatura pulpar acima de $5,5^{\circ} \mathrm{C}$ causaria danos irreversíveis à polpa dental.

Outros estudos laboratoriais demonstraram que as alterações de temperatura na câmara pulpar dos dentes irradiados com este laser são aceitáveis quando realizadas sob refrigeração constante (GERALDO-MARTINS et al., 2005). Nestas condições, a temperatura pulpar chegou a sofrer redução de temperatura ou uma elevação semelhante àquela ocorrida quando são utilizados instrumentos cortantes rotatórios (CAVALCANTI; LAGE-MARQUES; RODE, 2003). A irrigação constante é essencial para evitar aumentos de temperatura prejudiciais à polpa dental (CAVALCANTI; LAGE-MARQUES; RODE, 2003; GERALDO-MARTINS et al., 2005).

Dostálová et al.(1997) realizaram uma avaliação clínica da resposta pulpar à irradiação com o laser de Er:YAG, não encontrando reações pulpares compatíveis com inflamação. 
Diante de muitos resultados positivos, a utilização do laser de Er:YAG foi aprovada em 1997 pelo Food and Drug Administration (FDA) (COZEAN et al., 1997; PELAGALLI et al., 1997).

Com características semelhantes às do laser de Er:YAG, foi introduzido o laser de Er,Cr:YSGG (érbio, cromo: lítio, escândio, gálio, granada). Este equipamento tem um comprimento de onda de 2,78 $\mu \mathrm{m}$. Sua energia radiante é transmitida por fibra óptica e entregue por uma peça de mão com um cristal de safira embebido em ar e água. É absorvido pela água e pelos radicais hidroxila, presentes na hidroxiapatita (EVERSOLE; RIZOIU, 1995).

A utilização do laser de Er,Cr:YSGG foi aprovada em 1998 pelo Food and Drug Administration (FDA) (GUTKNECHT; EDUARDO, 2004).

De acordo com o fabricante, seu mecanismo de ablação é realizado através do processo hidrocinético, segundo o qual o laser de Er,Cr:YSGG é absorvido pelas moléculas de água do spray e da camada de água presente sobre o tecido alvo. Devido à grande afinidade da água pela luz laser, ocorre uma rápida microexplosão, gerada por forças mecânicas na superfície do tecido irradiado, havendo grande concentração de energia e poder de corte entre a ponta da fibra e a superfície dental (EVERSOLE; RIZOIU, 1995).

Em 1995, Eversole e Rizoiu utilizaram o laser de Er,Cr:YSGG in vivo em coelhos e cães, sem sinal de injúrias aos tecidos periodontais e dentais quando utilizada refrigeração água e ar. Nestas condições, a temperatura pulpar não sofreu alterações ou sofreu uma redução de até $2^{\circ} \mathrm{C} . \mathrm{b}$

A redução microbiana pelo laser Er,Cr:YSGG em canais radiculares, foi observada in vitro (FRANZEN et al., 2009; GORDON et al., 2007; SCHOOP et al., 
2007). Além disso, o laser também promoveu remoção da smear layer presente nas paredes dos canais e exposição dos túbulos dentinários(SCHOOP et al., 2007).

Os estudos clínicos com lasers de érbio mostraram sua eficácia na remoção seletiva de tecido cariado e de tecido dental sadio (ARMENGOL et al., 1999, RIZOIU et al., 1998), tendo eficácia semelhante à dos instrumentos cortantes rotatórios (COZEAN et al., 1997).

Os lasers de érbio podem ser utilizados para remoção de cárie e de tecido dental sadio (ARMENGOL et al., 1999), preparo de cavidades e condicionamento ácido, em esmalte e dentina (COZEAN et al., 1997). Apesar de exigir maior tempo de trabalho (AOKI et al., 1998; HOSSAIN et al., 2003), sua utilização é bem aceita pelos pacientes (COZEAN et al., 1997), que apresentam pouca ou nenhuma sensibilidade dolorosa (HADLEY et al., 2000; PELAGALLI et al., 1997). Quando utilizados sob refrigeração, não causam danos aos tecidos pulpares (AOKI et al., 1998; EVERSOLE; RIZOIU, 1995; HADLEY et al., 2000). Em alguns parâmetros, é observada a redução microbiana (AOKI et al., 1998; FRANZEN et al, 2009; GORDON et al., 2007; SCHOOP et al., 2007).

\section{2- Morfologia da dentina irradiada pelos lasers de érbio}

Os efeitos dos lasers de érbio nos tecidos duros dentais dependem do parâmetro utilizado e do tipo de substrato irradiado (BADER; KREJCI, 2006; HIBST; KELLER, 1989; KELLER; HIBST, 1989; LI; CODE; VAN DE MERWE, 1992). Com a interação adequada entre laser e substrato, é possível a formação de cavidades no 
tecido dental pelo processo de ablação e o condicionamento da superfície (DELME; DE MOOR, 2007; LI; CODE; VAN DE MERWE, 1992).

A eficiência do laser depende da sua interação com o tecido (ARMENGOL et al., 1999). Para a mesma energia radiante, a ablação na dentina é mais eficiente do que no esmalte, devido ao seu alto conteúdo de água (ARMENGOL et al., 1999; FREITAS et al., 2007).

Delmé e De Moor (2007) irradiaram superfícies de esmalte com lasers de erbio e observaram que elas se apresentam irregulares, com sinais de vitrificação. Zonas de melting e recristalização assim como micro-trincas foram claramente observadas por Cardoso et al., (2008b), mesmo quando a refrigeração foi utilizada. Esteves-Oliveira et al. (2007) observaram que as superfícies de esmalte irradiadas com os lasers de Er,Cr:YSGG possuem um padrão microrretentivo, com prismas expostos e ausência de smear layer .

Geralmente, as superfícies dentinárias preparadas com os lasers Er:YAG e Er,Cr;YSGG apresentam-se irregulares, sem smear layer, com túbulos dentinários abertos. A dentina peritubular fica protruída ao redor da entrada dos túbulos, com aspecto semelhante ao de um vulcão (AOKI et al., 1998; ARMENGOL et al., 1999; BERTRAND et al., 2004; CARDOSO et al., 2008a; CARDOSO et al., 2008b; CHOU; CHEN; DING, 2009; DE MUNCK et al., 2002; DELME; DE MOOR, 2007; DUNN; DAVIS; BUSH, 2005; EKWORAPOJ; SIDHU; MCCABE, 2007; FREITAS et al., 2007; HOSSAIN et al., 2003; LEE et al., 2007; MOLDES et al., 2009; MONGHINI et al., 2004; TRAJTENBERG; PEREIRA; POWERS, 2004; TACHIBANA et al., 2008; VAN MEERBEEK et al., 2003). Isso acontece porque a dentina intertubular é seletivamente mais ablacionada devido ao seu maior conteúdo 
orgânico, comparativamente à dentina peritubular (AOKI et al., 1998; FREITAS et al., 2007; HARASHIMA et al., 2005; HOSSAIN et al. 1999). A região central da irradiação corresponde à área de maior remoção de tecido, devido à maior concentração de energia do pulso (MORETTO, 2009).

O processo de ablação da dentina pode acarretar como consequência a formação de trincas na superfície e na sub-superfície (AOKI et al., 1998; CARDOSO et al 2008a; DE MUNCK et al., 2002; MONGHINI et al., 2004; MORETTO 2009; SETIEN et al., 2001; VAN MEERBEEK et al., 2003).

O calor residual depositado na estrutura dental decorrente da irradiação com lasers de érbio pode levar a carbonização e melting (DELMÉ; DE MOOR, 2007; HOSSAIN et al., 1999; LEE et al., 2007) além de alterações pulpares (TAYLOR; SHKLAR; ROEBER, 1965).

Alterações na estrutura química dos tecidos irradiados com lasers de érbio, como degradação do colágeno e perda de água foram observadas por Bachmann et al (2005). Estas alterações foram mais intensas nas regiões onde incidiu o pulso, e menos intensas nas áreas vizinhas e mais profundas.

O resfriamento com água é importante para evitar danos pulpares (GERALDO-MARTINS et al., 2005). Quando a refrigeração com água é realizada dentro de determinados parâmetros, não são observados os efeitos deletérios do calor (AOKI et al., 1998; ARMENGOL et al., 1999; FRIED; RAGADIO; CHAMPION, 2001; HOSSAIN et al., 1999; KELLER; HIBST, 1989; LEE et al., 2007). Moretto (2009) observou zonas de carbonização em dentina mesmo quando a irradiação foi realizada com refrigeração. 
Quando os tecidos dentais são irradiados sem refrigeração, observa-se a carbonização das estruturas. As cavidades adquirem um aspecto de "lava derretida" e é formada uma estrutura irregular e repleta de pequenos orifícios na dentina (HOSSAIN et al., 1999).

O laser de Er,Cr:YSGG produz cavidades muito similares às do laser de Er:YAG, porém elas são mais rugosas e apresentam uma menor quantidade de túbulos dentinários abertos (ESTEVES-OLIVEIRA et al., 2007; HARASHIMA et al., 2005) e seus efeitos térmicos são mais severos (HARASHIMA et al., 2005).

Moretto (2009) observou a presença de micro-trincas verticais e horizontais que se propagaram na dentina peritubular nas superfícies dentinárias irradiadas com os lasers de Er:YAG e Er,CR:YSGG. Todas as amostras apresentavam trincas em toda a superfície, que diminuíam a medida que a profundidade era maior. As microtrincas nos grupos irradiados com o laser de Er,Cr:YSGG eram mais evidentes, provavelmente devido à maior taxa de repetição, que pode elevar ao calor residual e induzir maiores alterações teciduais (GERALDOMARTINS et al., 2005).

\section{3- Adesão aos tecidos irradiados}

A adesão aos tecidos dentais é obtida quando a smear layer, ou camada de esfregaço, composta pelos debris produzidos pelo corte da estrutura dental é completamente removida ou modificada pelos agentes condicionantes presentes nos sistemas adesivos (EICK; WILKO; ANDERSON, 1970; PASHLEY, 
1991). Além da remoção da smear layer, os agentes condicionantes desmineralizam a superfície dentinária, expondo a rede de colágeno (PERDIGÃO; LOPES, 1999). A completa substituição do tecido desmineralizado pelo adesivo é fundamental para um selamento hermético da interface adesiva (PASHLEY et al., 1995).

Existem sérias dúvidas quanto ao protocolo ideal para a obtenção de uma superfície dentinária irradiada compatível com os procedimentos adesivos (GURGAN et al., 2009). É necessário o estabelecimento de um protocolo ideal para a utilização dos lasers de érbio na obtenção de cavidades para procedimentos adesivos (CARDOSO et al,. 2008a).

Pesquisas apontam as características morfológicas da dentina e esmalte irradiados com os lasers de érbio como possivelmente favoráveis à adesão por melhorarem a retenção micromecânica (ARANHA et al., 2007; CEBALLOS et al., 2001; GURGAN et al., 2008 e 2009; LI; CODE; VAN DE MERWE, 1992; RAMOS et al., 2008; TRAJTENBERG; PEREIRA; POWERS, 2004).

As superfícies irradiadas com os lasers de érbio não apresentam smear layer (AOKI et al., 1998; ARMENGOL et al., 1999; BERTRAND et al., 2004; CARDOSO et al., 2008a; CARDOSO et al., 2008b; CHOU; CHENG; DING, 2009; DE MUNCK et al., 2002; DELME; DE MOOR, 2007; DUNN; DAVIS; BUSH, 2005; EKWORAPOJ; SIDHU; MCCABE, 2007; FREITAS et al., 2007; HOSSAIN et al., 2003; LEE et al., 2007; MOLDES et al., 2009; MONGHINI et al., 2004; TRAJTENBERG; PEREIRA; POWERS, 2004; TACHIBANA et al., 2008; VAN MEERBEEK et al., 2003). Os lasers são mais eficientes em dentina intertubular do que em peritubular devido às diferença no volume do conteúdo mineral de ambas as estruturas. Por esta razão, ele não alarga os orifícios dos túbulos dentinários 
(BERTRAND et al., 2004; CEBALLOS et al., 2001). Os tags de resina se apresentam menos pronunciados (SCHEIN et al., 2003), mais regulares e em formato cilíndrico, com as bases mais estreitas.

Devido à complexa estrutura hidratada da dentina, a adesão a este tecido é ainda mais complexa do que a adesão ao esmalte (HIRAISHI et al., 2007).

Quando o laser de Er:YAG é utilizado em dentina, não existe desmineralização da superfície e a matriz de colágeno não é exposta (CEBALLOS et al., 2001). A adesão depende da exposição e da integridade da rede de fibrilas colágenas (ARANHA et al., 2007).

Estudos apontam que a irradiação com lasers de érbio gera valores de resistência de união semelhantes àqueles obtidos com o tratamento convencional (ERGÜCÜ et al., 2009, LIN et al., 1999; MAROTTI et al., 2008; USUMEZ; AYKENT, 2003). Gurgan et al. (2008) concluem que o uso do laser de Er,Cr:YSGG na dentina pode melhorar a resistência adesiva.

Chou, Chen e Ding (2009) encontraram uma correlação positiva entre a potência do laser de Er,Cr:YSGG e a resistência adesiva, quando utilizado para condicionamento da superfície. Aparentemente, os autores concluem que condicionamento da superfície com o laser de Er,Cr:YSGG pode ser uma alternativa ao condicionamento ácido.

Ramos et al. (2008) restauraram superfícies dentinárias tratadas com o laser de Er:YAG e, apesar das diferenças ultra-estruturais em relação ao grupo controle, não encontraram diferenças nos valores de resistência adesiva. 
Os tags formados em dentina irradiada são mais longos e são os responsáveis pela retenção mecânica entre dentina e adesivo, que pode elevar os valores de resistência adesiva (ARANHA et al., 2007).

Porém, a literatura apresenta resultados controversos quanto aos valores de resistência de união de tecidos irradiados pelos lasers de erbio, mesmo que as suas características pareçam favoráveis à retenção mecânica, como já descrito anteriormente (ESTEVES-OLIVEIRA et al., 2007).

De acordo com alguns autores, durante a irradiação, existem efeitos que podem interferir negativamente na adesão (ESTEVES-OLIVEIRA et al., 2007). De acordo com alguns autores, as cavidades preparadas com o laser de Er,Cr:YSGG não são receptivas aos materiais restauradores adesivos (CARDOSO et al., 2008a).

Bertrand et al. (2004) apontaram que, com o laser de Er:YAG, em parâmetros mais altos, a destruição do colágeno persistiu mesmo após o condicionamento ácido. Os efeitos termomecânicos da irradiação se estendem à sub-superfície, tanto no esmalte quanto na dentina, comprometendo a integridade da interface adesiva, diminuindo os valores da resistência de união (DUNN; DAVIS; BUSH; 2005).

A rede de fibrilas colágenas fusionadas impede a correta difusão do adesivo para as camadas mais profundas da dentina intertubular, prejudicando a resistência adesiva (CEBALLOS et al., 2001).

No trabalho de Cardoso et al. (2008), o esmalte irradiado com o laser de Er,Cr:YSGG apresentou valores de resistência adesiva inferiores, tanto para adesivos autocondicionantes quanto para adesivos condicione-e-lave, quando 
comparados a tecidos não irradiados. Os mesmos autores afirmam também que as alterações térmicas no esmalte irradiado, como melting e alterações químicas, podem torná-lo menos receptivo aos procedimentos adesivos.

Acredita-se que a presença de microtrincas na superfície dentinária após a irradiação, além da provável degradação da rede de fibrilas colágenas, influenciam negativamente a resistência adesiva (GURGAN et al., 2009). A irradiação com o laser de Er,Cr:YSGG não remove seletivamente os cristais de hidroxiapatita, danificando a rede de fibrilas colágenas (LEE et al., 2007). Aranha et al. (2007) encontraram a formação de um espaço entre a dentina irradiada e a resina composta, sugerindo alteração do colágeno.

Cardoso et al. (2008a) reportam que as irregularidades produzidas pelo laser de Er,Cr:YSGG na superfície da dentina são tão proeminentes que exercem um papel negativo na distribuição de tensões na interface adesiva. Nas áreas em que a camada adesiva é muito fina, ela é facilmente arrancada pela restauração de resina durante o teste de microtração.

Bertrand et al. (2004) mostraram que a deposição do calor produzido pela irradiação laser produz uma camada de material granular de espessura variável, que foi removida com o condicionamento ácido. Desta forma, as fibrilas colágenas foram capazes de interagir com os monômeros resinosos presentes nos adesivos, sendo possível a formação da camada híbrida. A espessura da camada híbrida formada nos tecidos preparados com instrumentos cortantes rotatórios e com laser de Er:YAG, desde que o condicionamento ácido tenha sido realizado, foi muito semelhante. Por sua vez, Aranha et al. (2007) apontam que a camada híbrida 
formada em tecidos irradiados é mais fina do que a obtida em tecidos preparados à maneira convencional.

Os tags de resina em dentina irradiada com o laser de Er:YAG e condicionadas com ácido fosfórico têm forma de funil, pois o condicionamento ácido desmineraliza a dentina peritubular, deixando os túbulos mais abertos. O condicionamento ácido também age na camada sub-superficial (BERTRAND et al., 2004). De Munck et al. (2002) e Lee et al. (2007) concluem que o condicionamento ácido é mandatório após a irradiação com laser.

Quando a irradiação com os lasers de érbio não foi acompanhada pelo condicionamento ácido, a camada híbrida não pôde ser identificada (BERTRAND et al., 2004; CEBALLOS et al., 2001) ou foi pobremente formada (SCHEIN et al., 2003).

Outros autores afirmam que a adesão a substratos dentais que foram condicionados com os lasers de érbio é mais fraca (DUNN; DAVIS; BUSH, 2005; FERREIRA et al., 2009).

Schein et al. (2003) reportaram que a qualidade da dentina após irradiação com o laser de Er:YAG e posterior condicionamento ácido é desfavorável para a hibridização, mecanismo desenvolvido para cavidades preparadas com instrumentos cortantes rotatórios. A presença de dentina peritubular mesmo após o condicionamento ácido da superfície irradiada, pode indicar resistência ácida.

Obeidi et al. (2009) concluíram que, quando é realizado condicionamento ácido por 40 segundos em esmalte irradiado pelo laser de Er,Cr:YSGG, ou escavação e condicionamento ácido por 20 segundos após a irradiação, a resistência é adesiva é melhorada. O mesmo ocorre para a dentina, quando é realizada a escavação e o condicionamento ácido por 40 segundos. Os 
autores creditam o resultado positivo à remoção do tecido afetado pela irradiação. No mesmo ano, Obeidi et al. concluíram que o tempo de condicionamento ácido ideal para a melhor adesão ao esmalte irradiado é 40 segundos. Também em 2009, Ferreira et al. afirmaram que um condicionamento ácido prolongado em tecidos irradiados pelos lasers de érbio influencia negativamente a resistência adesiva e não é capaz de remover a camada de colágeno alterado. Os tempos preconizados pelos fabricantes são 15 segundos em dentina e 20 segundos em esmalte.

Na tentativa de simplificar o processo de adesão, foram desenvolvidos sistemas adesivos com menor número de passos. Nestes sistemas, monômeros hidrofílicos e hidrofóbicos são misturados juntos com um alto conteúdo de solventes para mantê-los na solução (MONTICELLI et al., 2007).

Os sistemas adesivos condicione-e-lave ou total-etch podem se apresentar em dois ou três passos. No seu primeiro passo, a smear layer é removida com aplicação de ácido fosfórico a 37\%. Eles contêm primers hidrofílicos e hidrofóbicos, que interagem com o esmalte e a dentina desmineralizados, formando a camada híbrida, que é responsável pela retenção micromecânica dos compósitos aos tecidos duros dentais (NAKABAYASHI; KOJIMA; MASUHARA, 1982).

Os sistemas adesivos auto-condicionantes ou self-etch podem se apresentar em um ou dois passos. Os adesivos em frasco único são também conhecidos como all-in-one. Nesta classe de adesivos, os primers dissolvem a smear layer e parcialmente desmineralizam a sub-superfície da dentina. A smear layer dissolvida é incorporada ao processo de adesão (GURGAN et al., 2009). Em superfícies ácido resistentes, os ácidos fracos presentes nesta classe de adesivos possivelmente não conseguem promover alterações suficientes para garantir a sua 
penetração (ESTEVES-OLIVEIRA et al., 2007). Devem ser desenvolvidos novos adesivos com melhor interação com os tecidos irradiados (CARDOSO et al., 2008a).

Os adesivos total-etch e self-etch não conseguem conferir um isolamento hermético à dentina vital, comportando-se como membranas permeáveis. A ausência de monômeros hidrofóbicos permite que o fluido dentinário ultrapasse a camada adesiva. As bolhas formadas podem ser iniciadores de fraturas catastróficas na interface adesiva de cavidades pouco retentivas.

Os adesivos total-etch simplificados e os adesivos self-etch são semelhantes em dois aspectos: a espessura fina da camada híbrida formada e a presença de grupos iônicos e hidrofílicos retidos na camada híbrida, que continuam a atrair água da dentina vitalizada, levando à degradação (TAY et al., 2004a).

O gradiente osmótico causa a infiltração da água do meio bucal para o interior da interface adesiva. No esmalte, ocorre a formação de bolhas que, com o tempo, aumentam e se coalescem. Acredita-se que na dentina a água infiltrada na camada adesiva flui através dos túbulos dentinários e não ocorre a formação de bolhas (TAY et al., 2004b).

A longevidade das restaurações depende diretamente da durabilidade da adesão entre a resina e o substrato dentinário (TORKABADI; NAKAJIMA, 2008).

Os sistemas adesivos vêm apresentando bons resultados quando testada sua resistência adesiva nas primeiras 24 horas. Porém, a cavidade oral se apresenta como um desafio para a longevidade da camada adesiva de restaurações devido às alterações de temperatura, ciclos mastigatórios, sorção de água e alterações de pH (GURGAN et al., 2008; GURGAN et al., 2009). 
A resistência adesiva tende a decair com o passar do tempo de armazenagem. Após aproximadamente 3 meses, todas as classes de adesivo apresentam evidências mecânicas e morfológicas que podem ser comparados ao que ocorreria in vivo (DE MUNCK et al., 2005).

Conhecer o comportamento das restaurações adesivas ao longo do tempo é fundamental para o cirurgião dentista. A previsibilidade de um tratamento é de grande importância para o planejamento e seleção de casos.

Até a data desta redação, desconhecemos a literatura que enfoque o estudo da resistência adesiva à dentina irradiada pelo laser Er,Cr:YSGG ao longo do tempo. 


\section{3- PROPOSIÇÃO}

Este estudo tem como principal objetivo avaliar, in vitro, a resistência de união de diferentes sistemas adesivos ao substrato irradiado com o laser de Er,Cr:YSGG, em períodos de tempo de 1 e 90 dias após o procedimento restaurador.

A partir dos resultados obtidos, procuramos respostas para os seguintes questionamentos:

1. Existem diferenças nos valores de resistência adesiva entre os diferentes tratamentos da superfície dentinária (controle, laser $2 \mathrm{~W}$ e laser $4 \mathrm{~W}$ ), independentemente do sistema adesivo utilizado?

2. Com relação aos adesivos dentinários, existem diferenças no comportamento dos sistemas adesivos para cada um dos tratamentos de superfície utilizado (controle, laser $2 \mathrm{~W}$ e laser $4 \mathrm{~W}$ )?

3. Existe diferença no comportamento dos valores de resistência adesiva para os sistemas adesivos testados quando comparados aos valores pós 24 horas?

4. Qual o comportamento dos sistemas adesivos após a armazenagem dos espécimes em água destilada por 90 dias?

5. Entre os protocolos utilizados, qual o tratamento/sistema adesivo/tempo que apresentou resultados de resistência adesiva mais satisfatórios? 


\section{4- Materiais e Métodos}

\section{Delineamento experimental}

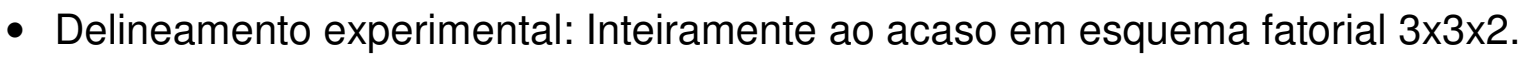

- Unidades Experimentais: Sessenta e quatro terceiros molares humanos hígidos $(n=6)$.

- Fatores em estudo:

* Fator 1: Tratamento do substrato dentinário em 3 níveis: Irradiação em 2 níveis e abrasionamento com lixa de SiC (carbeto de silício) \#180, \#240, \#320, \#400 e \#600 (Buehler LTD., Lake Buff, Illinois, EUA) montadas em politriz (Ecomet 3 machine, Buehler LTD., Lake Buff, Illinois, EUA) durante 30 segundos, com irrigação constante.

* Fator 2: Sistemas adesivos em 3 níveis: Single Bond Adpter 2 (3M/ESPE, Saint Paul, Minessota, EUA), Clearfil SE Bond (Kuraray Medical Inc., Kurashiki, Okayama, Japan) e Clearfil $S^{3}$ Bond (Kuraray Medical Inc., Kurashiki, Okayama, Japan);

- Fator 3: Armazenamento dos dentes restaurados em 2 níveis: baseline (24 horas) e 90 dias.

- Variáveis de resposta: análise da resistência de união através do teste de microtração (MPa) e determinação do padrão de fratura a partir da observação da interface dente-restauração em lente de aumento óptico de 40x após uso de corante. 


\section{Preparo das amostras}

Para esta pesquisa, foram utilizados 64 terceiros molares humanos hígidos e recém-extraídos provenientes do Banco de Dentes Humanos da Faculdade de Odontologia da FOUSP após a aprovação do Comitê de Ética em Pesquisa da mesma instituição (Protocolo 233/2009).

Os dentes foram submetidos à raspagem manual com cureta periodontal (Duflex, SS White, Rio de Janeiro, Rio de Janeiro, Brasil) para remoção de debris orgânicos e polidos com taça de borracha (KG Sorensen, Barueri, São Paulo, Brasil) em baixa rotação e pasta de pedra-pomes (SS White, Rio de Janeiro, Rio de Janeiro, Brasil) e água.

Em seguida, os dentes foram armazenados em água destilada, sob refrigeração, até o momento da sua utilização.

Os dentes tiveram as suas superfícies oclusais seccionadas com discos diamantados (KG Sorensen, Barueri, São Paulo, Brasil) em baixa rotação, sob refrigeração, até a altura do sulco principal. As superfícies obtidas foram então desgastadas com lixas de carbeto de silício de granulação \#180 montadas em politriz (Ecomet 3 machine, Buehler LTD., Lake Buff, Illinois, EUA), sob refrigeração contínua até a obtenção de uma superfície plana de dentina, livre de remanescente de esmalte. Após a constatação da ausência de esmalte por inspeção visual com auxílio de lupa estereoscópica, com aumento 40x (Olympus, Tóquio, Japão), o substrato foi padronizado com lixas de SiC \#240 (Buehler LTD., Lake Buff, Illinois, EUA) montadas em politriz (Ecomet 3 Machine, Buehler LTD., Lake Buff, Illinois, EUA) durante 30 segundos, com irrigação constante.

Os dentes foram incluídos em resina acrílica com auxílio de moldes 
plásticos, aleatoriamente divididos em três grupos experimentais, e as superfícies dentinárias preparadas de acordo com cada grupo:

\section{Grupos 1 e 2: Laser de Er,Cr:YSGG}

- Foi utilizado o laser Waterlase Millenium (Biolase, San Clemente, CA, EUA) com comprimento de onda de 2,78 $\mu \mathrm{m}$, que trabalha de modo pulsado, com duração de pulso variando de 140 a 200 us e uma taxa de repetição fixa de $20 \mathrm{~Hz}$, podendo variar a potência de 0 até 6 watts. A peça de mão utilizada foi a MPV, posicionada perpendicularmente à superfície da dentina, a $1 \mathrm{~mm}$ da superfície da amostra (modo focado). Foi utilizada a ponta de safira G4, com diâmetro de $600 \mu \mathrm{m}$. Os parâmetros utilizados estão descritos na tabela 4.1. A irradiação foi realizada sob constante refrigeração com água (55\%) e ar (65\%) e o modo de irradiação o de varredura, percorrendo toda a superfície, de modo a obter uma superfície de irradiação homogênea, cuidando-se para não sobrepor os pontos de irradiação.

Tabela 4.1- Parâmetros para irradiação dos grupos experimentais utilizando laser de Er,Cr:YSGG.

\begin{tabular}{ccccc}
\hline $\begin{array}{c}\text { Protocolos } \\
\text { laser Er; } \\
\text { Cr:YSGG }\end{array}$ & $\begin{array}{c}\text { Taxa de } \\
\text { repetição }(\mathrm{Hz})\end{array}$ & Energia $(\mathrm{mJ})$ & $\begin{array}{c}\text { Potência } \\
(\mathrm{W})\end{array}$ & $\begin{array}{c}\text { Exposição } \\
\text { radiante } \\
\left(\mathrm{J} / \mathrm{cm}^{2}\right)\end{array}$ \\
\hline G1 & 20 & 100 & 2 & 90,9 \\
G2 & 20 & 200 & 4 & 181,8 \\
\hline
\end{tabular}

Mesmo com o controle da quantidade de ar e água fornecida pelo equipamento, mensurou-se a taxa de água com auxílio de uma seringa BD 
descartável de $10 \mathrm{ml}$, na qual ficou constatado uma taxa de refrigeração de 24 $\mathrm{ml} / \mathrm{min}$.

O equipamento utilizado pertence ao Laboratório Especial de Laser em Odontologia, do Departamento de Dentística da Faculdade de Odontologia da USP (LELO-FOUSP) e foi adquirido através de um projeto CEPID/CEPOD/FAPESP (98/14270-8).

Durante a irradiação, foi utilizado um equipamento medidor de potência (Power Meter - Coherent, Newport, Estados Unidos) na qual contatou-se que os valores da Tabela 4.1 estavam efetivamente sendo utilizados.

Seguindo as normas de segurança, óculos de proteção específicos para este comprimento de onda foram utilizados, assim como todos os procedimentos de biossegurança.

\section{- Grupo 3: Lixa de Carbeto de Silício (SiC)- Granulação 600}

As superfícies planificadas de dentina foram abrasionadas com as lixas de carbeto de silício com granulação \#180, \#240, \#320, \#400 e \#600 montadas em politriz (Ecomet 3 Machine, Buehler LTD., Lake Buff, Illinois, EUA), refrigerada com água, para padronização do substrato dentinário. Cada lixa foi utilizada por 30 segundos e os dentes foram lavados em água destilada entre as diferentes granulações. 


\section{Procedimento adesivo}

Três sistemas adesivos foram selecionados para a pesquisa, sendo os dentes de cada grupo subdivididos entre eles: um autocondicionante de dois passos (Clearfil SE Bond/Kuraray), um com condicionamento ácido prévio (Single Bond/3MESPE) e um adesivo frasco único - "all-in-one" (Clearfil $S^{3}$ Bond/Kuraray). Informações relativas à composição de cada sistema adesivo pode ser encontrada na Tabela 4.2. 
Legenda da Figura 4.1 - Fluxograma com os procedimentos realizados para o teste de microtração.

1. Obtenção e limpeza dos dentes;

2. Obtenção de uma superfície de dentina livre de esmalte;

3. Padronização do substrato;

4. Inclusão da amostra em resina acrílica;

5. Tratamentos da superfície de dentina:

a. Polimento - Grupo controle;

b. Irradiação com laser de Er,Cr:YSGG - Grupos 2W e 4W;

6. Procedimento restaurador:

a. Aplicação do sistema adesivo;

b. Construção de um bloco de resina de forma incremental;

c. Armazenamento por 24 horas;

7. Confecção dos palitos:

a. Fixação do dente incluído na Isomet;

b. Corte na Isomet com um disco diamantado;

c. Obtenção dos palitos;

d. Aferição das medidas com o paquímetro digital;

e. Armazenamento em água destilada;

8. Ensaio de microtração:
a. Fixação dos palitos na Garra de Geraldelli;
b. Instron.
c. Avaliação do padrão de fratura. 
Figura 4.1- Fluxograma com os procedimentos realizados para o teste de microtração.
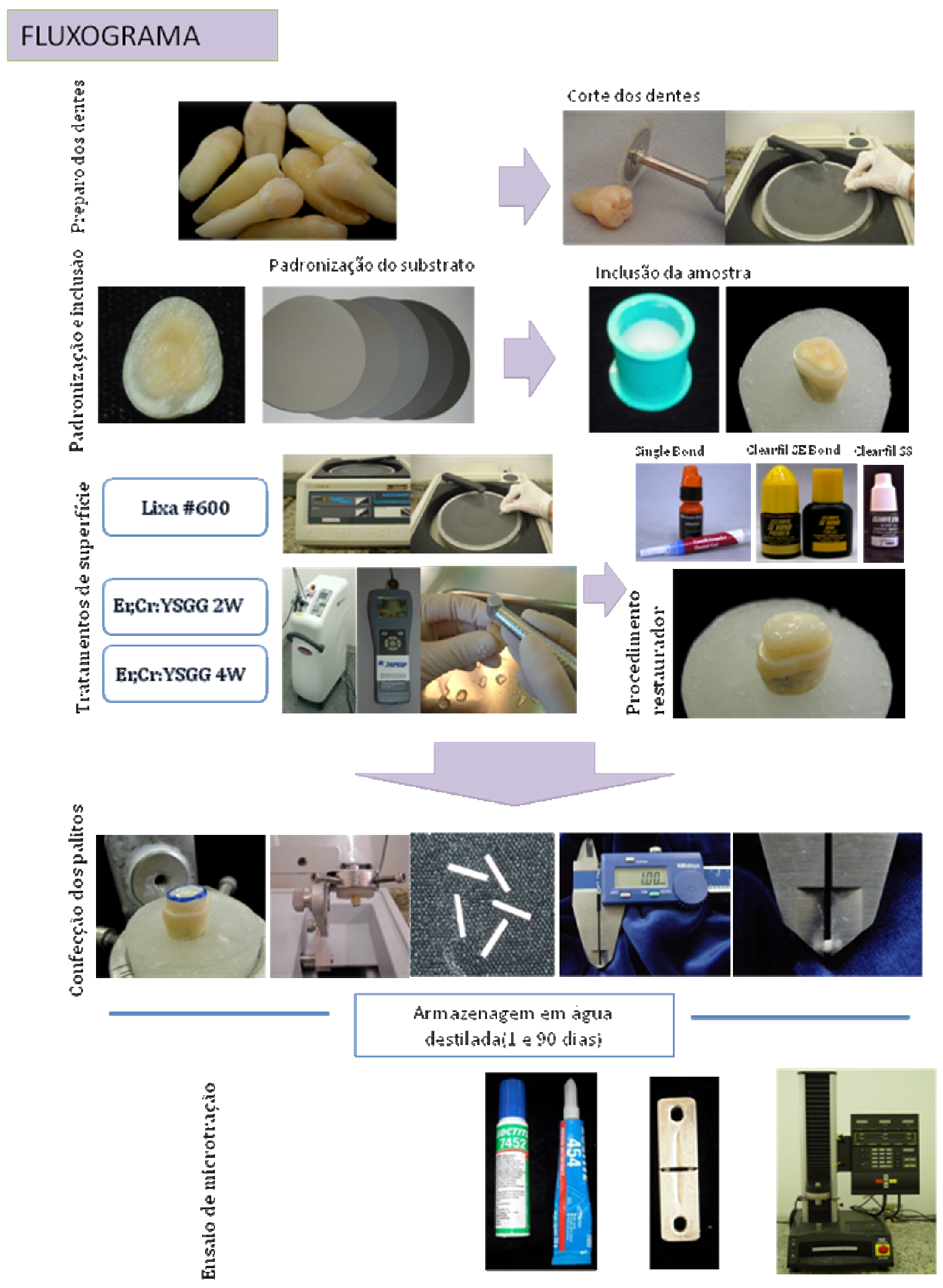
Tabela 4.2- Composição dos sistemas adesivos utilizados

\begin{tabular}{|c|c|c|c|}
\hline Sistema adesivo & Fabricante & Composição & $\mathrm{pH}$ \\
\hline $\begin{array}{l}\text { Adper Single } \\
\text { Bond }\end{array}$ & $\begin{array}{l}\text { 3M ESPE, St. Paul, } \\
\text { Minn, USA }\end{array}$ & $\begin{array}{l}\text { Água, etanol, HEMA, } \\
\text { Bis-GMA, outras resinas } \\
\text { dimetracrilatos e } \\
\text { copolímeros dos ácidos } \\
\text { policarboxílico e } \\
\text { dimetacrilato modificado } \\
\text { e } \\
\text { sistema fotoiniciador. }\end{array}$ & 4,25 \\
\hline Clearfil SE Bond & $\begin{array}{l}\text { Kuraray Medical, } \\
\text { Osaka, Japan }\end{array}$ & $\begin{array}{l}\text { Primer: HEMA, } \\
\text { dimetacrilato hidrofílico, } \\
\text { 10-MDP, N,N-dietanol } \\
\text { ptoluidina, CQ, água; } \\
\text { Adesivo: Sílica } \\
\text { silanizada, Bis-GMA, } \\
\text { HEMA, dimetacrilato } \\
\text { hidrofílico, 10-MDP, CQ, } \\
\text { toluidina. }\end{array}$ & $\begin{array}{l}\text { Primer } \\
\text { (pH: 1,9) } \\
\text { Adesivo: } \\
\text { (pH: } 2,8)\end{array}$ \\
\hline Clearfil $S^{3}$ Bond & $\begin{array}{l}\text { Kuraray Medical, } \\
\text { Osaka, Japan }\end{array}$ & $\begin{array}{l}\text { MDP, Bis-GMA, } \\
\text { dimetacrilato hidrófobo, } \\
\mathrm{CQ} \text {, álcool etílico, água, } \\
\text { sílica coloidal silanizada }\end{array}$ & 2,0 \\
\hline
\end{tabular}

As aplicações foram realizadas de acordo com as instruções do fabricante:

\section{- Adesivo Adper Single Bond TM (3M ESPE)}

Foi realizada a secagem da superfície, condicionamento com ácido fosfórico $37 \%$ por 15 segundos, lavagem com água durante 15 segundos para remoção do excesso de água com papel absorvente, aplicação de 2 camadas consecutivas de adesivo, agitando o material na superfície por 15 segundos. A superfície foi seca gentilmente com auxílio de jato de ar da seringa tríplice para evaporar o solvente. A fotoativação foi realizada por 10 segundos com auxílio de 
fotopolimerizador (Optilux, Demetron, Kerr, Estados Unidos).

\section{- Clearfil SE Bond (Kuraray)}

Após a secagem da superfície, foi aplicado o primer durante 20 segundos. Em seguida, foi aplicado leve jato de ar com auxílio da seringa tríplice para posterior aplicação da resina fluida. Aguardou-se 10 segundos e fotoativou durante 10 segundos (Optilux, Demetron, Kerr, Estados Unidos).

\section{- Clearfil $\mathrm{S}^{3}$ Bond (Kuraray)}

O adesivo foi aplicado sobre o substrato dentinário por 20 segundos. Foi realizada a secagem gentilmente da dentina por 5 segundos para evaporação do solvente e fotoativar por mais 20 segundos (Optilux, Demetron, Kerr, Estados Unidos).

Após o tratamento de superfície e a aplicação do sistema adesivo, foi construído um bloco de dimensões $5 \times 5 \times 5 \mathrm{~mm}$ de forma incremental com a resina composta Z250 (3M/ESPE). Cada camada foi fotopolimerizada por 20 segundos a $650 \mathrm{~mW} / \mathrm{cm}^{2}$ (Optilux, Demetron, Kerr, Estados Unidos). As amostras, após restauradas permaneceram armazenadas em água destilada a $37^{\circ} \mathrm{C}$ de acordo com o tempo determinado para cada grupo (Tabela 4.3). 
Tabela 4.3- Descrição dos tratamentos, sistemas adesivos utilizados e o tempo de avaliação para o teste de microtração

\begin{tabular}{ccc}
\hline Tratamento & Sistema adesivo & $\begin{array}{c}\text { Tempo de avaliação } \\
\text { (dias) }\end{array}$ \\
\hline $\begin{array}{c}\text { Controle } \\
\text { G3 }\end{array}$ & Single Bond & 1 \\
$n=18$ & Clearfil SE Bond & 90 \\
& $n=6$ & 1 \\
& Clearfil S ${ }^{3}$ Bond & 90 \\
Laser de & Single Bond & 1 \\
Er,Cr:YSGG & $n=6$ & 90 \\
G1 & Clearfil SE Bond & 1 \\
$n=18$ & $n=6$ & 90 \\
& Clearfil S ${ }^{3}$ Bond & 1 \\
Laser de & Single Bond & 90 \\
Er,Cr:YSGG & $n=6$ & 1 \\
G2 & Clearfil SE Bond & 90 \\
$n=18$ & $n=6$ & 1 \\
& Clearfil S ${ }^{3}$ Bond & 90 \\
& $n=6$ & 1 \\
& & 1 \\
\hline & & 90 \\
\hline
\end{tabular}

\section{Teste de Microtração}

Após um período de 24 horas de armazenamento em água destilada a $37^{\circ} \mathrm{C}$, as amostras foram posicionadas na máquina de corte seriados (Isomet 1000, Buheler Ltd, Lake Buff, IL, EUA), onde os dentes foram seccionados perpendicularmente ao seu longo eixo, nos sentidos mesio-distal e vestíbulo-lingual com disco diamantado (11-4254, Buehler Ltd., Lake Buff, IL, EUA) a uma velocidade de 180 r.p.m., sob refrigeração constante com água. Foram obtidos corpos de prova em forma de palito com dimensão de $1 \pm 0,1 \mathrm{~mm}^{2}$. Os valores das áreas de secção transversal foram obtidos com o auxílio de um paquímetro digital (Mitutoyo Sul Americana Ltda., Suzano, São Paulo, Brasil). 
figura 4.2- Delineamento do teste de microtração - Moretto (2009)

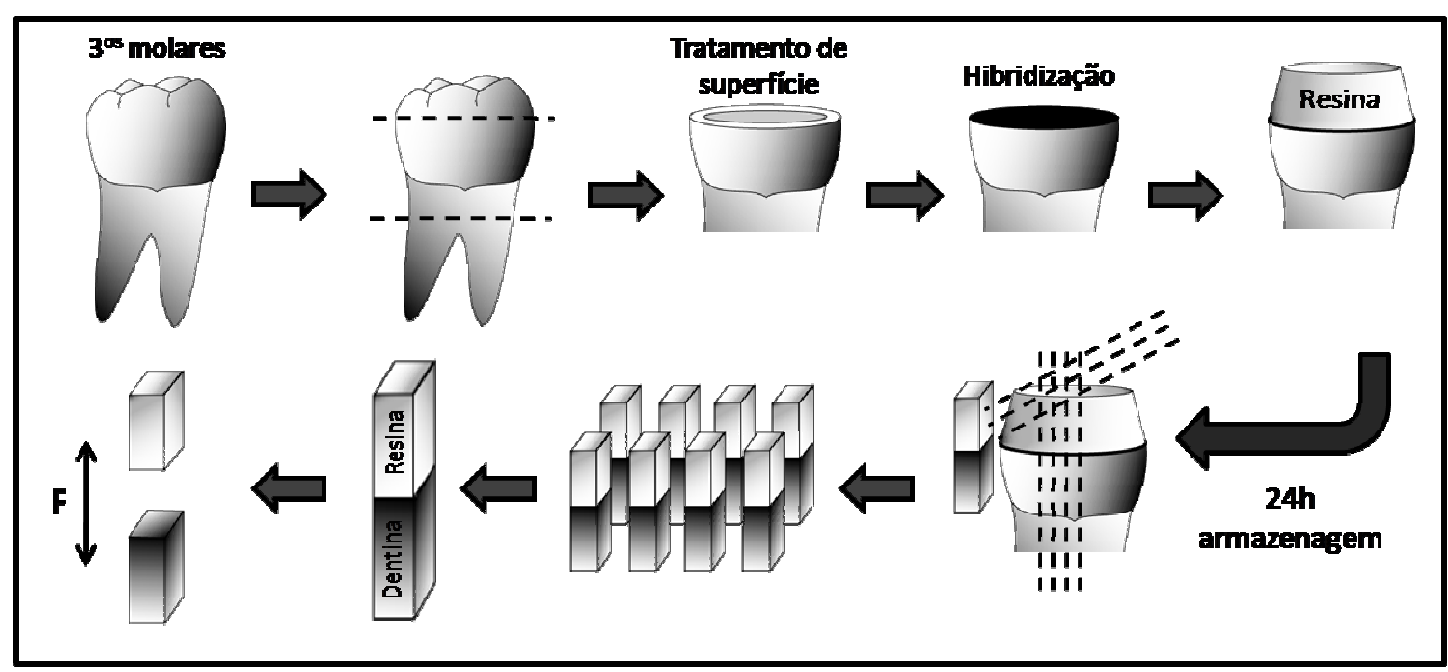

A média de palitos obtidas para cada dente está descrita nos apêndices A e B.

Após os cortes, metade dos palitos de cada dente foi ensaiada imediatamente. O estudo da resistência de união empregou a metodologia de microtração descrita por Sano et al. (1994) e modificado por Shono et al. (1999). Os espécimes foram colados com cianocrilato (Super Bonder; Loctite, São Paulo, Brasil) em um dispositivo próprio e testado em uma máquina universal de ensaio (Instron 4442, Canton, MA, EUA) com velocidade de $0,5 \mathrm{~mm} / \mathrm{min}$.

O restante dos espécimes foi identificado e armazenado em água destilada a $37^{\circ} \mathrm{C}$, e após o tempo de 90 dias, foram ensaiados da mesma maneira que os espécimes iniciais. Foi escolhida como meio de armazenamento a água destilada, de acordo com trabalhos da literatura.

Os espécimes que foram fraturados ou perdidos durante o corte ou durante o tempo de armazenamento foram desprezados. Aqueles que fraturaram 
durante a colagem foram contatos com valor de resistência de união igual a zero.

\section{Análise do padrão de fratura}

Após o rompimento da união, todos os corpos-de-prova do ensaio de microtração foram armazenados para avaliação através da lupa estereoscópica com aumento de 40x para determinar os modos de fraturas.

Foi utilizada a metodologia de avaliação dos modos de fratura descrita por Oliveira et al. (2005), na qual é utilizado o corante Ponceau S diluído em água destilada. Os palitos permaneceram durante 10 minutos no corante, sendo a seguir, lavados em água destilada para remoção do excesso do corante. Nesta metodologia, a dentina fica corada de vermelho, enquanto o adesivo e a resina permanecem descorados. Dessa forma, as fraturas foram classificadas da seguinte forma:

- Tipo I (adesiva): quando uma das faces se apresentava corada;

- Tipo II (coesiva em dentina): quando ambas as faces fraturadas apareciam coradas;

- Tipo III (coesiva em resina composta): quando ambas as faces fraturadas permaneciam descoradas;

- Tipo IV (mista): presença de falha adesiva e coesiva em dentina /adesivo e ou resina composta.

O número de falhas ocorridas para cada tipo foi determinado em porcentagens. 
Legenda da figura 4.3- Fluxograma do procedimento de análise do padrão de fratura

1. Preparo da solução de Ponceau S com água destilada;

2. Imersão dos palitos na solução por 10 minutos;

3. Lavagem dos palitos;

4. Observação do padrão de fratura em Lupa estereoscópica;

5. Determinação do padrão de fratura. 
Figura 4.3- Fluxograma do procedimento de análise do padrão de fratura

\section{ANÁLISE DO PADRÃO DE FRATURA}
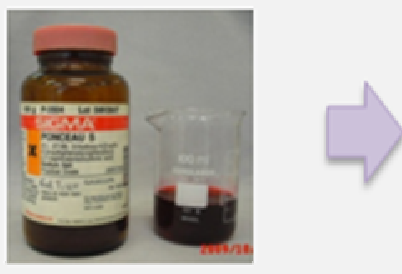

Tipo I (adesiva)

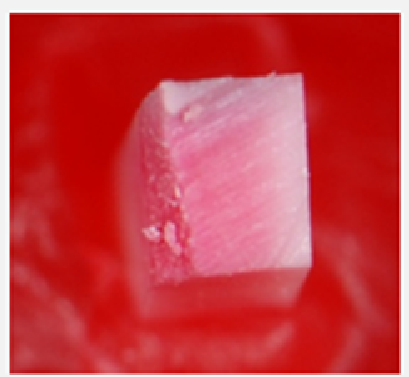

Tipo III (coesiva em resina composta)

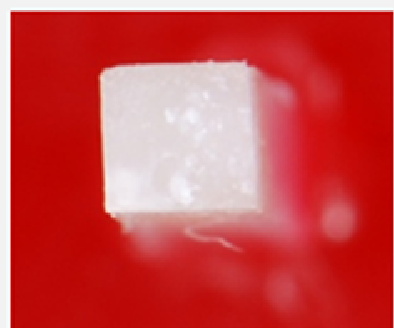

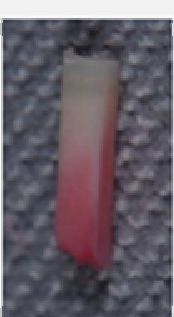

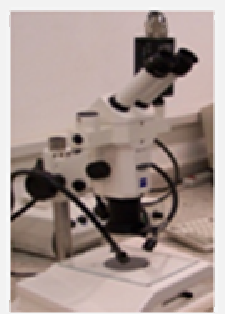

Tipo II (coesiva em dentina)

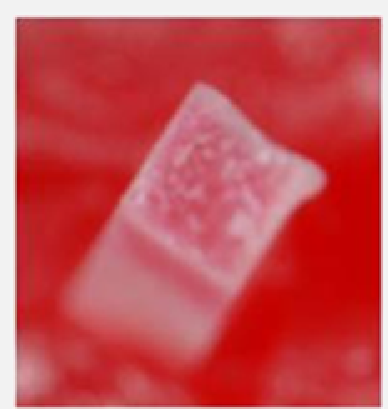

Tipo IV (mista)

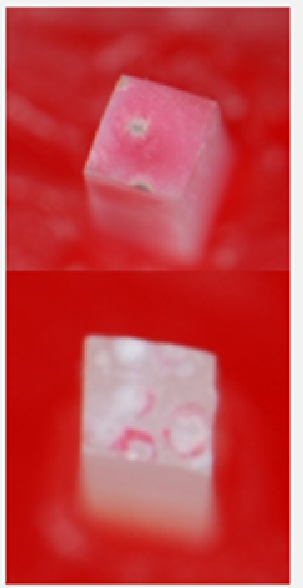




\section{Análise Estatística}

O modelo estatístico escolhido para a análise dos dados deste estudo experimental foi o teste paramétrico de Análise de Variância (ANOVA) de dois fatores independentes, para cada tempo experimental (1 dia - Mpa 1dia e 90 dias MPa 90 dias) sendo a variável dependente, resistência adesiva (unidade $=\mathrm{MPa}$ ) e os fatores de variação, tipo de adesivo e tratamento de superfície. Posteriormente, o efeito do tempo foi avaliado através de testes $T$ pareados para cada condição experimental avaliada em 1 dia e 90 dias. 


\section{5 - Resultados}

Este trabalho experimental possui uma variável dependente, resistência adesiva, cuja unidade experimental é Megapascal (MPa). A variável foi avaliada em dois momentos diferentes (1 dia - Mpa 1 dia e 90dias - Mpa 90dias). Para cada momento de análise, os fatores de variação foram dois, adesivos em três níveis (Single Bond, Clearfill SE Bond e S3), e tratamentos de superfície em três níveis (Controle - Lixa \#600, Laser Er:YSGG 2W e Laser Er:YSGG 4W).

A tabela 5.1 apresenta a estatística descritiva e os parâmetros estatísticos dos dados. 
Tabela 5.1 - Estatística descritiva e os parâmetros estatísticos dos dados.

\begin{tabular}{|c|c|c|c|c|c|c|c|c|c|c|}
\hline Tempo & Adesivos & Tratamentos & $\mathbf{N}$ & Média & Variância & D.P. & Erro & Max. & Min. & C.V.(\%) \\
\hline \multirow[t]{16}{*}{ MPa 1 dia } & SB & Controle & 6 & 32.36 & 13.75 & 3.71 & 1.51 & 36.69 & 27.92 & $11.46 \%$ \\
\hline & & Laser $2 \mathrm{~W}$ & 6 & 18.43 & 63.22 & 7.95 & 3.25 & 28.07 & 3.79 & $43.14 \%$ \\
\hline & & Laser $4 \mathrm{~W}$ & 6 & 25.96 & 28.79 & 5.37 & 2.19 & 33.19 & 19.41 & $20.67 \%$ \\
\hline & & Total & 18 & 25.58 & 65.45 & 8.09 & 1.91 & 36.69 & 3.79 & $31.62 \%$ \\
\hline & SE & Controle & 6 & 27.68 & 71.56 & 8.46 & 3.45 & 37.67 & 15.48 & $30.57 \%$ \\
\hline & & Laser $2 \mathrm{~W}$ & 6 & 20.30 & 41.38 & 6.43 & 2.63 & 26.82 & 12.68 & $31.69 \%$ \\
\hline & & Laser 4W & 6 & 27.60 & 83.74 & 9.15 & 3.74 & 40.18 & 14.02 & $33.15 \%$ \\
\hline & & Total & 18 & 25.19 & 70.53 & 8.40 & 1.98 & 40.18 & 12.68 & $33.34 \%$ \\
\hline & S3 & Controle & 6 & 29.52 & 24.46 & 4.95 & 2.02 & 34.99 & 20.35 & $16.75 \%$ \\
\hline & & Laser $2 \mathrm{~W}$ & 6 & 18.26 & 43.41 & 6.59 & 2.69 & 26.24 & 10.80 & $36.07 \%$ \\
\hline & & Laser $4 \mathrm{~W}$ & 6 & 15.80 & 103.05 & 10.15 & 4.14 & 26.83 & 4.35 & $64.24 \%$ \\
\hline & & Total & 18 & 21.20 & 88.02 & 9.38 & 2.21 & 34.99 & 4.35 & $44.26 \%$ \\
\hline & Total & Controle & 18 & 29.85 & 36.23 & 6.02 & 1.42 & 37.67 & 15.48 & $20.16 \%$ \\
\hline & & Laser $2 \mathrm{~W}$ & 18 & 19.00 & 44.43 & 6.67 & 1.57 & 28.07 & 3.79 & $35.09 \%$ \\
\hline & & Laser 4W & 18 & 23.12 & 92.23 & 9.60 & 2.26 & 40.18 & 4.35 & $41.54 \%$ \\
\hline & & Total & 54 & 23.99 & 75.85 & 8.71 & 1.19 & 40.18 & 3.79 & $36.30 \%$ \\
\hline \multirow[t]{16}{*}{ MPa 90 dias } & SB & Controle & 6 & 31.70 & 27.27 & 5.22 & 2.13 & 39.75 & 25.30 & $16.47 \%$ \\
\hline & & Laser 2W & 6 & 12.87 & 42.51 & 6.52 & 2.66 & 21.35 & 5.88 & $50.67 \%$ \\
\hline & & Laser 4W & 6 & 15.82 & 44.03 & 6.64 & 2.71 & 25.76 & 7.22 & $41.94 \%$ \\
\hline & & Total & 18 & 20.13 & 105.87 & 10.29 & 2.43 & 39.75 & 5.88 & $51.12 \%$ \\
\hline & SE & Controle & 6 & 17.52 & 84.79 & 9.21 & 3.76 & 25.73 & 0.39 & $52.56 \%$ \\
\hline & & Laser $2 \mathrm{~W}$ & 6 & 11.51 & 59.53 & 7.72 & 3.15 & 19.24 & 1.84 & $67.05 \%$ \\
\hline & & Laser 4W & 6 & 12.08 & 78.22 & 8.84 & 3.61 & 23.98 & 0.00 & $73.22 \%$ \\
\hline & & Total & 18 & 13.70 & 73.22 & 8.56 & 2.02 & 25.73 & 0.00 & $62.45 \%$ \\
\hline & S3 & Controle & 6 & 35.66 & 42.75 & 6.54 & 2.67 & 45.14 & 28.97 & $18.34 \%$ \\
\hline & & Laser $2 \mathrm{~W}$ & 6 & 9.45 & 78.50 & 8.86 & 3.62 & 20.82 & 0.00 & $93.75 \%$ \\
\hline & & Laser 4W & 6 & 9.41 & 29.80 & 5.46 & 2.23 & 18.03 & 1.43 & $58.00 \%$ \\
\hline & & Total & 18 & 18.17 & 206.25 & 14.36 & 3.39 & 45.14 & 0.00 & $79.03 \%$ \\
\hline & Total & Controle & 18 & 28.29 & 109.74 & 10.48 & 2.47 & 45.14 & 0.39 & $37.03 \%$ \\
\hline & & Laser 2W & 18 & 11.28 & 55.19 & 7.43 & 1.75 & 21.35 & 0.00 & $65.89 \%$ \\
\hline & & Laser $4 \mathrm{~W}$ & 18 & 12.44 & 52.04 & 7.21 & 1.70 & 25.76 & 0.00 & $58.00 \%$ \\
\hline & & Total & 54 & 17.33 & 130.97 & 11.44 & 1.56 & 45.14 & 0.00 & $66.02 \%$ \\
\hline
\end{tabular}




\section{Modelo Experimental}

O modelo estatístico escolhido para a análise dos dados deste estudo experimental foi o teste paramétrico de Análise de Variância (ANOVA) de dois fatores independentes, para cada tempo experimental (1 dia - Mpa 1dia e 90 dias $\mathrm{MPa} 90$ dias) sendo a variável dependente, resistência adesiva (unidade $=\mathrm{MPa}$ ) e os fatores de variação, tipo de adesivo e tratamento de superfície. Posteriormente, o efeito do tempo foi avaliado através de testes $T$ pareados para cada condição experimental avaliada em 1 dia e 90 dias.

\section{Estudo do efeito dos fatores Adesivos e Tratamento de Superfície para a variável MPa para cada tempo MPA 1 dia e MPa 90 dias.}

\section{Teste de normalidade}

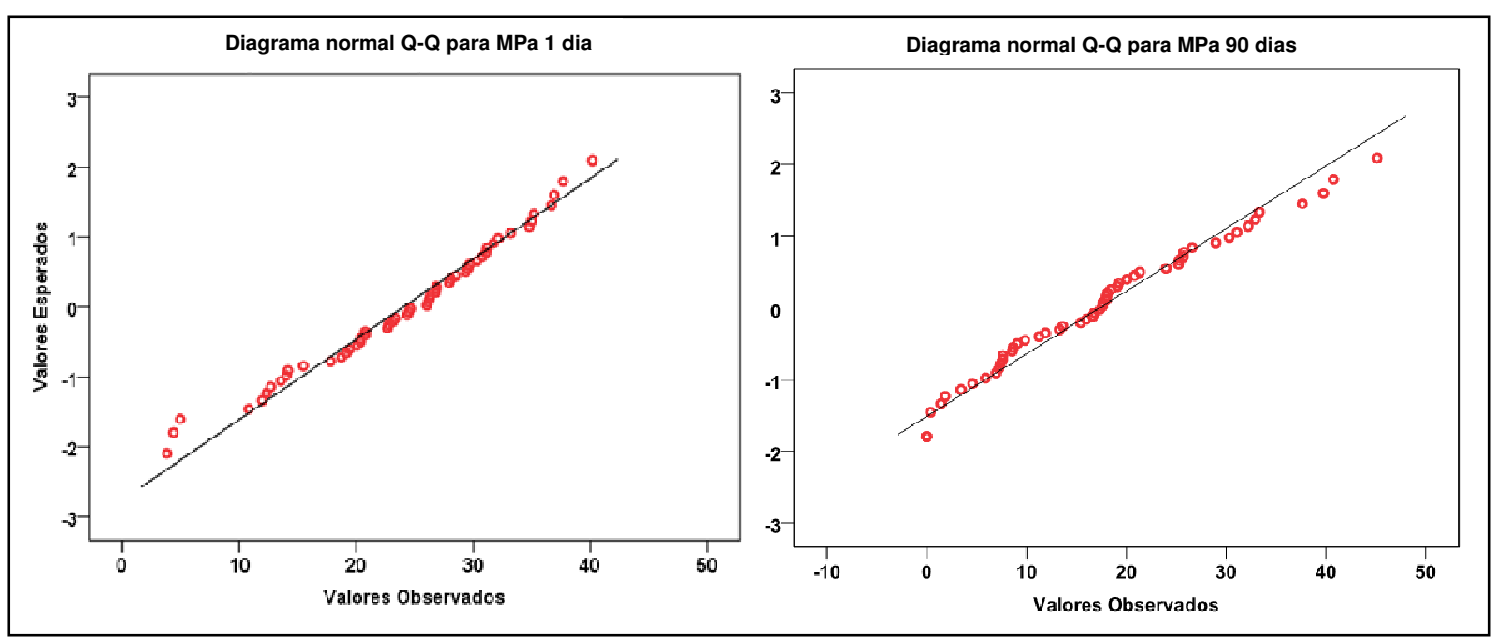

Figura 5.1- Diagramas de distribuição normal para a variável dependente MPa para os tempos de 1 dia e 90 dias

Observando-se a figura acima, pode-se constatar uma relação linear entre os valores observados da variável dependente e os valores esperados 
(teóricos), para ambos os casos MPa 1dia e MPa 90 dias. Este perfil linear sugere que a variável nos dois tempos, está normalmente distribuída.

Tabela 5.2 - Teste de normalidade de Shapiro Wilk (W) para a variável MPa nos tempos de 1 dia e 90 dias

\section{Shapiro-Wilk}

Estatística gl Sig (p).

(W)

MPa 1 dia 0.973

MPa $\quad 90 \quad 0.965$

$54 \quad 0.257$

dias

0.119

O teste de normalidade de Shapiro Wilk (Tabela 5.2) confirma a figura 5.1 e apontou que a variável $\mathrm{MPa}$ (MPa 1 dia e MPa 90 dias), está normalmente distribuída, com valores de $\mathrm{p}>0.05$

\section{Teste de homogeneidade}

Tabela 5.3 - Teste de homogeneidade de Levene para a variável dependente MPa (MPa 1 dia e MPa 90 dias)

\begin{tabular}{|c|c|c|c|c|}
\hline $\begin{array}{ll}\text { Teste } & \mathrm{d} d \\
\text { Levene }^{\mathrm{a}}\end{array}$ & $\bar{F}$ & gl1 & $g / 2$ & Sig (p). \\
\hline MPa 1 dia & 1.466 & 8 & 45 & 0.197 \\
\hline MPa 90 dias & 0.619 & 8 & 45 & 0.757 \\
\hline \multicolumn{5}{|c|}{ 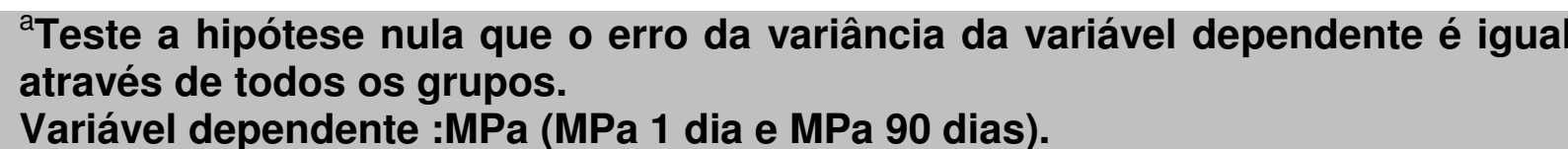 } \\
\hline
\end{tabular}

O teste de homogeneidade de Levene (Tabela 5.3) apontou que para a variável MPa (MPa 1 dia; $F(8,45)=1.466 \mathrm{p}=0.197$ e MPa 90 dias $\mathrm{F}(8 ; 45)=0.619$ $p=0.797$ ), os valores de " $p$ " são não significantes, sendo então os dados homogêneos. 


\section{Análise de Variância (ANOVA)}

Tabela 5.4 - Análise de variância para MPa 1 dia e MPa 90dias

\begin{tabular}{|c|c|c|c|c|c|c|c|}
\hline $\begin{array}{l}\text { Fonte de } \\
\text { Variação }\end{array}$ & $\begin{array}{l}\text { Variável } \\
\text { Dependent } \\
\text { e }\end{array}$ & S.Q. & GL & QM & $\bar{F}$ & $\begin{array}{l}\text { Sig } \\
\text { (p). }\end{array}$ & $\begin{array}{l}\mathbf{F} \\
\text { Crítico } \\
\mathrm{a}\end{array}$ \\
\hline \multirow{2}{*}{ Adesivo } & MPa 1 dia & 212.260 & 2 & 106.130 & 2.018 & 0.145 & 3.204 \\
\hline & $\begin{array}{ll}\text { MPa } & 90 \\
\text { dias } & \end{array}$ & 390.739 & 2 & 195.369 & 3.608 & 0.035 & 3.204 \\
\hline \multirow{2}{*}{$\begin{array}{l}\text { Tratament } \\
\text { o }\end{array}$} & MPa 1 dia & 1081.147 & 2 & 540.573 & $\begin{array}{l}10.27 \\
8\end{array}$ & 0.000 & 3.204 \\
\hline & $\begin{array}{l}\mathrm{MPa} \\
\text { dias }\end{array}$ & 3253.118 & 2 & $\begin{array}{l}1626.55 \\
9\end{array}$ & $\begin{array}{l}30.03 \\
5\end{array}$ & 0.000 & 3.204 \\
\hline Adesivo * & MPa 1 dia & 360.030 & 4 & 90.008 & 1.711 & 0.164 & 2.579 \\
\hline $\begin{array}{l}\text { Tratament } \\
\text { o }\end{array}$ & 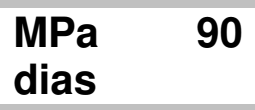 & 860.634 & 4 & 215.158 & 3.973 & 0.008 & 2.579 \\
\hline Erro & MPa 1 dia & 2366.823 & 45 & 52.596 & & & \\
\hline (Resíduo) & $\begin{array}{ll}\begin{array}{ll}\mathrm{MPa} \\
\text { dias }\end{array} & 90\end{array}$ & 2436.982 & 45 & 54.155 & & & \\
\hline \multirow[t]{2}{*}{ Total } & MPa 1 dia & $\begin{array}{l}35098.77 \\
0\end{array}$ & 54 & & & & \\
\hline & $\begin{array}{l}\text { MPa } \\
\text { dias }\end{array}$ & $\begin{array}{l}23167.38 \\
0\end{array}$ & 54 & & & & \\
\hline
\end{tabular}

S.Q. = Soma dos Quadrados; Q.M. = Quadrado Médio; GL = Graus de Liberdade

O resultado do teste de ANOVA (Tabela 5.4) aponta que para MPa 1 dia, o fator Tratamento $F(2,45)=10.27 p<0.05$ é significante, ao passo que o fator Adesivo $F(2,45)=2.01 \quad p>0.05$ e a interação $F(4,45)=1.71 \quad p>0.05$ são não significantes.

Para MPa 90 dias, ambos os fatores Tratamento $F(2,45)=30.03 p<0.05$, e Adesivo $F(2,45)=3.60 \quad p<0.05$ são significantes, assim como a interação $F(4,45)=3.97 p<0.05$.

A tabela da ANOVA também nos mostra haver diferenças mais evidentes, para MPa de 90 dias, no que diz respeito ao teste " $F$ ". Podemos ver que todos os valores de "F" calculado para MPa 90 dias são maiores que os valores Críticos, o que denota o aparecimento de significância estatística para ambos os 
fatores e a interação, como citado no parágrafo acima, e também valores maiores que os calculados para MPa 1 dia.

O teste paramétrico complementar de múltipla comparação de Tukey foi aplicado para detectar as possíveis diferenças entre os grupos experimentais para cada fator e interação para MPa 1dia e MPa 90 dias.

As tabelas 5.5 e 5.6 trazem os testes complementares de múltipla comparação de Tukey para as médias do fator Adesivo para MPa 1 dia e MPa 90 dias.

Tabela 5.5 - Teste de Tukey (HSD) para os grupos do Fator Adesivo para MPa 1 dia

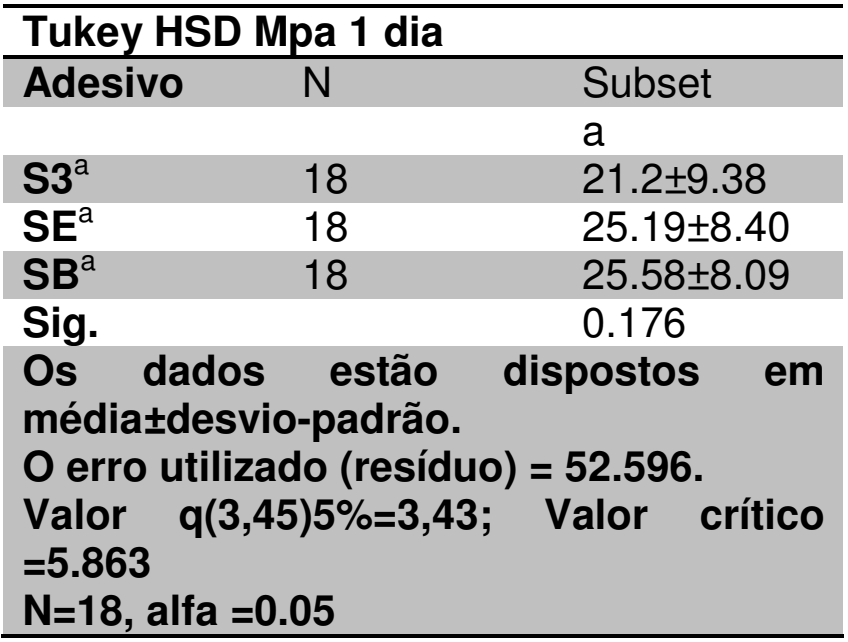

Letras (ou índices) diferentes denotam diferença estatística

Tabela 5.6 - Teste de Tukey (HSD) para os grupos do Fator Adesivo para MPa 90 dias

\begin{tabular}{|c|c|c|c|}
\hline \multicolumn{4}{|c|}{ Tukey HSD (Mpa 90 dias) } \\
\hline \multirow{2}{*}{ Adesivo } & \multicolumn{3}{|c|}{ Adesivo } \\
\hline & & a & b \\
\hline $\mathbf{S E}^{\mathrm{a}}$ & 18 & $13.70 \pm 8.56$ & \\
\hline $\mathbf{S 3}^{\mathrm{a}, \mathrm{b}}$ & 18 & $18.17 \pm 14.36$ & $18.17 \pm 14.3$ \\
\hline $\mathbf{S B}^{\mathrm{b}}$ & 18 & & $20.13 \pm 10.29$ \\
\hline Sig. & & 0.174 & 0.707 \\
\hline \multicolumn{4}{|c|}{$\begin{array}{l}\text { Os dados estão dispostos em média } \pm \text { desvio-padrão. } \\
\text { O erro utilizado (resíduo) }=54.155 \text {. } \\
\text { Valor } q(3,45) 5 \%=3,43 ; \text { Valor crítico }=5.949 \\
N=18 \text { alfa }=0.05\end{array}$} \\
\hline
\end{tabular}

Letras (ou índices) diferentes denotam diferença estatística

$\mathrm{Na}$ tabela 5.5, pode-se observar que para MPa 1 dia não há diferença entre os níveis (grupos) do fator Adesivo, como demonstrado pelo teste $\mathrm{F}$ da ANOVA 
(Tabela 5.4), pois nenhum dos grupos apresenta diferenças entre si maiores que o valor crítico de 5.863.

Para MPa 90 dias (Tabela 5.6) de maneira geral, existe diferença entre os grupos SE (13.70 \pm 8.56$)$ e SB $(20.13 \pm 10.29)$, sendo ambos semelhantes ao grupo S3

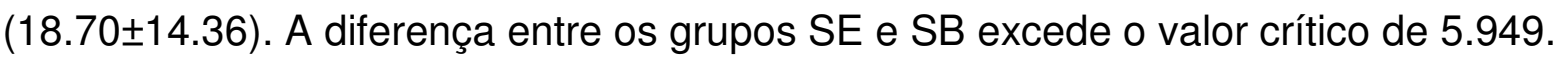

As tabelas 5.7 e 5.8 trazem os testes complementares de múltipla comparação de Tukey para as médias do fator Tratamento para MPa 1 dia e MPa 90 dias.

Tabela 5.7 - Teste de Tukey (HSD) para os grupos do Fator Tratamento para MPa 1 dia

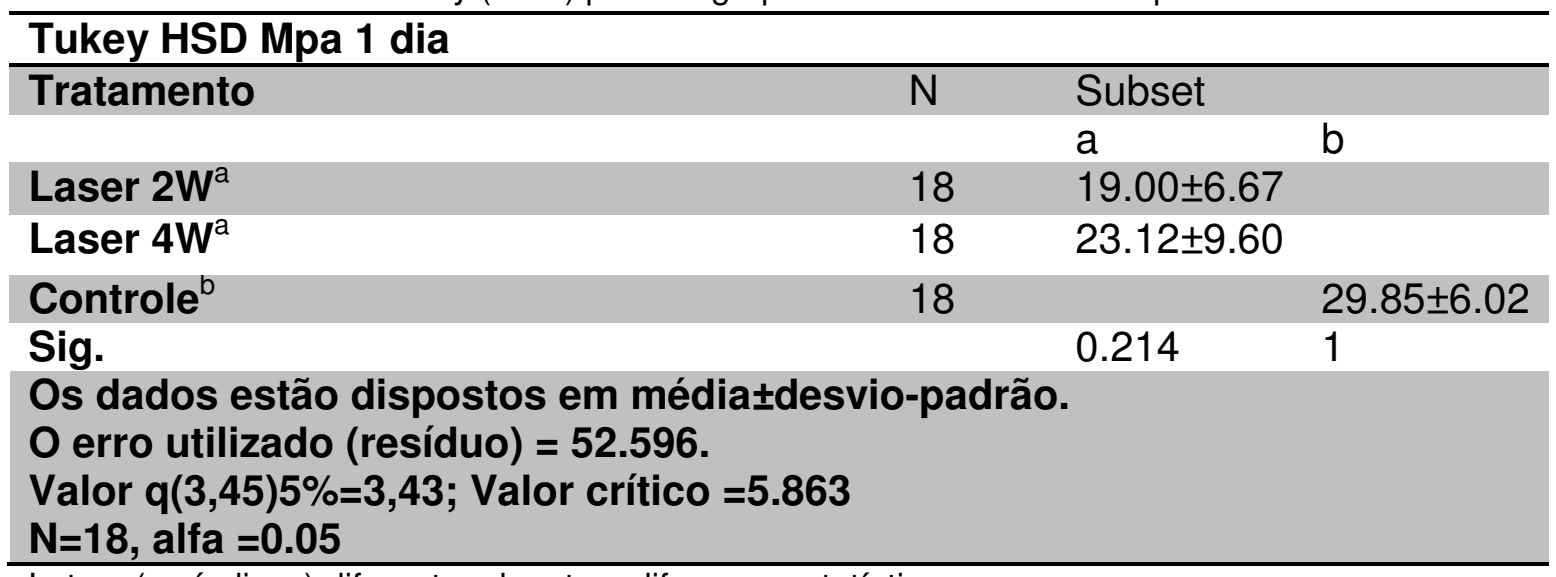

Letras (ou índices) diferentes denotam diferença estatística

Tabela 5.8 - Teste de Tukey (HSD) para os grupos do Fator Tratamento para MPa 90 dias

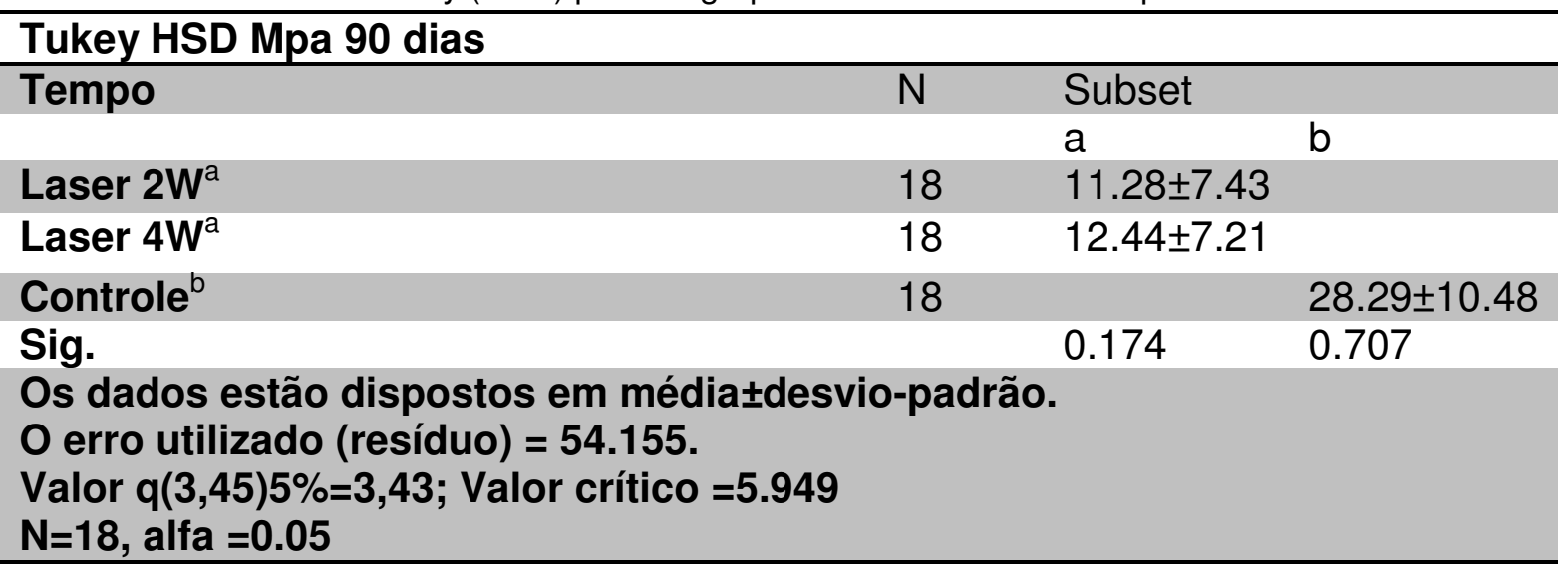

Letras (ou índices) diferentes denotam diferença estatística 
As tabelas 5.7 e 5.8 mostram que tanto para MPa 1 dia, tanto para MPa 90 dias, o comportamento dos grupos do Fator Tratamento foi o mesmo. Para MPa 1dia (Tabela 5.7) os grupos Laser $2 \mathrm{~W}(19.00 \pm 6.67)$ e Laser $4 \mathrm{~W} \quad(23.12 \pm 9.60)$ apresentaram valores de resistência adesiva semelhantes entre si e menores

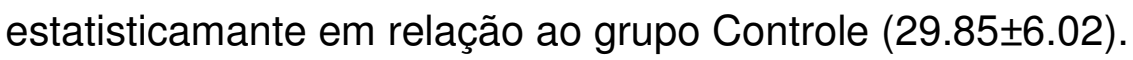

Para MPa 90 dias o mesmo foi observado e de maneira geral os grupos Laser $2 \mathrm{~W}(11.28 \pm 7.43)$ e Laser $4 \mathrm{~W}(12.44 \pm 7.21)$ foram semelhantes entre si e menores

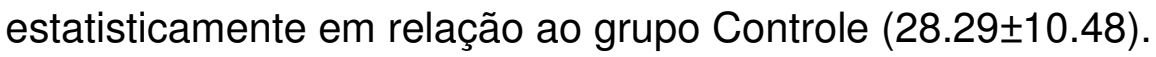

As tabelas 5.9 e 5.10 trazem o teste complementar de múltipla comparação de Tukey para as médias da Interação entre Adesivos e Tratamento.

Tabela 5.9 - Teste de Tukey (HSD) par os grupos da interação Adesivos x Tratamento para MPa 1 dia

\begin{tabular}{lllll}
\hline Tukey HSD ( Mpa 1 dia) & \multicolumn{3}{l}{ Subset } & \\
\hline Grupos & $\mathrm{N}$ & $\mathrm{A}$ & $\mathrm{b}$ & $\mathrm{C}$ \\
Laser 4W S3 $^{\mathrm{a}}$ & 6 & $15.80 \pm 10.15$ & & \\
Laser 2W S3 $^{\mathrm{a}, \mathrm{b}}$ & 6 & $18.26 \pm 6.59$ & $18.26 \pm 6.60$ & \\
Laser 2W SB $^{\mathrm{a}, \mathrm{b}}$ & 6 & $18.43 \pm 7.95$ & $18.43 \pm 7.96$ & \\
Laser 2W SE $^{\mathrm{a}, \mathrm{b}, \mathrm{c}}$ & 6 & $20.30 \pm 6.43$ & $20.30 \pm 6.44$ & $20.30 \pm 6.45$ \\
Laser 4W SB $^{\mathrm{a}, \mathrm{b}, \mathrm{c}}$ & 6 & $25.96 \pm 5.37$ & $25.96 \pm 5.38$ & $25.96 \pm 5.39$ \\
Laser 4W SE$^{\mathrm{a}, \mathrm{b}, \mathrm{c}}$ & 6 & $27.60 \pm 9.15$ & $27.60 \pm 9.16$ & $27.60 \pm 9.17$ \\
Controle SE $^{\mathrm{a}, \mathrm{b}, \mathrm{c}}$ & 6 & $27.68 \pm 8.46$ & $27.68 \pm 8.47$ & $27.68 \pm 8.48$ \\
Controle S3 $^{\mathrm{b}, \mathrm{c}}$ & 6 & & $29.52 \pm 4.95$ & $29.52 \pm 4.96$ \\
Controle SB $^{\mathrm{c}}$ & 6 & & & $32.36 \pm 3.71$ \\
Sig. & & 0.13 & 0.18 & 0.12
\end{tabular}

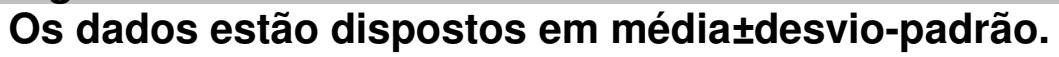

O erro utilizado (resíduo) $=\mathbf{5 2 . 5 9 6}$.

Valor $q(9,45) 5 \%=4.61$; Valor crítico $=13.671$

$\mathrm{N}=6$, alfa $=0.05$

Letras (ou índices) diferentes denotam diferença estatística 
Tabela 5.10 - Teste de Tukey (HSD) par os grupos da interação Adesivos x Tratamento para MPa 90 dias

\begin{tabular}{|c|c|c|c|}
\hline Tukey HSD (Mpa 90 dias) & & Subset & \\
\hline Grupos & $\mathrm{N}$ & $\bar{a}$ & $\mathrm{~b}$ \\
\hline Laser 4W S3 ${ }^{\mathrm{a}}$ & 6 & $9.41 \pm 5.46$ & \\
\hline Laser $2 \mathrm{~W} \mathrm{S3}{ }^{\mathrm{a}}$ & 6 & $9.45 \pm 8.86$ & \\
\hline Laser $2 \mathrm{~W} \mathrm{SE}^{\mathrm{a}}$ & 6 & $11.51 \pm 7.72$ & \\
\hline Laser $4 \mathrm{~W} \mathrm{SE}^{\mathrm{a}}$ & 6 & $12.08 \pm 8.84$ & \\
\hline Laser $2 \mathrm{~W} \mathbf{S B}^{\mathrm{a}}$ & 6 & $12.87 \pm 6.52$ & \\
\hline Laser $4 \mathrm{~W} \mathrm{SB}^{\mathrm{a}}$ & 6 & $15.82 \pm 6.64$ & \\
\hline Controle SE ${ }^{\mathrm{a}}$ & 6 & $17.52 \pm 9.21$ & \\
\hline Controle SB ${ }^{b}$ & 6 & & $31.70 \pm 5.22$ \\
\hline Controle S3 $^{\mathrm{b}}$ & 6 & & $35.66 \pm 6.54$ \\
\hline Sig. & & 0.61 & 0.99 \\
\hline \multicolumn{4}{|c|}{$\begin{array}{l}\text { Os dados estão dispostos em média } \pm \text { desvio-padrão. } \\
\text { O erro utilizado (resíduo) }=54.155 \\
\text { Valor } q(9,45) 5 \%=4.61 ; \text { Valor crítico }=13.872 \\
\mathrm{~N}=6, \text { alfa }=0.05\end{array}$} \\
\hline
\end{tabular}

Os gráficos 5.1 e 5.2 trazem a ilustração do comportamento dos intervalos de confiança para os grupos da interação entre Adesivos e Tratamento para MPa 1dia e Mpa 90 dias respectivamente.

Gráfico 5.1 Intervalos de confiança de 95\% para os grupos da interação Adesivos x Tratamnetos para $\mathrm{MPa} 1$ dia. Erro padrão $=2.961$

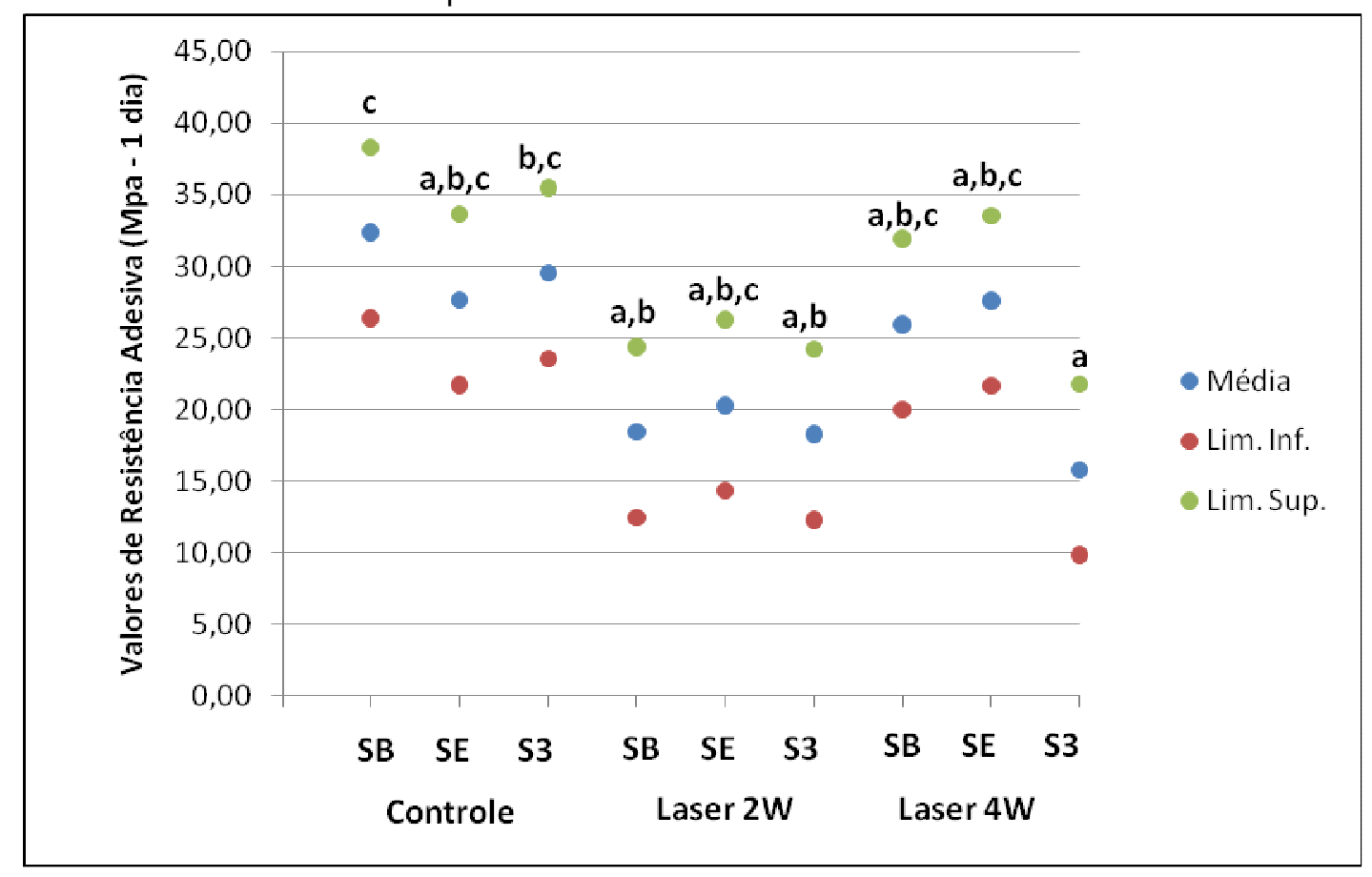

Letras (ou índices) diferentes denotam diferença estatística 
Gráfico 5.2 Intervalos de confiança de 95\% para os grupos da interação Adesivos x Tratamentos para MPa 90 dias. Erro padrão $=3.004$

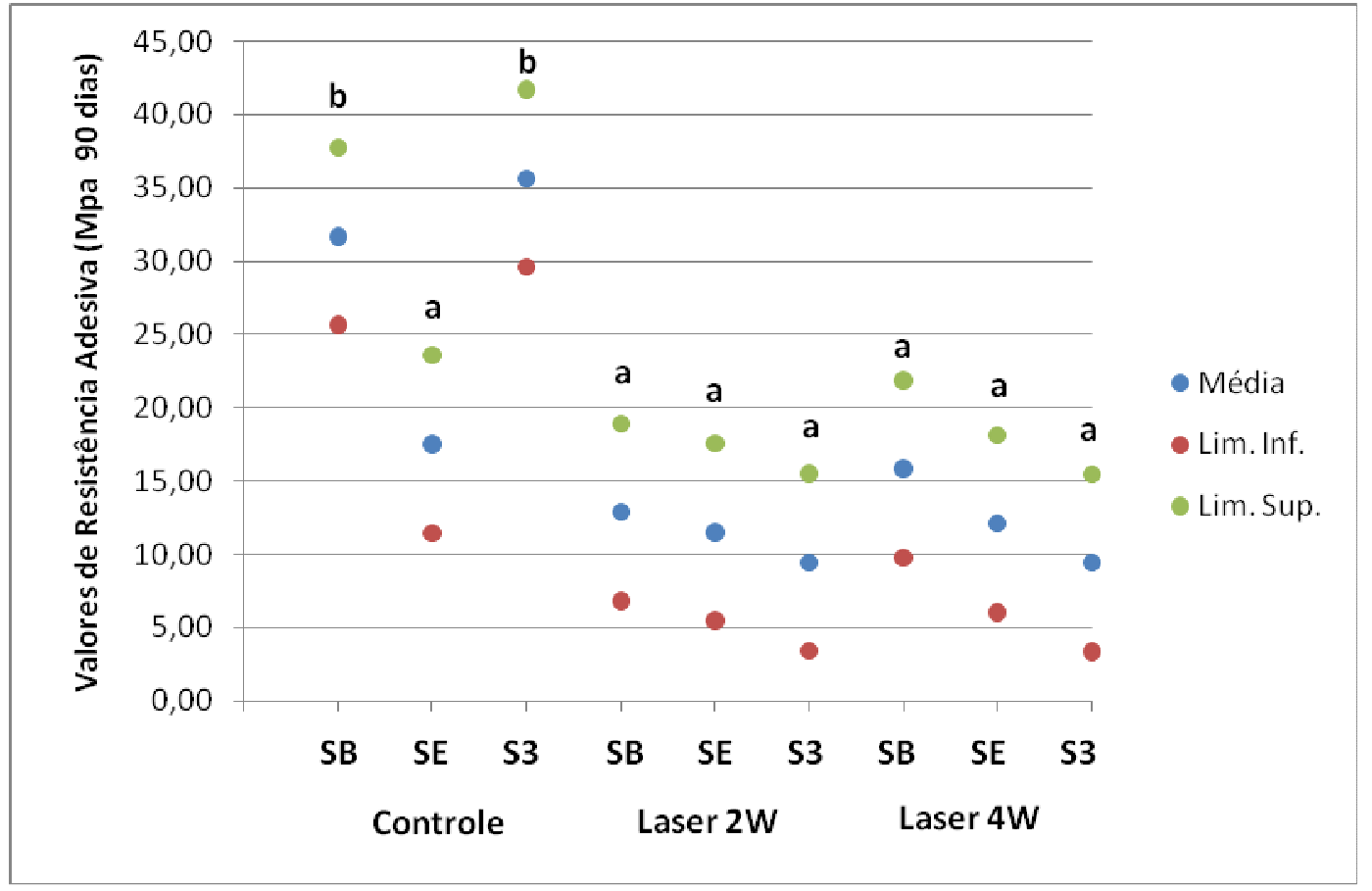

Letras (ou índices) diferentes denotam diferença estatística

A tabela 5.9 traz as comparações entre os grupos para MPa 1 dia. Pode-se notar uma grande semelhança estatística entre os grupos. Os grupos Laser 2W SE, Laser 4W SB, Laser 4W SE e Controle SE são todos semelhantes entre si e também aos demais tratamentos. Observa-se também que para o Adesivo SE, nenhum dos tratamentos é diferente entre si. Para o Adesivo S3 e SB diferenças ocorreram. Para - Adesivo SB, os tratamentos Controle e Laser de $2 \mathrm{~W}$ são diferentes estatisticamente entre si e semelhantes ao tratamento Laser 4W. Para o Adesivo S3, os tratamentos Controle e Laser $4 \mathrm{~W}$ são diferentes entre si e semelhantes ao tratamento Laser 2W. Estes comportamentos estão ilustrados no gráfico 5.1.

A tabela 5.10 traz as comparações entre os grupos para MPa 90 dias. Notase uma clara diferença entre os tratamentos. Os grupos Controle para o Adesivo SB e S3 apresentam maiores valores de resistência adesiva em comparação aos 
demais grupos, que por sua vez são semelhantes estatisticamente entre si. 0 Adesivo SE não apresentou diferença entre os tratamentos Controle, Laser 2W e Laser 4W, comportamento semelhante ao apresentado para MPa 1 dia. Os Adesivos SB e S3 apresentam comportamento estatístico semelhante, com os tratamentos controle apresentando valores de resistência adesiva maiores estatisticamente em relação aos tratamentos Laser $2 \mathrm{~W}$ e Laser $4 \mathrm{~W}$, que por sua vez são semelhantes entre si. Estes comportamentos estão ilustrados no gráfico 5.2.

A tabela 5.11 traz as comparações entre os tempos experimentais, para cada grupo através de teste T pareado.

Tabela 5.11 - Teste T pareados entre os tempo de 1 dia e 90dias para cada grupo experimental.

\begin{tabular}{lllll}
\hline Grupos & MPa 1dia & Mpa 90 dias & t calculado & Sig. $(\mathbf{p})$ \\
\hline Controle SB & $32.36 \pm 3.71$ & $31.70 \pm 5.22$ & 0.23 & 0.83 \\
Controle SE & $27.68 \pm 8.46$ & $17.52 \pm 9.21$ & 3.19 & 0.02 \\
Controle S3 & $29.52 \pm 4.95$ & $35.66 \pm 6.54$ & -2.97 & 0.03 \\
Laser 2W SB & $18.43 \pm 7.95$ & $12.87 \pm 6.52$ & 2.19 & 0.08 \\
Laser 2W SE & $20.30 \pm 6.43$ & $11.51 \pm 7.72$ & 6.91 & 0.00 \\
Laser 2W S3 & $18.26 \pm 6.59$ & $9.45 \pm 8.86$ & 2.27 & 0.07 \\
Laser 4W SB & $25.96 \pm 5.37$ & $15.82 \pm 6.64$ & 3.35 & 0.02 \\
Laser 4W SE & $27.60 \pm 9.15$ & $12.08 \pm 8.84$ & 2.93 & 0.03 \\
Laser 4W S3 & $15.80 \pm 10.15$ & $9.41 \pm 5.46$ & 1.76 & 0.14 \\
\hline
\end{tabular}

Dados dispostos em média \pm desvio-padrão

t crítico $(5 \mathrm{gl}, 5 \%)=2.57$

$\mathrm{n}=6$

Letras (ou índices) diferentes denotam diferença estatística

A tabela 5.11 mostra as comparações pontuais entre os dois tempos experimentais para cada grupo. Pode-se notar que, de maneira geral, os valores de resistência adesiva diminuem com o aumento do tempo de armazenamento, porém os resultados só foram significantes, onde o valor t calculado excedeu o valor crítico de 2.57, para os grupos Controle SE, Laser 2W SE, Laser 4W SB e Laser 4W SE. O 
grupo Controle S3 também apresentou diferença estatisticamente significante entre os tempos, porém observou-se um comportamento inverso, ou seja, um aumento dos valores de resistência adesiva para o tempo de 90 dias.

Também se pode observar, de maneira interessante, que o Adesivo SE apresentou decréscimo significante dos valores de resistência adesiva de 1 dia para 90 dias, para todas as condições de tratamento : Controle, Laser 2W e Laser 4W.

\section{Análise do padrão de fratura}

Os resultados da análise do padrão de fratura para 24 horas e 90 dias podem ser observados nos gráficos 5.3 e 5.4, respectivamente.

Gráfico 5.3- Análise do padrão de fratura após 24 horas

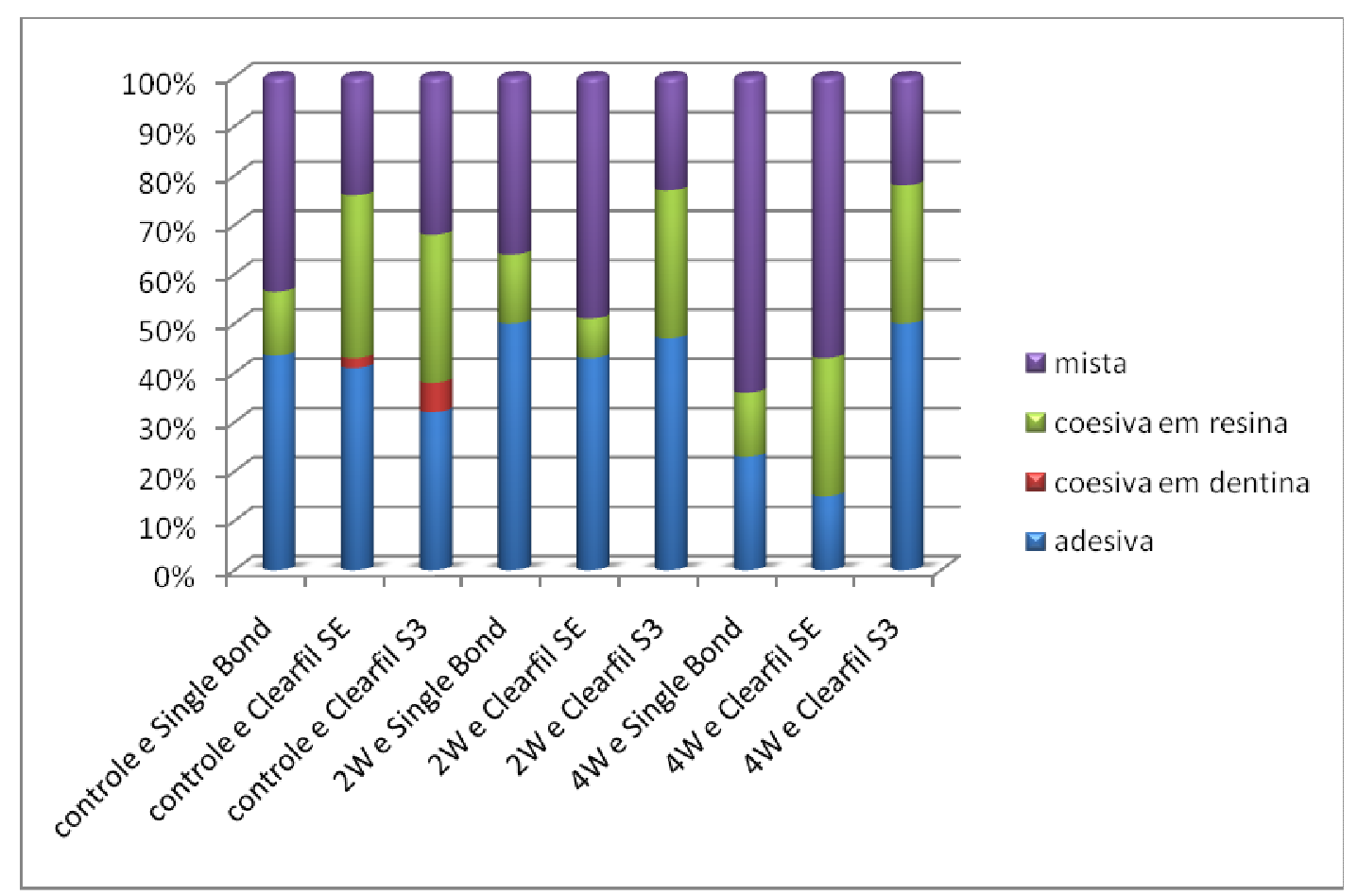


Gráfico 5.4- Análise do padrão de fratura após 90 dias

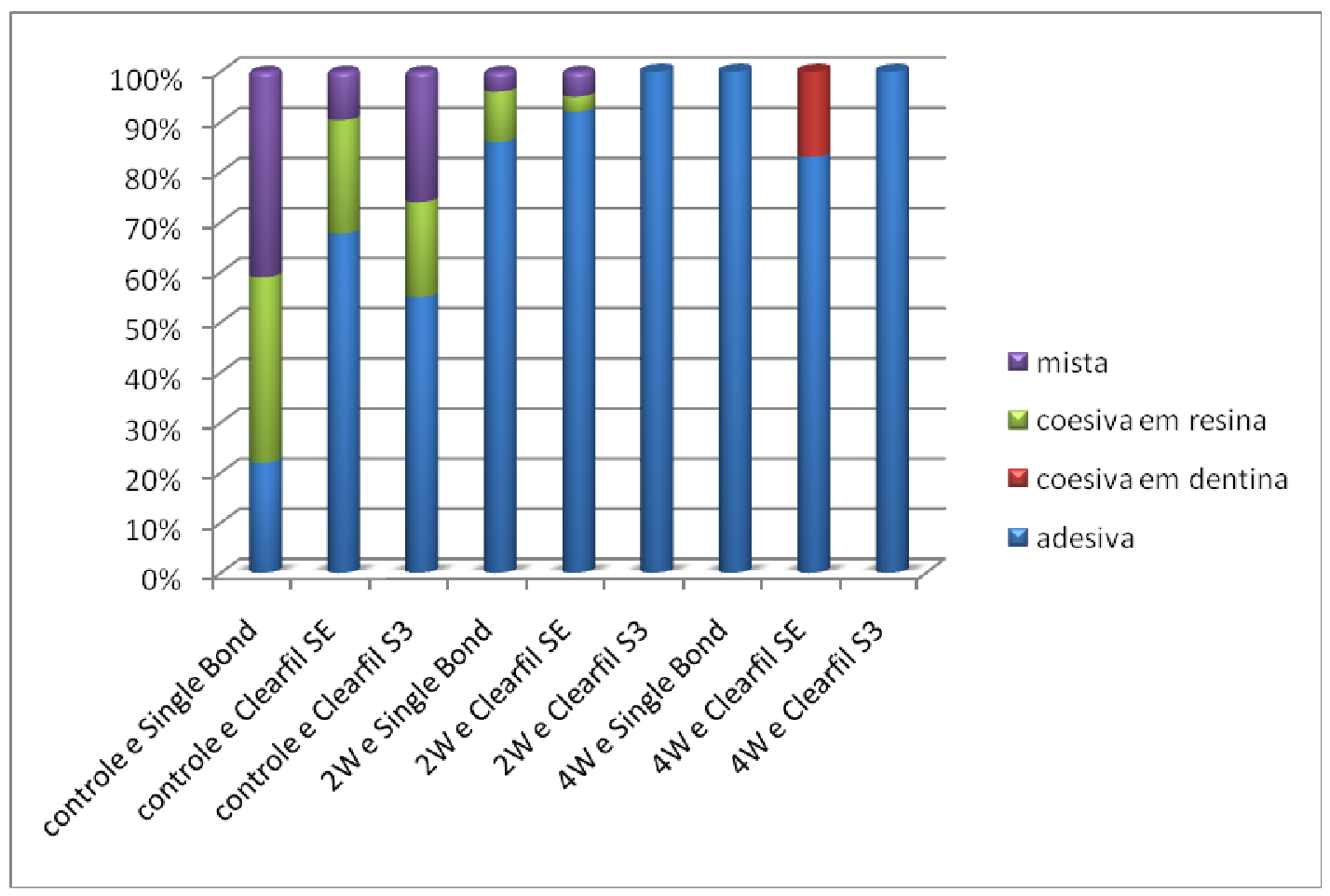




\section{6-DıscussÃo}

A conservação da estrutura dental, assim como a longevidade das restaurações adesivas, são tópicos de grande interesse no momento atual da pesquisa em Odontologia.

Frente à filosofia dos tratamentos minimamente invasivos, a utilização dos lasers de érbio para preparos cavitários apresenta-se como uma alternativa vantajosa aos instrumentos cortantes rotatórios. Porém, pouco se sabe sobre a longevidade de restaurações adesivas realizadas após a utilização destes equipamentos. Assim sendo, este trabalho teve como objetivo avaliar a estabilidade de superfícies dentinárias tratadas com o laser de Er,Cr:YSGG e restauradas com três tipos distintos de sistemas adesivos ao longo de três meses de armazenamento em água destilada.

Os resultados do presente estudo mostram que os valores de resistência de união obtidos após 1 e 90 dias de armazenagem são inferiores nas superfícies tratadas com o laser de Er,Cr:YSGG, em ambos os protocolos, independente do sistema adesivo utilizado. Após os 90 dias de armazenamento, as superfícies irradiadas apresentaram decréscimo dos valores da resistência adesiva, sendo, da mesma forma, inferiores ao grupo controle.

Poucos são os estudos descritos na literatura nos quais parâmetros do laser de Er,Cr:YSGG são avaliados com relação aos valores de resistência de união. Uma grande quantidade de estudos com o laser de Er:YAG podem ser encontrados. No entanto, sabe-se que os efeitos dos lasers de Er:YAG e Er,Cr:YSGG na estrutura 
dental são bastante semelhantes (VAN MEERBEEK et al., 2003). Devido à grande afinidade destes equipamentos pela água, as moléculas de água presentes na superfície da dentina absorvem a radiação incidente, sofrem um brusco aumento de temperatura e se expandem, levando à ejeção do tecido, em um processo conhecido como ablação (EVERSOLE; RIZOIU, 1995).

Apesar da semelhança e proximidade no espectro eletromagnético, sabe-se que os lasers de Er:YAG e Er,Cr:YSGG diferem entre si não só pelo comprimento de onda, mas também pela absorção aos tecidos. O laser de Er,Cr:YSGG $(2,78 \mu \mathrm{m})$ tem uma maior afinidade pelo grupo hidroxila presente na hidroxiapatita quando comparado ao laser de Er:YAG $(2,94 \mu \mathrm{m})$, que tem seu comprimento de onda mais próximo do pico de absorção da água, o que pode influenciar na interação destes equipamentos com a dentina e, consequentemente, no padrão morfológico da superfície irradiada.

De acordo com Harashima et al. (2005), o laser de Er,Cr:YSGG cria superfícies mais rugosas e necessita de uma temperatura mais elevada para realizar o processo de ablação. Enquanto este laser inicia a ablação em aproximadamente $800^{\circ} \mathrm{C}$, o laser de Er:YAG inicia o mesmo processo em aproximadamente $300^{\circ} \mathrm{C}$ (HADLEY et al., 2000) .

No recente trabalho de Moretto (2009), nas micrografias das superfícies irradiadas com lasers de érbio, obtidas em MEV, foi observado que ambos os equipamentos (Er:YAG e Er,Cr:YSGG) apresentaram um padrão morfológico bastante semelhante, entretanto, os grupos irradiados com o laser de Er,Cr:YSGG, apresentaram uma superfície mais escamosa, corroborando com os estudos anteriores. 
Porém, para ambos os equipamentos, quando a irradiação é realizada com refrigeração constante, a superfície produzida apresenta-se sem smear layer e sem sinais de melting e carbonização ao redor da entrada dos túbulos, com aspecto semelhante ao de um vulcão (BERTRAND et al., 2004; CARDOSO et al., 2008a; CARDOSO et al., 2008b; CHOU; CHENG; DING, 2009; DE MUNCK et al., 2002; DELME; DE MOOR, 2007; DUNN; DAVIS; BUSH, 2005; EKWORAPOJ; SIDHU; MCCABE, 2007; FREITAS et al., 2007; HOSSAIN et al., 2003; LEE et al., 2007; MOLDES et al., 2009; MONGHINI et al., 2004; TRAJTENBERG; PEREIRA; POWERS, 2004; TACHIBANA et al., 2008; MORETTO, 2009).

É interessante observar que, no presente estudo, mesmo com a refrigeração constante e controlada, todas as superfícies irradiadas, em ambos os protocolos utilizados ( $2 \mathrm{~W}$ e $4 \mathrm{~W}$ ) apresentaram algum sinal de carbonização. A rugosidade era bastante evidente, podendo ser observada sem magnificação. Essa carbonização pode ser resultado da taxa de repetição que o laser de Er,Cr:YSGG apresenta, fixa e mais alta.

Embora a literatura demonstre que ambos os lasers são seguros quanto à manutenção da vitalidade pulpar e apresentam vantagens como o menor desconforto ao paciente e a descontaminação do tecido irradiado, são esperados efeitos deletérios à estrutura da dentina em decorrência da deposição de calor, que podem afetar negativamente a adesão (BARROS, 2007). Sendo a taxa de repetição do laser de Er,Cr:YSGG fixa em $20 \mathrm{~Hz}$, pode ocorrer um maior estresse do tecido durante a irradiação e aumento do calor residual mencionado e, hipoteticamente, levar a resultados e valores de resistência de união inferiores, como os encontrados no presente estudo. 
Vale lembrar que no início dos estudos, a literatura apresentava trabalhos in vitro com valores de resistência adesiva promissores quando se relacionava aos tecidos irradiados com os lasers Er:YAG e Er,Cr:YSGG e materiais restauradores adesivos. O padrão morfológico mencionado anteriormente, era considerado favorável à retenção micromecânica de materiais restauradores por diversos autores, que relatam valores de resistência adesiva iguais ou até superiores àqueles obtidos pelos métodos tradicionais. Porém, estes resultados apresentam-se controversos com relação aos protocolos utilizados, as técnicas restauradoras executadas e aos testes metodológicos empregados.

Atualmente, são vários os estudos que encontram valores de resistência adesiva aos tecidos irradiados inferiores àqueles obtidos pelos métodos tradicionais como os resultados do presente estudo. Essa questão nos faz repensar e reconsiderar a irradiação do substrato dentinário com os lasers de érbio, já que os efeitos deletérios discutidos podem comprometer a adesão entre o substrato e o material restaurador.

Outros trabalhos da literatura mostram que a utilização dos lasers de érbio nos tecidos dentais pode levar à degradação de sua estrutura, como a formação de trincas, que se estendem à sub-superfície dos tecidos irradiados e a denaturação do colágeno (BARROS, 2007; MORETTO, 2009).

Sabe-se que o colágeno tem um papel muito importante na adesão. A retenção micromecânica entre a resina e a dentina depende da interação adequada entre os monômeros resinosos dos sistemas adesivos e a matriz orgânica da dentina, para que ocorra a formação da camada híbrida. A formação de uma 
camada híbrida e de tags de resina são essenciais no estabelecimento de uma satisfatória resistência de união entre resina e dentina.

A camada híbrida, na interface colágeno-resina, é a porção mais vulnerável das interfaces adesivas. Por este motivo, a adesão ao esmalte tem sido observada como um sucesso, enquanto a adesão em dentina ainda é um desafio. Dessa forma, podemos afirmar que a obtenção da adesão à dentina é considerada como um evento não homogêneo e de pouca previsibilidade, sendo altamente influenciado pelas características deste substrato. Partindo deste ponto, devemos estar atentos à morfologia da dentina irradiada pelos lasers de erbio.

Estudos in vitro mostram que as irregularidades produzidas pela irradiação com o laser de Er,Cr:YSGG são tão proeminentes que impedem a distribuição uniforme de tensões ao longo da interface adesiva. Além disso, estas irregularidades favorecem a formação de regiões com grande acúmulo de adesivo e outras regiões nas quais a espessura da camada adesiva não chega a atingir uma espessura mínima, sendo facilmente destacada no teste de microtração (CARDOSO 2008b; ARANHA et al.,2007; MORETTO, 2009). Essas áreas de grande acúmulo de adesivo correspondem à região de maior concentração de energia do pulso emitido pelo laser. Em contra partida, na região dos picos do feixe, observa-se camadas finas do adesivo. Essas irregularidades podem levar à formação de defeitos na camada híbrida.

De maneira geral, pode-se afirmar que no presente estudo foram encontrados valores de resistência de união inferiores em todos os grupos irradiados pelo laser de Er,Cr:YSGG, independentemente do sistema adesivo utilizado, reafirmando os resultados de diversos estudos. 
Quando avaliamos a resistência de união a tecidos irradiados, devemos estar atentos a algumas variáveis. Diferenças em fatores como o protocolo, sistemas adesivos e condicionamento da superfície podem produzir resultados significativamente diferentes. Como neste estudo trabalhamos com um controle e aplicamos os sistemas adesivos da mesma forma em todos os grupos, podemos dizer que estas variáveis foram bem controladas e nos permitiram a comparação entre os diferentes tratamentos da superfície dentearia.

Com relação aos diferentes tipos de adesivos dentinários estudados, observou-se que para um mesmo tratamento da superfície dentinária, todos os sistemas adesivos apresentaram semelhança nos valores de resistência adesiva. $\mathrm{Na}$ avaliação imediata (1 dia), os adesivos Single Bond e Clearfil S3 apresentaram comportamentos semelhantes e superiores ao Clearfil SE Bond.

De maneira interessante, observou-se que o Clearfil SE Bond apresentou decréscimo significante dos valores de resistência adesiva de 1 dia para 90 dias, para todas as condições de tratamento: controle, Laser 2W e Laser 4W.

Para superfícies não irradiadas, cabe a especulação de que, talvez, a susceptibilidade do colágeno à hidrólise esteja vinculada às soluções empregadas na desmineralização da dentina, reacendendo o questionamento sobre a agressividade de determinados condicionadores nas propriedades deste substrato e estimulando os procedimentos restauradores que se fundamentam na utilização de ácidos mais fracos, quer seja em sistemas adesivos convencionais (NAKABAYASHI; PASHLEY, 1998), quer seja pelo emprego de sistemas auto-condicionantes. Isto reflete uma demonstração adicional de que a excessiva desmineralização da dentina 
pode resultar em interfaces adesivas mais vulneráveis à degradação. Em superfícies tratam laser de érbio, essa especulação também pode ser empregada.

No adesivo auto-condicionante Clearfil Se Bond, o primer é formado a partir de um ácido fraco. Hipoteticamente, os valores inferiores e menos estáveis promovidos por este adesivo em todos os tratamentos de superfície realizados, podem ser conseqüência do remanescente de fibrilas colágenas parcialmente denaturadas, presentes na camada superficial, não removidas pelo primer ácido, sendo não suficiente para interagir com a dentina irradiada (DE MUNCK, 2002). A camada híbrida pobremente formada sofreu mais os efeitos da degradação, apresentando acentuado decréscimo nos valores de resistência adesiva. A formação de uma zona de interdifusão é pouco provável, e a adesão fica baseada apenas nos tags (DUNN; DAVIS; BUSH, 2005). Acredita-se que clinicamente, em superfícies tratadas com lasers de érbio e utilização de adesivos auto-condicionantes, seja necessário o condicionamento da superfície com ácido fosfórico em tempos a serem determinados por trabalhos futuros.

A análise dos valores de resistência de união dados poderia sugerir que o sistema Clearfil SE Bond foi mais susceptível aos efeitos da armazenagem em água do que os sistemas Single Bond e Clearfil S3 e, em decorrência deste fato, proporcionaria à formação de interfaces adesivas menos estáveis, em cavidades realizadas com o laser de Er,Cr:YSGG.

Além da denaturação das fibrilas colágenas na camada superficial, a irradiação com os lasers de érbio cria uma superfície ácido resistente, podendo reduzir a eficácia do condicionamento ácido da dentina irradiada (DE MUNCK et al., 2001). 
Os sistemas adesivos vêm apresentando bons resultados quando testada sua resistência adesiva nas primeiras 24 horas. Porém, a cavidade oral se apresenta como um desafio para a longevidade da camada adesiva de restaurações devido às alterações de temperatura, ciclos mastigatórios, sorção de água e alterações de pH (GURGAN et al., 2008; GURGAN et al., 2009).

A interface substrato-adesivo está sujeita à degradação química e mecânica. Quimicamente, as reações mais importantes são a hidrólise e a plastificação dos componentes resinosos, sendo ambos relacionados à entrada de água (HASHIMOTO; OHNO, 2000).

O fator que mais exerce influência sobre a longevidade das restaurações é a hidrólise dos componentes da camada híbrida, como o colágeno e a resina. In vitro, a forma mais eficiente de se avaliar a degradação da interface adesiva é a sua exposição direta à água. Em três meses de armazenamento, é possível a observação de transformações comparáveis ao envelhecimento in vivo (DE MUNCK et al., 2005). As alterações nos valores de resistência de união de espécimes armazenados em água são semelhantes àquelas obtidas quando o meio para o armazenamento é a saliva artificial (KITASANO; BURROW, 2000). Além disso, estudos mostram uma diferença na resistência adesiva quando se variam os períodos de tempo que as amostras preparadas ficam armazenadas em água até ser realizado o teste de resistência adesiva (TORKABADI; NAKAJIMA, 2008).

A ação plastificadora da água tem sido freqüentemente apontada como responsável pela alteração do comportamento mecânico da estrutura macro e microscópica dos materiais (FERRACANE; BERGE; CONDON., 1998; TANAKA et al., 1999). De um modo geral, nossos achados confirmam observações já relatadas por outros estudos, ou seja, que a armazenagem em água ou em soluções aquosas 
por períodos mais longos, pode ter efeito significativo na redução dos valores de resistência de união dos diferentes sistemas adesivos aplicados à dentina (ARMSTRONG; KELLER; BOYER, 2001; BURROW; TAGAMI; HOSODA., 1993; HASHIMOTO et al., 2001).

O gradiente osmótico causa a infiltração da água do meio bucal para o interior da interface adesiva. No esmalte, ocorre a formação de bolhas que, com o tempo, aumentam e se coalescem. Acredita-se que na dentina a água infiltrada na camada adesiva flui através dos túbulos dentinários e não ocorre a formação de bolhas (TAY et al., 2004b).

Embora o entendimento do processo de permeação dos monômeros compreenda mecanismos complexos, essencialmente, as possíveis falhas deste processo são diretamente influenciadas por variáveis do substrato, sobretudo relacionadas com sua permeabilidade (PASHLEY; CARVALHO, 1997), e também com a difusividade do material resinoso (NAKABAYASHI et al., 1992).

A permeabilidade dentinária está assegurada pela presença dos túbulos dentinários, através dos quais a difusão dos monômeros é facilitada. Entretanto, é a permeação da resina nos espaços interfibrilares a responsável pela formação da camada híbrida e, portanto, pela maior retenção das restaurações adesivas. A condição de permeabilidade intertubular ideal à formação de uma camada híbrida homogênea e livre de porosidades, somente será realizada caso sejam mantidos os espaços interfibrilares expostos pela remoção mineral da dentina (PASHLEY et al., 2000). No entanto, alguns estudos demonstraram que a camada híbrida é na verdade uma camada passível de conter porosidades (Sano et al., 1994). 
Essas porosidades remanescentes podem funcionar como vias de difusão de fluidos externos (SANO et al., 1995), os quais podem ser responsáveis pela degradação da união ao longo do tempo (Armstrong et al., 2001; Burrow et al., 1996; Shono et al., 1999;. Teoricamente, tanto as fibrilas de colágeno expostas, e não protegidas pela resina, quanto o componente resinoso estariam sujeitos à deterioração. Carrilho et al. (2002) faz uma reflexão sobre as argumentações apresentadas por Tay e Pashley (2001)com relação ao diagnóstico da estabilidade das interfaces adesivas. Para este autores, o diagnóstico precoce dos sinais que indicam uma possível deterioração da interface pode estar, em parte, sendo ignorado devido à generalização do conceito de que as restaurações fracassadas podem ser facilmente substituídas, repetindo assim, o ciclo restaurador repetitivo, ignorando a filosofia da Odontologia contemporânea de máxima conservação da estrutura dental.

O adesivo Single Bond, no qual é necessário realizar o condicionamento da superfície com ácido fosfórico 35\% e o adesivo Clearfil S3, auto condicionante de frasco único, apresentaram comportamento estatístico semelhante aos 90 dias, com os tratamentos controle apresentando valores de resistência adesiva superiores estatisticamente em relação aos tratamentos Laser $2 \mathrm{~W}$ e $4 \mathrm{~W}$. Os adesivos total-etch simplificados e os adesivos self-etch são semelhantes em dois aspectos: a espessura fina da camada híbrida formada e a presença de grupos iônicos e hidrofílicos retidos na camada híbrida, que continuam a atrair água da dentina vitalizada, levando à degradação (TAY et al., 2004a).

O dano subsuperficial das superfícies irradiadas pode ser o fator que mais compromete a resistência adesiva e pode comprometer a longevidade (DE MUNCK et al., 2001). Os resultados da análise do padrão de fratura indicaram a 
predominância de fraturas adesivas em todos os grupos irradiados após os 90 dias de armazenamento, indicando a presença de uma interface adesiva susceptível aos efeitos da degradação. Assim, concluímos que a morfologia da dentina desempenha um papel muito importante na realização dos procedimentos restauradores adesivos.

O sistema adesivo Single Bond, o único sistema total-etch utilizado neste estudo, apresentou os melhores valores de resistência de união. Este resultado está de acordo com outros estudos, que afirmam que o condicionamento dos tecidos irradiados com ácido fosfórico a 37\% remove as fibrilas colágenas danificadas e regulariza a superfície, favorecendo a formação da camada híbrida. Creditamos o acentuado decréscimo da resistência adesiva no grupo $4 \mathrm{~W}$ após o período de 90 dias de armazenamento, às profundas alterações da estrutura dentinária causadas por esse protocolo de irradiação.

Para o grupo controle, os espécimes tratados com o sistema adesivo Clearfil S3 apresentaram melhores valores de resistência adesiva após os 90 dias de armazenamento em água.

Ambos os adesivos, total-etch e self-etch, não conseguem conferir um isolamento hermético à dentina vital, comportando-se como membranas permeáveis. A ausência de monômeros hidrofóbicos permite que o fluido dentinário ultrapasse a camada adesiva. As bolhas formadas podem ser iniciadores de fraturas catastróficas na interface adesiva de cavidades pouco retentivas.

É muito importante salientar que o teste de microtração é um procedimento muito sensível. Diversos fatores podem alterar seus resultados tais como a etapa de corte dos palitos, medição com o paquímetro, colagem no jig de Geraldelli e montagem do conjunto na máquina de ensaios universal podem induzem tensões que podem influenciar negativamente os resultados. Outros 
fatores, como presença de esmalte remanescente, contaminação da superfície adesiva com a cola de cianoacrilato e atrito entre as partes do jig podem elevar os valores de resistência adesiva

O teste de microtração é utilizado na maioria dos estudos in vitro da resistência adesiva em substratos irradiados, para a avaliação da resistência adesiva entre o substrato dentinário e materiais restauradores. Este método permite o ensaio mecânico de espécimes com área de aproximadamente $1 \mathrm{~mm}^{2}$. Como as superfícies irradiadas pelos lasers de érbio são bastante irregulares e rugosas, a possibilidade de avaliação de diversas áreas individualmente é interessante.

Alem disso, no presente estudo, por exemplo, a adoção do método de microtração permitiu que espécimes obtidos sob a mesma condição de preparo pudessem ser avaliadas de acordo com as diferentes variáveis experimentais.

Diante dos resultados não-favoráveis do tratamento de superfície com lasers em dois diferentes protocolos com todos os sistemas adesivos utilizados, é importante lembrar que os sistemas adesivos utilizados para esta pesquisa foram desenvolvidos para tecidos preparados com instrumentos cortantes rotatórios. Os tecidos preparados pelos lasers de érbio apresentam uma morfologia peculiar, anteriormente descritas, com alterações em elementos de grande importância para a obtenção de valores satisfatórios de resistência adesiva.

O desenvolvimento de sistemas adesivos com estratégias de adesão que não envolvam a interação com os componentes orgânicos do tecido pode ser uma alternativa para tecidos irradiados. Outra alternativa é o desenvolvimento de métodos para a preservação da rede de fibrilas colágenas durante a irradiação, como a utilização de substâncias crosslinkers (agentes promovedores de ligações 
cruzadas) para assim garantir a adequada formação da camada híbrida nestes casos.

Os espécimes preparados para o teste de microtração apresentam uma grande área da interface adesiva exposta ao contato com a água na qual foram armazenados. Dificilmente encontraremos uma relação semelhante a esta em restaurações in vivo. Além disso, as cavidades conservadoras muitas vezes apresentam forma retentiva e paredes em esmalte, o que pode alterar o comportamento da infiltração pela água.

Concluindo, neste momento dos estudos relacionados à adesão aos tecidos irradiados, faz-se necessário aprofundar os conhecimentos sobre o substrato dentinário e relacioná-lo aos adesivos já disponíveis comercialmente. As hipóteses de alterações no colágeno e de resistência ácida devem ser elucidadas e trabalhos clínicos controlados, randomizados e duplo-cegos devem ser conduzidos para complementar os achados deste trabalho in vitro.

Conhecer o comportamento das restaurações adesivas ao longo do tempo é fundamental para o cirurgião dentista. A previsibilidade de um tratamento é de grande importância para o planejamento e seleção de casos e sucesso no tratamento restaurador. 


\section{7- CONCLUSÕES}

A análise dos valores obtidos com os ensaios realizados, juntamente com a revisão da literatura, nos permitiu concluir que:

1. Os grupos irradiados com o laser de Er,Cr:YSGG em $2 W$ e $4 W$ apresentaram decréscimo dos valores da resistência adesiva, independentemente do sistema adesivo utilizado

2. Em cada um dos tratamentos de superfície utilizados (controle, laser $2 \mathrm{~W}$ e laser $4 \mathrm{~W}$ ), os adesivos se comportaram de forma semelhante.

3. Com exceção do grupo controle do adesivo Clearfil $S^{3}$, todos os grupos apresentaram decréscimo nos valores de resistência adesiva após 90 dias de armazenamento em água.

4. Entre todos os sistemas adesivos utilizados, o Single Bond apresentou os melhores valores de resistência adesiva, com exceção do grupo controle/Clearfil S3 após 90 dias. 


\section{REFERÊNCIAS BIBLIOGRÁFICAS}

Al-Nahedh $\mathrm{H}$, Ateyah NZ. Effect of different bonding conditions on the shear bond strength of two compomers to bovine dentin. J Contemp Dent Pract. 2006 Sep 1; $7(4): 9-16$.

Aoki A, Ishikawa I, Yamada T, Otsuki M, Watanabe H, Tagami J, Ando Y, Yamamoto $\mathrm{H}$. Comparison between Er:YAG laser and conventional technique for root caries treatment in vitro. J Dent Res. 1998 Jun;77(6):1404-14.

Aranha AC, De Paula Eduardo C, Gutknecht N, Marques MM, Ramalho KM, Apel C. Analysis of the interfacial micromorphology of adhesive systems in cavities prepared with Er,Cr:YSGG, Er:YAG laser and bur. Microsc Res Tech. 2007 Aug; 70(8): 74551.

Armengol V, Jean A, Rohanizadeh R, Hamel $H$. Scanning electron microscopic analysis of diseased and healthy dental hard tissues after Er:YAG laser irradiation: in vitro study. J Endod. 1999 Aug;25(8):543-6.

Armstrong SR, Keller JC, Boyer DB. Mode of failure in the dentin-adhesive resinresin composite bonded joint as determined by strength-based (muTBS) and fracture-based (CNSB) mechanical testing. Dent Mater 2001;17(3):201-10.

Bachmann L, Diebolder R, Hibst R, Zezell DM. Changes in chemical composition and collagen structure of dentine tissue after erbium laser irradiation. Spectrochim Acta A Mol Biomol Spectrosc. 2005 Sep;61(11-12):2634-9. Epub 2004 Nov 19.

Bader C, Krejci I. Indications and limitations of Er:YAG laser applications in dentistry. Am J Dent. 2006 Jun;19(3):178-86

Barros JA. Análise da influência do calor residual na adesão dentinária após a irradiação com o laser de Er,Cr:YSGG [Dissertação de Mestrado]. São Paulo: IPEN 2007. 
Bertrand Mf, Hessleyer D, Muller-Bolla M, Nammour S, Rocca Jp. Scanning electron microscopic evaluation of resin-dentin interface after Er:YAG laser preparation. Lasers Surg Med. 2004;35(1):51-7.

Burrow MF, Tagami J, Hosoda $\mathrm{H}$. The long term durability of bond strengths to dentin. Bull Tokyo Med Dent Univ 1993 Dec:40(4): 173-191.

Cardoso MV, Coutinho E, Ermis RB, Poitevin A, Van Landuyt K, De Munck J, Carvalho RC, Lambrechts P, Van Meerbeek B. Influence of Er,Cr:YSGG laser treatment on the microtensile bond strength of adhesives to dentin. : J Adhes Dent. 2008a Feb;10(1):25-33.

Cardoso MV, De Munck J, Coutinho E, Ermis RB, Van Landuyt K, De Carvalho RC, Van Meerbeek B. Influence of Er,Cr:YSGG laser treatment on microtensile bond strength of adhesives to enamel. Oper Dent. 2008b Jul-Aug;33(4):448-55.

Carrilho MRO. Efeito da armazenagem sobre as propriedades mecânicas da união dentina/resina composta e seus constituinte [Tese de Doutorado]. São Paulo: Faculdade de Odontologia da USP; 2002.

Cavalcanti BN, Lage-Marques JL, Rode SM. Pulpal temperature increases with Er:YAG laser and high-speed handpieces. J Prosthet Dent. 2003 Nov;90(5):447-51.

Ceballos L, Osorio R, Toledano M, Marshall GW. Microleakage of composite restorations after acid or Er-YAG laser cavity treatments. Dent Mater. $2001 \mathrm{Jul} ;$ 17(4): 340-6.

Cederlund A, Lindskog S, Blomlöf J. Effect of chemo-mechanical caries removal system (Carisolv $\left.{ }^{\circledR}\right)$ on dentin topography of non-carious dentin. Acta Odontol Scand. 1999; 57(4): 185-89.

Chou JC, Chen CC, Ding SJ. Effect of Er,Cr:YSGG laser parameters on shear bond strength and microstructure of dentine. Photomed Laser Surg. 2009 Jun;27(3):481-6.

Cozean C, Arcoria Cj, Pelagalli J, Powell Gl. Dentistry for the 21st century? Erbium:YAG laser for teeth. J Am Dent Assoc. 1997 Aug;128(8):1080-7. 
De Munck J, Van Landuyt K, Peumans M, Poitevin A, Lambrechts P, Braem M, Van Meerbeek B. A critical review of the durability of adhesion to tooth tissue: methods and results. J Dent Res 2005;84(2):118-32.

De Munck J, Van Meerbeek B, Yudhira R, Lambrechts P, Vanherle G. Micro-tensile bond strength of two adhesives to Erbium:YAG-lased vs. bur-cut enamel and dentin. Eur J Oral Sci. 2002 Aug;110(4):322-9.

Delmé KI, De Moor RJ. Scanning electron microscopic evaluation of enamel and dentin surfaces after Er:YAG laser preparation and laser conditioning. Photomed Laser Surg. 2007 Oct;25(5):393-401.

Dostálová T, Jelínková H, Krejsa O, Hamal K, Kubelka J, Procházka S. Dentin and pulp response to Erbium:YAG laser ablation: a preliminary evaluation of human

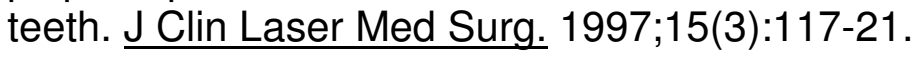

Dunn WJ, Davis JT, Bush AC. Shear bond strength and SEM evaluation of composite bonded to Er:YAG laser-prepared dentin and enamel. Dent Mater. 2005 Jul;21(7):616-24.

Eick JD, Wilko RA, Anderson CH, Sorensen SE. Scanning electron microscopy of cut tooth surfaces and identification of debris by use of the electron microprobe. J Dent Res. 1970 Nov-Dec;49(6):Suppl:1359-68.

Ekworapoj P, Sidhu SK, McCabe JF. Effect of different Power parameters of Er,Cr:YSGG laser on human dentine. Lasers Med Sci 2007;22(3):175-82.

EI-Araby AM, Talic YF. The effect of thermocycling on the adhesion of self-etching adhesives on dental enamel and dentin. J Contemp Dent Pract. 2007 Feb 1;8(2):1724.

Ergücü Z, Celik EU, Unlü N, Türkün M, Ozer F. Effect of Er,Cr:YSGG laser on the microtensile bond strength of two different adhesives to the sound and cariesaffected dentin. Oper Dent. 2009 Jul-Aug;34(4):460-6. 
Esteves-Oliveira M, Zezell DM, Apel C, Turbino ML, Aranha ACC, Eduardo CP, Gutknecht N. Bond Strength of Self-Etching Primer to Bur Cut, Er,Cr:YSGG, and Er:YAG Lased Dental Surfaces. Photomed Laser Surg. 2007; 25(5): 373-80.

Eversole LR, Rizoiu I, Kimmel Al. Pulpal response to cavity preparation by an erbium, chromium:YSGG laser-powered hydrokinetic system. J Am Dent Assoc. 1997 Aug;128(8):1099-106.

Eversole LR, Rizoiu IM. Preliminary investigations on the utility of an erbium, chromium YSGG laser. J Calif Dent Assoc 1995;23(12):41-7.

Ferracane JL, Berge HX, Condon,JR. In Vitro aging of dental composite in water: effect of degree conversion, filler volume, and filler/matrix coupling. J Biomed Mater Res 1998,Dec:42(3): 465-472.

Ferreira LS, Apel C, Francci C, Simoes A, Eduardo CP, Gutknecht N. Influence of etching time on bond strength in dentin irradiated with erbium lasers. Lasers Med Sci. 2009 Aug 6. [Epub ahead of print]

Franzen R, Esteves-Oliveira M, Meister J, Wallerang A, Vanweersch L, Lampert F, Gutknecht N. Decontamination of deep dentin by means of erbium, chromium:yttrium-scandium-gallium-garnet laser irradiation. Lasers Med Sci. 2009 Jan;24(1):75-80. Epub 2007 Nov 20.

Freitas PM, Navarro RS, Barros JA, De Paula Eduardo C. The use of Er:YAG laser for cavity preparation: an SEM evaluation. Microsc Res Tech. 2007 Sep;70(9):803-8.

Fried D, Ragadio J, Champion A. Residual heat deposition in dental enamel during IR laser ablation at 2.79, 2.94, 9.6, and 10.6 microm. Lasers Surg Med. $2001 ; 29(3): 221-9$.

Geraldo-Martins VR, Tanji EY, Wetter NU, Nogueira RD, Eduardo CP. Intrapulpal temperature during preparation with the Er:YAG laser: an in vitro study. Photomed Laser Surg. 2005 Apr;23(2):182-6.

Geraldo-Martins VR. Análise do selamento marginal de restaurações realizadas após remoção de cárie radicular com laser de Er, Cr: YSGG. [Tese de Doutorado]. São Paulo: Faculdade de Odontologia da USP; 2007. 
Goldman L, Gray JA, Goldman J, Goldman B, Meyer R. Effect of laser beam impacts on teeth. J Am Dent Assoc. 1965 Mar;70:601-6.

Goldman L, Hornby P, Meyer R, Goldman B. Impact of the laser on dental caries. Nature 1964 203:417.

Gordon TE. Some effects of laser impacts on extracted teeth. J Dent Res $1966 ; 45(2): 372-5$.

Gordon W, Atabakhsh Va, Meza F, Doms A, Nissan R, Rizoiu I, Stevens RH. The antimicrobial efficacy of the erbium, chromium:yttrium-scandium-gallium-garnet laser with radial emitting tips on root canal dentin walls infected with Enterococcus faecalis. J Am Dent Assoc. 2007 Jul;138(7):992-1002.

Gurgan S, Kiremitci A, Cakir FY, Gorucu J, Alpaslan T, Yazici E, Gutknecht N. Shear bond strength of composite bonded to Er,Cr:YSGG laser-prepared dentin. Photomed Laser Surg. 2008 Oct;26(5):495-500.

Gurgan S, Kiremitci A, Cakir FY, Yazici E, Gorucu J, Gutknecht N. Shear bond strength of composite bonded to erbium:yttrium-aluminum-garnet laser-prepared dentin. Lasers Med Sci. 2009 Jan;24(1):117-22. Epub 2007 Dec 12.

Gutknecht N, Eduardo C de P. A odontologia e o laser: atuação do laser na especialidade odontológica. Buckup HT. São Paulo: Quintessence; 2004.

Gwinnett AJ. Quantitative contribution of resin infiltration/hybridization to dentin bonding. Am J Dent. 1993 Feb;6(1):7-9.

$\mathrm{H}$, Pashley El, Carvalho Rm, Tay Fr. The effects of dentin permeability on restorative dentistry. Dent Clin North Am. 2002 Apr;46(2):211-45.

Hadley J, Young DA, Eversole LR, Gornbein JA. A laser-powered hydrokinetic system for caries removal and cavity preparation. J Am Dent Assoc. 2000 Jun;131(6):777-85.

Harashima T, Kinoshita J, Kimura Y, Brugnera A, Zanin F, Pecora JD, Matsumoto K. Morphological comparative study on ablation of dental hard tissues at cavity 
preparation by Er:YAG and Er,Cr:YSGG lasers. Photomed Laser Surg. 2005 Feb;23(1):52-5.

Hashimoto M, Ohno H, Kaga M, Endo K, Sano, H, Oguchi H. Resin-tooth adhesive interfaces after long-term function. Am J Dent 2001 Aug;14(4):211-215.

Hashimoto M, Ohno H. In vivo degradation of resin-dentin bonds in humans over 1 to 3 years. J Dent Res 2000;79(6):1385-91.

Hibst R, Keller U. Experimental studies of the application of the Er:YAG laser on dental hard substances: I. Measurement of the ablation rate. Lasers Surg Med 1989;(4):338-44.

Hiraishi N, Breschi L, Prati C, Ferrari M, Tagami J, King NM. Technique sensitivity associated with air-drying of HEMA-free, single-bottle, one-step self-etch adhesives. Dent Mater 2007;23(4):498-505.

Hossain M, Nakamura Y, Tamaki Y, Yamada Y, Murakami Y, Matsumoto K. Atomic analysis and knoop hardness measurement of the cavity floor prepared by Er,Cr:YSGG laser irradiation in vitro. J Oral Rehabil. 2003a May;30(5):515-21.

Hossain M, Nakamura Y, Yamada Y, Kimura Y, Matsumoto N, Matsumoto K. Effects of Er,Cr:YSGG laser irradiation in human enamel and dentin: ablation and morphological studies. J Clin Laser Med Surg. 1999;17(4):155-9.

Hugo B, Stassinakis A. Preparation and restoration of small interproximal carious lesions with sonic instruments. Pract Periodont Aesthet Dent. 1998; 10(3): 353-59

Ishizaki NT, Matsumoto K, Kimura Y, Wang X, Kinoshita JI, Okano SM, Jayawardena JA. Thermographical and Morphological Studies of Er,Cr:YSGG Laser Irradiation on Root Canal Walls. Photomed Laser Surg 2004; 22(4): 291-97.

Jordehi AY, Ghasemi A, Zadeh MM, Fekrazad R. Evaluation of microtensile bond strength of glass ionomer cements to dentin after conditioning with the $\mathrm{Er}, \mathrm{Cr}$ :YSGG laser. Photomed Laser Surg. 2007 Oct;25(5):402-6.

Keller U, Hibst R. Experimental studies of the application of the Er:YAG laser on dental hard substances: II. Light microscopic and SEM investigations. Lasers Surg Med. 1989;9(4):345-51. 
Kinersly T, Jarabak JP, Phatak NM, Dement J. Laser effects on tissue and materials related to dentistry. J Am Dent Assoc. 1965 Mar;70:593-600.

Kitasako Y, Burrow MF. The influence of storage solution on dentin bond durability of resin cement. Dent Mater 2000;16(1):1-6.

Lee BS, Lin PY, Chen MH, Hsieh TT, Lin CP, Lai JY, Lan WH. Tensile bond strength of $\mathrm{Er}, \mathrm{Cr}$ :YSGG laser-irradiated human dentin and analysis of dentin-resin interface. Dent Mater. 2007 May;23(5):570-8. Epub 2006 Jul 3.

Li ZZ, Code JE, Van De Merwe WP. Er:YAG laser ablation of enamel and dentin of human teeth: determination of ablation rates at various fluences and pulse repetition rates. Lasers Surg Med. 1992;12(6):625-30.

Lin S, Caputo AA, Eversole LR, Rizoiu I. Topographical characteristics and shear bond strength of tooth surfaces cut with a laser-powered hydrokinetic system. J Prosthet Dent. 1999 Oct;82(4):451-5.

Marotti J, Geraldo-Martins VR, Bello-Silva MS, de Paula Eduardo C, Apel C, Gutknecht N. Influence of etching with erbium, chromium:yttrium-scandium-galliumgarnet laser on microleakage of class V restoration. Lasers Med Sci. 2008 Nov 15. [Epub ahead of print]

Moldes VL, Capp CI, Navarro RS, Matos AB, Youssef MN, Cassoni A. In vitro microleakage of composite restorations prepared by Er:YAG/Er,Cr:YSGG lasers and conventional drills associated with two adhesive systems. J Adhes Dent. 2009 Jun;11(3):221-9.

Monghini EM, Wanderley RL, Pécora JD, Palma Dibb RG, Corona SA, Borsatto MC. Bond strength to dentin of primary teeth irradiated with varying Er:YAG laser energies and SEM examination of the surface morphology. Lasers Surg Med. $2004 ; 34(3): 254-9$.

Monticelli F, Osorio R, Proença JP, Toledano M. Resistance to degradation of resindentin bonds using a one-step HEMA-free adhesive. J Dent 2007;35(2):181-6. 
Moretto SG. Análise morfológica e da resistência e da resistência de união da superfície dentinária irradiads com os lasers de Er:YAG e Er,Cr:YSGG [Dissertação de Mestrado]. São Paulo: Faculdade de Odontologia da USP; 2009.

Nakabayashi N, Kojima K, Masuhara E. The promotion of adhesion by the infiltration of monomers into tooth substrates. J Biomed Mater Res. 1982 May;16(3):265-73.

Nakabayashi N, Takarada K. Effect of HEMA on bonding to dentin. Dent Mater 1992 Mar; 8(2): 125-130.

Nakabayashi, N.; Pashley, D. H. Hybridization of dental hard tissues. 1998.

Obeidi A, Liu PR, Ramp LC, Beck P, Gutknecht N. Acid-etch interval and shear bond strength of Er,Cr:YSGG laser-prepared enamel and dentin. Lasers Med Sci. 2009 Mar 14. [Epub ahead of print]

Oliveira DC, Manhães LA, Marques MM, Matos AB. Microtensile bond strength analysis of different adhesive systems and dentin prepared with high-speed and Er:YAG laser: a comparative study. Photomed Laser Surg. 2005 Apr;23(2):219-24.

Oliveira MT. Efeito das tecnologias alternativas para preparo cavitário nos procedimentos adesivos com sistemas autocondicionantes. [Dissertação de Mestrado]. Piracicaba: Faculdade de Odontologia da Unicamp; 2005.

Pashley DH, Carvalho RM. Dentine permeability and dentine adhesion. J Dent 1997 Sep;25(5): 355-372.

Pashley DH, Zhang Y, Agee K.A., Rouse CJ, Carvalho MR, Russell CM. Permeability of demineralized dentin to HEMA. J Adhes Dent 2000;16(1): 39-50.

Pashley DH, Sano H, Ciucchi B, Yoshiyama M, M. Adhesion testing of dentin bonding agents: a review. Dent Mater. 1995 Mar;11(2):117-25.

Pashley DH. Dentin bonding: overview of the substrate with respect to adhesive material. J Esthet Dent. 1991 Mar-Apr;3(2):46-50.

Pelagalli J, Gimbel CB, Hansen RT, Swett A, Winn DW 2nd. Investigational study of the use of Er:YAG laser versus dental drill for caries removal and cavity preparation-phase I. J Clin Laser Med Surg. 1997;15(3):109-15. 
Perdigão J, Lopes M. Dentin bonding--questions for the new millennium. J Adhes Dent. 1999 Autumn;1(3):191-209.

Ramos AC, Esteves-Oliveira M, Arana-Chavez VE, de Paula Eduardo C. Adhesives bonded to erbium:yttrium-aluminum-garnet laser-irradiated dentin: transmission electron microscopy, scanning electron microscopy and tensile bond strength analyses. Lasers Med Sci. 2008 Aug 21. [Epub ahead of print]

Rizoiu I, Kohanghadosh F, Kimmel AI, Eversole LR. Pulpal thermal responses to an erbium,chromium: YSGG pulsed laser hydrokinetic system. Oral Surg Oral Med Oral Pathol Oral Radiol Endod. 1998 Aug;86(2):220-3.

Sano H, Shono T, Sonoda H, Takatsu T, Ciucchi B, Carvalho R, et al. Relationship between surface area for adhesion and tensile bond strength--evaluation of a microtensile bond test. Dent Mater 1994;10(4):236-40.

Sano H, Takatsu T, Ciucchi B, Horner JA, Matthews WG, Pashley DH. Nanoleakage: leakage within the hybrid layer. Oper

Dent 1995 Jan/Feb; 20(1):18-25.

Say EC, Nakajima M, Senawongse P, Soyman M, Özer F, Ogata M, Tagami J. Microtensile bond strength of a filled vs unfilled adhesive to dentin using self-etch and total-etch technique. Journal of Dentistry . 2006; 34: 283-291.

Sazak H, Türkmen C, Günday M. Effects of Nd: YAG laser, air-abrasion and acidetchin on human enamel and dentin. Oper Dent. 2001; 26(5): 476-81.

Schein MT, Bocangel JS, Nogueira GE, Schein PA. SEM evaluation of the interaction pattern between dentin and resin after cavity preparation using ER:YAG laser. J Dent. 2003 Feb;31(2):127-35.

Schoop U, Goharkhay K, Klimscha J, Zagler M, Wernisch J, Georgopoulos A, Sperr W, Moritz A.The use of the erbium, chromium:yttrium-scandium-gallium-garnet laser in endodontic treatment: the results of an in vitro study. J Am Dent Assoc. 2007 Jul;138(7):949-55. 
Secilmis A, Altintas S, Usumez A, Berk G. Evaluation of mineral content of dentin prepared by erbium, chromium:yttrium scandium gallium garnet laser. Lasers Med Sci. 2007 Oct 20.

Setien VJ, Cobb DS, Denehy GE, Vargas MA. Cavity preparation devices: effect on microleakage of Class $\mathrm{V}$ resin-based composite restorations. Am J Dent. 2001 Jun;14(3):157-62.

Shono Y, Terashita M, Shimada J, Kozono Y, Carvalho RM, Russell CM, et al. Durability of resin-dentin bonds. J Adhes Dent 1999;1(3):211-8.

Stern $\mathrm{RH}$, Sognnaes RF. Laser beam effect on dental hard tissues. J Dent Res $1964 ; 43(5 s p): 873$.

Sunico MC, Shinkai K, Medina VO 3rd, Shirono M, Tanaka N, Katoh Y. Effect of surface conditioning and restorative material on the shear bond strength and resindentin interface of a new one-bottle nanofilled adhesive. Dent Mater. 2002 Nov;18(7):535-42.

Tachibana A, Marques MM, Soler JM, Matos AB. Erbium, chromium:yttrium scandium gallium garnet laser for caries removal: influence on bonding of a selfetching adhesive system. Lasers Med Sci. 2008 Oct;23(4):435-41. Epub 2007 Oct 26.

Tanaka J, Ishikawa K., Yatani H, Yamashita A., Suzuki K. Correlation of dentin bond durability with water absorption of bonding layer. Dent Mater J 1999 Mar;18(1):11-18. Tay FR, Frankenberger R, Krejci I, Bouillaguet S, Pashley DH, Carvalho RM, et al. Single-bottle adhesives behave as permeable membranes after polymerization. I. In vivo evidence. J Dent 2004a;32(8):611-21.

Tay FR, Lai CN, Chersoni S, Pashley DH, Mak YF, Suppa P, et al. Osmotic blistering in enamel bonded with one-step self-etch adhesives. J Dent Res 2004;83(4):290-5.

Tay FR, Pashley DH. Aggressiveness of contemporary self-etching systems. I: Depth of penetration beyond dentin smear layers. Dent Mater 2001;17(4):296-308.

Taylor R, Shklar G, Roeber F. The effects of laser radiation on teeth, dental pulp, and oral mucosa of experimental animals. Oral Surg Oral Med Oral Pathol. 1965 Jun;19:786-95. 
Torkabadi S, Nakajima M. Bonding durability of HEMA-free and HEMA-containing one-step adhesives to dentine surrounded by bonded enamel. J Dent 2008;36(1):806.

Trajtenberg CP, Pereira PN, Powers JM. Resin bond strength and micromorphology of human teeth prepared with an Erbium:YAG laser. Am J Dent. 2004 Oct;17(5):3316.

Tyas MJ, Anusavice KJ, Frencken JE, Mount GJ. Minimal intervention dentistry--a review. FDI Commission Project 1-97. Int Dent J 2000;50(1):1-12.

Usumez A, Aykent F. Bond strengths of porcelain laminate veneers to tooth surfaces prepared with acid and Er,Cr:YSGG laser etching. J Prosthet Dent. 2003; 90(1): 2430.

Van Meerbeek B, De Munck J, Mattar D, Van Landuyt K, Lambrechts P. Microtensile bond strengths of an etch\&rinse and self-etch adhesive to enamel and dentin as a function of surface treatment. Oper Dent. 2003 Sep-Oct;28(5):647-60.

Van Meerbeek B, Inokoshi S, Braem M, Lambrechts P, Vanherle G. Morphological aspects of the resin-dentin interdiffusion zone with different dentin adhesive systems. J Dent Res. 1992 Aug;71(8):1530-40.

Yoshiyama M, Carvalho R, Sano H, Horner J, Brewer PD, Pashley DH Interfacial morphology and strength of bonds made to superficial versus deep dentin. Am J Dent. 1995 Dec; 8(6):297-302.

Zach L, Cohen G. Pulp response to externally applied heat. Oral Surg Oral Med Oral Pathol 1965;19:5 
APÊNDICE A - Dados obtidos com o teste de microtação em 24 horas.

\begin{tabular}{|c|c|c|c|c|c|c|c|c|c|}
\hline \multicolumn{5}{|c|}{ controle e Single Bond-dente 1} & \multicolumn{5}{|c|}{ controle e Single Bond - dente 2} \\
\hline Lado 1 & Lado 2 & Área & $\mathrm{N}$ & $\mathrm{MPa}$ & Lado 1 & Lado 2 & Área & $\mathrm{N}$ & $\mathrm{MPa}$ \\
\hline 1,06 & 1,06 & 1,1236 & 45,24 & 40,26344 & 0,94 & 1,06 & 0,9964 & 37,5 & 37,63549 \\
\hline 1,1 & 1,1 & 1,21 & 30,21 & 24,80165 & 1,07 & 1,18 & 1,2626 & 55,22 & 43,73515 \\
\hline 1,09 & 1,17 & 1,2753 & 40,28 & 31,58473 & 0,95 & 1,02 & 0,969 & 34,55 & 35,65531 \\
\hline 1,01 & 1,05 & 1,0605 & 30,64 & 28,89203 & 0,95 & 0,84 & 0,798 & 34,97 & 43,82206 \\
\hline 1,17 & 0,94 & 1,0998 & 59,06 & 53,70067 & 1,02 & 1,12 & 1,1424 & 0 & 0 \\
\hline 1,05 & 0,98 & 1,029 & 30,66 & 29,79592 & 0,84 & 1,12 & 0,9408 & 33,74 & 35,8631 \\
\hline 1,11 & 1,02 & 1,1322 & 15,13 & 13,36336 & 1,03 & 1,18 & 1,2154 & 56,05 & 46,1165 \\
\hline 1,11 & 1,07 & 1,1877 & 31,99 & 26,93441 & 0,99 & 1,17 & 1,1583 & 38,56 & 33,29017 \\
\hline \multirow{3}{*}{\multicolumn{5}{|c|}{ Média dos palitos 31,16703 }} & 1,21 & 0,96 & 1,1616 & 42,89 & 36,92321 \\
\hline & & & & & \multicolumn{5}{|c|}{ Média dos palitos $\mathbf{3 4 , 7 8 2 3 3}$} \\
\hline & & & & & \multicolumn{5}{|c|}{ controle e Single Bond - dente 4} \\
\hline \multicolumn{5}{|c|}{ controle e Single Bond - dente 3} & 1 & & Áreo & $N$ & \\
\hline \multirow[t]{2}{*}{ Lado 1} & \multirow[t]{2}{*}{ Lado 2} & \multirow[t]{2}{*}{ Área } & \multirow[t]{2}{*}{$\mathrm{N}$} & \multirow[t]{2}{*}{$\mathrm{MPa}$} & & & & & \\
\hline & & & & & 0,9 & 1,04 & 0,936 & 26,5 & 28,31197 \\
\hline 1,12 & 0,94 & 1,0528 & 21,54 & 20,45973 & 1 & 1,08 & 1,08 & 26,05 & 24,53704 \\
\hline 0,99 & 1,03 & 1,0197 & 34,35 & 33,68638 & 1,03 & 1,04 & 1,0712 & 32,9 & 30,71322 \\
\hline 1,13 & 0,98 & 1,1074 & 51,73 & 46,71302 & 1,05 & 1,26 & 1,323 & 41,88 & 31,65533 \\
\hline 1,02 & 0,9 & 0,918 & 56,05 & 61,05664 & 1,09 & 1,1 & 1,199 & 47,32 & 39,46622 \\
\hline 1,03 & 1,12 & 1,1536 & 41,33 & 35,82698 & 1,08 & 1,09 & 1,1772 & 0 & 0 \\
\hline 1,02 & 0,92 & 0,9384 & 27,33 & 29,12404 & 1,07 & 1,03 & 1,1021 & 71,97 & 65,3026 \\
\hline 0,99 & 1,01 & 0,9999 & 46,83 & 46,83468 & 1,05 & 1,15 & 1,2075 & 20,98 & 17,37474 \\
\hline 0,98 & 1,16 & 1,1368 & 41,21 & 36,25088 & 1,08 & 1,1 & 1,188 & 18,23 & 15,34512 \\
\hline 1,03 & 0,99 & 1,0197 & 15,09 & 14,79847 & 1,03 & 1,3 & 1,339 & 28,95 & 21,62061 \\
\hline \multirow{3}{*}{\multicolumn{5}{|c|}{ Média dos palitos 36,68527}} & 1,17 & 1,07 & 1,2519 & 48,59 & 38,813 \\
\hline & & & & & \multicolumn{5}{|c|}{ Média dos palitos $\mathbf{2 8 , 4 6 7 2 6}$} \\
\hline & & & & & \multicolumn{5}{|c|}{ controle e Single Bond - dente 6} \\
\hline \multicolumn{5}{|c|}{ controle e Single Bond - dente 5} & Lado 1 & Lado 2 & Área & $\mathrm{N}$ & $\mathrm{MPa}$ \\
\hline \multirow[t]{2}{*}{ Lado 1} & \multirow[t]{2}{*}{ Lado 2} & \multirow[t]{2}{*}{ Área } & \multirow[t]{2}{*}{$\mathrm{N}$} & \multirow[t]{2}{*}{$\mathrm{MPa}$} & & & & & \\
\hline & & & & & 1,01 & 1,04 & 1,0504 & 13,69 & 13,03313 \\
\hline 0,9 & 0,93 & 0,837 & 33,44 & 39,95221 & 0,84 & 1,05 & 0,882 & 40,35 & 45,7483 \\
\hline 1,06 & 1,02 & 1,0812 & 36,98 & 34,20274 & 1 & 1,06 & 1,06 & 43,96 & 41,4717 \\
\hline 1,02 & 1,13 & 1,1526 & 17,7 & 15,35659 & 0,81 & 1,03 & 0,8343 & 40,35 & 48,3639 \\
\hline \multirow[t]{4}{*}{0,89} & 1,01 & 0,8989 & 19,92 & 22,16042 & 1,23 & 1,03 & 1,2669 & 42,79 & 33,77536 \\
\hline & \multirow{3}{*}{\multicolumn{4}{|c|}{ Média dos palitos 27,91799}} & 0,96 & 1,04 & 0,9984 & 30,17 & 30,21835 \\
\hline & & & & & 1,06 & 1,21 & 1,2826 & 43,06 & 33,57243 \\
\hline & & & & & \multicolumn{5}{|c|}{ Média dos palitos 35,16902} \\
\hline
\end{tabular}




\begin{tabular}{|c|c|c|c|c|c|c|c|c|c|}
\hline \multicolumn{5}{|c|}{ controle e Clearfil SE - dente 1} & \multicolumn{5}{|c|}{ controle e Clearfil SE - dente 2} \\
\hline Lado 1 & Lado 2 & Área & $\mathrm{N}$ & $\mathrm{MPa}$ & Lado 1 & Lado 2 & Área & $\mathrm{N}$ & $\mathrm{MPa}$ \\
\hline 0,99 & 1,01 & 0,9999 & 33,84 & 33,84338 & 1,01 & 0,86 & 0,8686 & 34,77 & 40,02993 \\
\hline 1,11 & 0,96 & 1,0656 & 9,26 & 8,68994 & 0,88 & 0,94 & 0,8272 & 23,33 & 28,20358 \\
\hline 0,94 & 1,01 & 0,9494 & 27,49 & 28,95513 & 0,87 & 0,95 & 0,8265 & 40,59 & 49,11071 \\
\hline 1,1 & 0,99 & 1,089 & 12 & 11,01928 & 1,02 & 1 & 1,02 & 28,86 & 28,29412 \\
\hline 1,02 & 1,05 & 1,071 & 26,89 & 25,10738 & 0,92 & 0,93 & 0,8556 & 31,15 & 36,4072 \\
\hline 1 & 1 & 1 & 16,35 & 16,35 & 0,91 & 0,83 & 0,7553 & 39,02 & 51,66159 \\
\hline 1,01 & 1,03 & 0,9999 & 39,38 & 37,85447 & 0,9 & 0,86 & 0,774 & 16,25 & 20,99483 \\
\hline \multicolumn{5}{|c|}{ Média dos palitos $\mathbf{2 3 , 1 1 7 0 8}$} & 0,96 & 0,89 & 0,8544 & 39,88 & 46,67603 \\
\hline \multicolumn{5}{|c|}{ controle e Clearfil SE - dente 3} & \multicolumn{5}{|c|}{ Média dos palitos 37,67225} \\
\hline Lado 1 & Lado 2 & Área & $\mathrm{N}$ & $\mathrm{MPa}$ & \multicolumn{5}{|c|}{ controle e Clearfil SE - dente 4} \\
\hline 0,97 & 0,95 & 0,9215 & 32,03 & 34,75855 & \multirow[t]{2}{*}{ Lado 1} & \multirow[t]{2}{*}{ Lado 2} & \multirow[t]{2}{*}{ Área } & \multirow[t]{2}{*}{$\mathrm{N}$} & \multirow[t]{2}{*}{$\mathrm{MPa}$} \\
\hline 0,97 & 0,96 & 0,9312 & 35,36 & 37,97251 & & & & & \\
\hline 1,03 & 0,94 & 0,9682 & 27,62 & 28,52716 & 0,9 & 0,86 & 0,774 & 26,5 & 34,23773 \\
\hline 0,89 & 0,87 & 0,7743 & 35,44 & 45,77037 & 0,99 & 0,96 & 0,9504 & 26,04 & 27,39899 \\
\hline 0,94 & 1,02 & 0,9588 & 28,75 & 29,9854 & 0,99 & 0,73 & 0,7227 & 11,41 & 15,78802 \\
\hline 0,85 & 0,98 & 0,833 & 32,34 & 38,82353 & 0,9 & 0,97 & 0,873 & 19,46 & 22,29095 \\
\hline 0,96 & 1,01 & 0,9696 & 22,62 & 23,32921 & 0,97 & 0,95 & 0,9215 & 25,3 & 27,45524 \\
\hline 0,9 & 1 & 0,9 & 50,23 & 55,81111 & 0,99 & 0,95 & 0,9405 & 16,38 & 17,41627 \\
\hline 1,04 & 0,86 & 0,8944 & 33,66 & 37,63417 & 0,92 & 0,99 & 0,9108 & 26,3 & 28,87571 \\
\hline 0,99 & 0,88 & 0,8712 & 18,32 & 21,02847 & 0,85 & 0,94 & 0,799 & 28,39 & 35,53191 \\
\hline 0,95 & 0,9 & 0,855 & 44,68 & 52,25731 & \multirow{2}{*}{\multicolumn{5}{|c|}{ Média dos palitos $\mathbf{2 6 , 1 2 4 3 5}$}} \\
\hline \multicolumn{5}{|c|}{ Média dos palitos 36,8998} & & & & & \\
\hline \multicolumn{5}{|c|}{ controle e Clearfil SE - dente 5} & \multicolumn{5}{|c|}{ controle e Clearfil SE - dente 6} \\
\hline Lado 1 & Lado 2 & Área & $\mathrm{N}$ & $\mathrm{MPa}$ & Lado 1 & Lado 2 & Área & $\mathrm{N}$ & $\mathrm{MPa}$ \\
\hline 0,88 & 0,97 & 0,8536 & 34,72 & 40,67479 & 0,91 & 0,92 & 0,8372 & 9,91 & 11,83708 \\
\hline 0,9 & 0,96 & 0,864 & 32,27 & 37,34954 & 0,85 & 0,91 & 0,7735 & 12,77 & 16,50937 \\
\hline 0,96 & 0,95 & 0,912 & 44,01 & 48,25658 & 0,94 & 0,94 & 0,8836 & 28,21 & 31,92621 \\
\hline 0,86 & 0,85 & 0,731 & 11,7 & 16,00547 & 1,05 & 0,99 & 1,0395 & 28,77 & 27,67677 \\
\hline 0,93 & 0,97 & 0,9021 & 9,96 & 11,0409 & 0,86 & 0,96 & 0,8256 & 0,5 & 0,60562 \\
\hline 1 & 0,94 & 0,94 & 33,06 & 35,17021 & 0,88 & 1 & 0,88 & 3,8 & 4,318182 \\
\hline 0,92 & 0,95 & 0,874 & 9,32 & 10,66362 & \multirow{3}{*}{\multicolumn{5}{|c|}{ Média dos palitos 15,4788}} \\
\hline 1,02 & 0,9 & 0,918 & 13,69 & 14,91285 & & & & & \\
\hline \multicolumn{5}{|c|}{ Média dos palitos $\mathbf{2 6 , 7 5 9 2 5}$} & & & & & \\
\hline
\end{tabular}




\begin{tabular}{|c|c|c|c|c|c|c|c|c|c|}
\hline \multicolumn{5}{|c|}{ Controle e Clearfil $S^{3}$ - dente 1} & \multicolumn{5}{|c|}{ Controle e Clearfil $S^{3}$ - dente 2} \\
\hline Lado 1 & Lado 2 & Área & $\mathrm{N}$ & $\mathrm{MPa}$ & Lado 1 & Lado 2 & Área & $\mathrm{N}$ & $\mathrm{MPa}$ \\
\hline 1,11 & 0,97 & 1,0767 & 27,81 & 25,82892 & 1,05 & 0,98 & 1,029 & 25,5 & 24,78134 \\
\hline 1,04 & 1,06 & 1,1024 & 11,89 & 10,78556 & 1,02 & 0,97 & 0,9894 & 38,94 & 39,35719 \\
\hline 0,96 & 1,04 & 0,9984 & 28,54 & 28,58574 & 0,97 & 0,99 & 0,9603 & 33,53 & 34,91617 \\
\hline 1,06 & 0,95 & 1,007 & 36,39 & 36,13704 & 1 & 0,93 & 0,93 & 22,38 & 24,06452 \\
\hline 1,07 & 1,04 & 1,1128 & 47,03 & 42,26276 & 0,97 & 0,97 & 0,9409 & 46,35 & 49,26135 \\
\hline 1,2 & 0,99 & 1,188 & 38,64 & 32,52525 & 0,93 & 0,99 & 0,9207 & 34,58 & 37,55838 \\
\hline \multicolumn{5}{|c|}{ Média dos nalitos 29.35421} & \multicolumn{5}{|c|}{ Média dos palitos 3498983} \\
\hline \multicolumn{5}{|c|}{ Controle e Clearfil S $\mathrm{S}^{3}$ - dente 3} & \multirow{2}{*}{\multicolumn{5}{|c|}{ Controle e Clearfil $S^{3}$ - dente 4}} \\
\hline \multirow[t]{2}{*}{ Lado 1} & \multirow[t]{2}{*}{ Lado 2} & \multirow[t]{2}{*}{ Área } & \multirow[t]{2}{*}{$\mathrm{N}$} & \multirow[t]{2}{*}{$\mathrm{MPa}$} & & & & & \\
\hline & & & & & Lado 1 & Lado 2 & Área & $\mathrm{N}$ & $\mathrm{MPa}$ \\
\hline 0,98 & 1,04 & 1,0192 & 35,79 & 35,11578 & & & & & \\
\hline 0,98 & 1,05 & 1,029 & 35,79 & 34,78134 & 1,07 & 1,02 & 1,0914 & 15,23 & 13,95455 \\
\hline 0,87 & 0,99 & 0,8613 & 42,83 & 49,72716 & 0,92 & 0,87 & 0,8004 & 33,17 & 41,44178 \\
\hline 0,97 & 1,01 & 0,9797 & 17,03 & 17,38287 & 0,92 & 0,95 & 0,874 & 32,38 & 37,04805 \\
\hline 0,98 & 1,04 & 1,0192 & 36,09 & 35,41013 & 0,95 & 1,02 & 0,969 & 16,38 & 16,90402 \\
\hline 1,01 & 1,2 & 1,212 & 24,6 & 20,29703 & 1 & 0,95 & 0,95 & 32,07 & 33,75789 \\
\hline \multicolumn{5}{|c|}{ Média dos palitos 32,11905} & 0,92 & 0,95 & 0,874 & 36,31 & 41,54462 \\
\hline \multicolumn{5}{|c|}{ Controle e Clearfil $S^{3}$ - dente 5} & \multicolumn{5}{|c|}{ Média dos palitos $\mathbf{3 0 , 7 7 5 1 5}$} \\
\hline Lado 1 & Lado 2 & Área & $\mathrm{N}$ & $\mathrm{MPa}$ & \multicolumn{5}{|c|}{ Controle e Clearfil S $S^{3}$ dente 6} \\
\hline 0,98 & 0,98 & 0,9604 & 25,58 & 26,63474 & \multirow[t]{2}{*}{ Lado 1} & \multirow[t]{2}{*}{ Lado 2} & \multirow[t]{2}{*}{ Área } & \multirow[t]{2}{*}{$\mathrm{N}$} & \multirow[t]{2}{*}{$\mathrm{MPa}$} \\
\hline 0,93 & 0,95 & 0,8835 & 10,36 & 11,72609 & & & & & \\
\hline 0,95 & 0,85 & 0,8075 & 15,89 & 19,67802 & 0,9 & 0,97 & 0,873 & 11,26 & 12,89805 \\
\hline 0,98 & 1,07 & 1,0486 & 13,99 & 13,3416 & 1,01 & 1,11 & 1,1211 & 28,12 & 25,08251 \\
\hline 0,99 & 0,98 & 0,9702 & 31,19 & 32,14801 & 0,98 & 0,96 & 0,9408 & 16,6 & 17,64456 \\
\hline 1 & 0,97 & 0,97 & 18,04 & 18,59794 & 0,99 & 0,91 & 0,9009 & 59,17 & 65,67877 \\
\hline \multicolumn{5}{|c|}{ Média dos palitos 20,3544} & 0,94 & 1,11 & 1,0434 & 19,42 & 18,61223 \\
\hline \multirow{2}{*}{\multicolumn{5}{|c|}{ Laser Er,Cr:YSGG 2W e Single Bond - dente 1}} & 1,08 & 1 & 1,08 & 40,2 & 37,22222 \\
\hline & & & & & \multicolumn{5}{|c|}{ Média dos palitos 29,52306 } \\
\hline Lado 1 & Lado 2 & Área & $\mathrm{N}$ & $\mathrm{MPa}$ & Laser $\mathrm{Er}$ & r:YSGG & & B & \\
\hline 0,77 & 0,86 & 0,6622 & 8,38 & 12,65479 & & & & & \\
\hline 1,01 & 1,26 & 1,2726 & 22,11 & 17,37388 & Lado 1 & Lado 2 & Área & $\mathrm{N}$ & $\mathrm{MPa}$ \\
\hline 0,97 & 1,3 & 1,261 & 22,54 & 17,8747 & & & & & \\
\hline 0,93 & 1,02 & 0,9486 & 23,03 & 24,27788 & 1,18 & 1,06 & 1,2508 & 9,27 & 7,411257 \\
\hline 1,2 & 1,04 & 1,248 & 6,87 & 5,504808 & 1,07 & 0,99 & 1,0593 & 1,8 & 1,699235 \\
\hline 1,08 & 0,93 & 1,0044 & 25,69 & 25,57746 & 1,18 & 1,06 & 1,2508 & 7,07 & 5,652382 \\
\hline 0,96 & 1,01 & 0,9696 & 29,81 & 30,74464 & 1,07 & 1,02 & 1,0914 & 3,5 & 3,20689 \\
\hline & & Média & dos palito & s 19,14402 & 1,02 & 1,07 & 1,0914 & 1,06 & 0,97123 \\
\hline
\end{tabular}




\begin{tabular}{|c|c|c|c|c|c|c|c|c|c|}
\hline \multicolumn{5}{|c|}{ Laser Er,Cr:YSGG 2W e Single Bond - dente 3} & \multicolumn{5}{|c|}{ Laser Er,Cr:YSGG 2W e Single Bond - dente 4} \\
\hline Lado 1 & Lado 2 & Área & $\mathrm{N}$ & $\mathrm{MPa}$ & Lado 1 & Lado 2 & Área & $\mathrm{N}$ & $\mathrm{MPa}$ \\
\hline 1,06 & 0,94 & 0,9964 & 7,71 & 7,737856 & 0,98 & 1,23 & 1,2054 & 14,43 & 11,97113 \\
\hline 1,03 & 0,97 & 0,9991 & 27,07 & 27,09438 & 1,22 & 1,03 & 1,2566 & 27,14 & 21,59796 \\
\hline 1,05 & 1,05 & 1,1025 & 36,7 & 33,28798 & 1,02 & 1,04 & 1,0608 & 38,62 & 36,40649 \\
\hline 1,01 & 1,05 & 1,0605 & 9,98 & 9,410655 & 1,06 & 1,06 & 1,1236 & 44,7 & 39,78284 \\
\hline 1,07 & 0,95 & 1,0165 & 29,42 & 28,94245 & 0,99 & 1,05 & 1,0395 & 26,68 & 25,66619 \\
\hline 1,6 & 1,08 & 1,728 & 34,74 & 20,10417 & 1,01 & 0,87 & 0,8787 & 28,99 & 32,99192 \\
\hline 1,03 & 0,98 & 1,0094 & 14,07 & 13,93897 & \multirow{2}{*}{\multicolumn{5}{|c|}{ Média dos palitos $\mathbf{2 8 , 0 6 9 4 2}$}} \\
\hline \multicolumn{5}{|c|}{ Média dos palitos 20,07378 } & & & & & \\
\hline \multicolumn{5}{|c|}{ Laser Er,Cr:YSGG 2W e Single Bond - dente 5} & \multicolumn{5}{|c|}{ Laser Er,Cr:YSGG 2W e Single Bond - dente 6} \\
\hline Lado 1 & Lado 2 & Área & $\mathrm{N}$ & IVITd & Lado 1 & Lado 2 & Área & $\mathrm{N}$ & $\mathrm{MPa}$ \\
\hline & & & & & 1,02 & 0,9 & 0,918 & 17,99 & 19,59695 \\
\hline 1,11 & 0,99 & 1,0989 & 25,45 & 23,15952 & 0,97 & 0,97 & 0,9409 & 14,85 & 15,78276 \\
\hline 1,03 & 0,95 & 0,9785 & 23,45 & 23,96525 & 1,06 & 0,97 & 1,0282 & 25,15 & 24,46022 \\
\hline 1,03 & 0,95 & 0,9785 & 23,54 & 24,05723 & 0,98 & 1,08 & 1,0584 & 17,65 & 16,67611 \\
\hline 1,09 & 0,95 & 1,0355 & 11,13 & 10,74843 & 0,98 & 0,97 & 0,9506 & 41,14 & 43,27793 \\
\hline 1,09 & 1,03 & 1,1227 & 14,28 & 12,71934 & 1,1 & 0,96 & 1,056 & 12,71 & 12,03598 \\
\hline 0,96 & 0,96 & 0,9216 & 19,1 & 20,72483 & 1 & 0,96 & 0,96 & 18,38 & 19,14583 \\
\hline 0,99 & 1,04 & 1,0296 & 26,98 & 26,20435 & 1,06 & 0,98 & 1,0388 & 15,8 & 15,20986 \\
\hline 0,92 & 1,11 & 1,0212 & 7,570 & 7,412848 & \multirow{2}{*}{\multicolumn{5}{|c|}{ Média dos palitos $\mathbf{2 0 , 7 7 3 2 1}$}} \\
\hline 1,11 & 0,96 & 1,0656 & 20,82 & 19,53829 & & & & & \\
\hline \multicolumn{5}{|c|}{ Média dos palitos $\mathbf{1 8 , 7 2 5 5 7}$} & \multicolumn{5}{|c|}{ Laser Er,Cr:YSGG 2W e Clearfil SE - dente 2} \\
\hline \multicolumn{5}{|c|}{ Laser Er,Cr:YSGG 2W e Clearfil SE - dente 1} & Lado 1 & Lado 2 & Área & $\mathrm{N}$ & $\mathrm{MPa}$ \\
\hline \multirow[t]{2}{*}{ Lado 1} & \multirow[t]{2}{*}{ Lado 2} & \multirow[t]{2}{*}{ Área } & \multirow[t]{2}{*}{$\mathrm{N}$} & $\mathrm{MPa}$ & 1,02 & 0,93 & 0.9486 & 23.07 & 24,32005 \\
\hline & & & & & 0,9 & 1,02 & 0,918 & 12,58 & 13,7037 \\
\hline$\frac{0,99}{112}$ & $\frac{0,96}{104}$ & $\frac{0,9504}{1,1648}$ & $\frac{2,11}{173}$ & & 0,98 & 0,98 & 0,9604 & 10,82 & 11,26614 \\
\hline$\frac{1,12}{1}$ & 1,04 & 1,1648 & 17,3 & 14, & 0,97 & 1,05 & 1,0185 & 22,9 & 22,48405 \\
\hline $\begin{aligned} 1 \\
0,91\end{aligned}$ & 0,97 & 0,8827 & 26,55 & $\begin{array}{l}30,09649 \\
30,07817\end{array}$ & 0,97 & 0,95 & 0,9215 & 14,07 & 15,26858 \\
\hline 0,98 & 1,07 & 1,0486 & 35,34 & 33,70208 & 1,05 & 0,99 & 1,0395 & 22,77 & 21,90476 \\
\hline 0,89 & 0,94 & 0,8366 & 4,56 & 5,450634 & 0,96 & 0,98 & 0,9408 & 15,76 & 16,7517 \\
\hline 0,87 & 0,94 & 0,8178 & 28,47 & 34,81291 & 1,03 & 0,96 & 0,9888 & 16,58 & 16,7678 \\
\hline \multicolumn{5}{|c|}{ Média dos palitos $\mathbf{2 4 , 6 0 8 0 7}$} & \multicolumn{5}{|c|}{ Média dos palitos $\mathbf{1 7 , 8 0 8 3 5}$} \\
\hline
\end{tabular}




\begin{tabular}{|c|c|c|c|c|c|c|c|c|c|}
\hline \multicolumn{5}{|c|}{ Laser Er,Cr:YSGG 2W e Clearfil SE - dente 3} & \multicolumn{5}{|c|}{ Laser Er,Cr:YSGG 2W e Clearfil SE - dente 4} \\
\hline Lado 1 & Lado 2 & Área & $\mathrm{N}$ & $\mathrm{MPa}$ & Lado 1 & Lado 2 & Área & $\mathrm{N}$ & $\mathrm{MPa}$ \\
\hline 1,01 & 0,98 & 0,9898 & 26,48 & 26,75288 & 1,02 & 1,08 & 1,1016 & 8,14 & 7,389252 \\
\hline 1,01 & 1,06 & 1,0706 & 38,94 & 36,37213 & 0,93 & 1,09 & 1,0137 & 17,57 & 17,33254 \\
\hline 1,11 & 1,03 & 1,1433 & 31,07 & 27,17572 & 0,97 & 1,07 & 1,0379 & 14,87 & 14,32701 \\
\hline 1,02 & 1,02 & 1,0404 & 15,15 & 14,56171 & 1,13 & 1,16 & 1,3108 & 17,11 & 13,0531 \\
\hline 0,97 & 1,02 & 0,9894 & 24,5 & 24,76248 & 1,07 & 1,2 & 1,284 & 23,11 & 17,99844 \\
\hline 0,98 & 0,97 & 0,9506 & 30,31 & 31,88513 & 1,06 & 1,19 & 1,2614 & 22,17 & 17,57571 \\
\hline 1,04 & 0,99 & 1,0296 & 32,79 & 31,84732 & 1,07 & 1,06 & 1,1342 & 0,5 & 0,440839 \\
\hline 1,05 & 0,99 & 1,0395 & 28,99 & 27,88841 & 1,06 & 1,18 & 1,2508 & 18,23 & 14,57467 \\
\hline 1 & 1 & 1 & 15,56 & 15,56 & 0,92 & 1,03 & 0,9476 & 18,32 & 19,33305 \\
\hline \multicolumn{5}{|c|}{ Média dos palitos $\mathbf{2 6 , 3 1 1 7 5}$} & \multicolumn{5}{|c|}{ Média dos palitos $\mathbf{1 3 , 5 5 8 2 9}$} \\
\hline \multicolumn{5}{|c|}{ Laser Er,Cr:YSGG 2 W e Clearfil SE - dente 5} & \multicolumn{5}{|c|}{ Laser Er,Cr:YSGG 2W e Clearfil SE - dente 6} \\
\hline Lado 1 & Lado 2 & Área & $\mathrm{N}$ & $\mathrm{MPa}$ & Lado 1 & Lado 2 & Área & $\mathrm{N}$ & $\mathrm{MPa}$ \\
\hline 1,02 & 1,13 & 1,1526 & 26,24 & 22,76592 & 1,14 & 1,16 & 1,3224 & 46,71 & 35,32214 \\
\hline 1,05 & 1,03 & 1,0815 & 25,23 & 23,32871 & 1,14 & 1,04 & 1,1856 & 24,17 & 20,3863 \\
\hline 0,97 & 1,11 & 1,0767 & 18,55 & 17,22857 & 0,93 & 1,06 & 0,9858 & 32,08 & 32,5421 \\
\hline 1,05 & 1,3 & 1,365 & 7,75 & 5,677656 & 0,95 & 0,91 & 0,8645 & 19,15 & 22,15153 \\
\hline 1,02 & 0,99 & 1,0098 & 10,34 & 10,23965 & 1,11 & 0,94 & 1,0434 & 28,12 & 26,95035 \\
\hline 1,28 & 0,97 & 1,2416 & 10,98 & 8,843428 & 1,01 & 1,11 & 1,1211 & 42,9 & 38,26599 \\
\hline 1,09 & 1,09 & 1,1881 & 0,5 & 0,42084 & 1 & 1,08 & 1,08 & 22,94 & 21,24074 \\
\hline 0,96 & 1,11 & 1,0656 & 8,44 & 7,92042 & 0,94 & 1,13 & 1,0622 & 23,81 & 22,41574 \\
\hline 1,04 & 1,11 & 1,1544 & 20,43 & 17,69751 & 0,96 & 1,05 & 1,008 & 22,27 & 22,09325 \\
\hline \multicolumn{5}{|c|}{ Média dos palitos 12,6803} & \multicolumn{5}{|c|}{ Média dos palitos 26,81868} \\
\hline \multicolumn{5}{|c|}{ Laser Er,Cr:YSGG 2W e Clearfil S $S^{3}$ - dente 1} & \multicolumn{5}{|c|}{ Laser Er,Cr:YSGG 2W e Clearfil S ${ }^{3}$ - dente 2} \\
\hline Lado 1 & Lado 2 & Área & $\mathrm{N}$ & $\mathrm{MPa}$ & Lado 1 & Lado 2 & Área & $\mathrm{N}$ & $\mathrm{MPa}$ \\
\hline 1,05 & 1,1 & 1,155 & 23,97 & 20,75325 & 1 & 1 & 1 & 13,25 & 13,25 \\
\hline 1,01 & 1,11 & 1,1211 & 26,58 & 23,70886 & 1,02 & 0,72 & 0,7344 & 11,03 & 15,01906 \\
\hline 1 & 1,06 & 1,06 & 15,01 & 14,16038 & 1,01 & 0,97 & 0,9797 & 26,67 & 27,22262 \\
\hline 0,88 & 1,02 & 0,8976 & 12,38 & 13,79234 & 1,07 & 1,06 & 1,1342 & 32,94 & 29,0425 \\
\hline 0,92 & 0,97 & 0,8924 & 0 & 0 & 1,09 & 0,95 & 1,0355 & 24,72 & 23,87253 \\
\hline 0,99 & 0,93 & 0,9207 & 12,1 & 13,14217 & 0,92 & 0,91 & 0,8372 & 41,06 & 49,04443 \\
\hline 1,13 & 1,05 & 1,1865 & 0,1 & 0,084282 & \multirow{3}{*}{\multicolumn{5}{|c|}{ Média dos palitos $\mathbf{2 6 , 2 4 1 8 6}$}} \\
\hline 1,05 & 1,09 & 1,1445 & 0,9 & 0,78637 & & & & & \\
\hline \multicolumn{5}{|c|}{ Média dos palitos10,80346 } & & & & & \\
\hline
\end{tabular}




\begin{tabular}{|c|c|c|c|c|c|c|c|c|c|}
\hline \multicolumn{5}{|c|}{ Laser Er,Cr:YSGG 2 W e Clearfil $\mathrm{S}^{3}$ - dente 3} & \multicolumn{5}{|c|}{ Laser Er,Cr:YSGG 2W e Clearfil $\mathrm{S}^{3}$ - dente 4} \\
\hline Lado 1 & Lado 2 & Área & $\mathrm{N}$ & $\mathrm{MPa}$ & Lado 1 & Lado 2 & Área & $\mathrm{N}$ & $\mathrm{MPa}$ \\
\hline 1,07 & 1,14 & 1,2198 & 14,52 & 11,90359 & 1,03 & 0,97 & 0,9991 & 21,73 & 21,74957 \\
\hline 0,92 & 1,09 & 1,0028 & 69,93 & 69,73474 & 1,1 & 0,99 & 1,089 & 40,67 & 37,34619 \\
\hline 1,12 & 0,91 & 1,0192 & 20,21 & 19,82928 & 1,06 & 0,98 & 1,0388 & 23,99 & 23,09395 \\
\hline 1,14 & 0,93 & 1,0602 & 10,85 & 10,23392 & 1 & 1,02 & 1,02 & 25,87 & 25,36275 \\
\hline 0,91 & 0,96 & 0,8736 & 14,48 & 16,57509 & 1,1 & 1 & 1,1 & 31,34 & 28,49091 \\
\hline 1,1 & 0,99 & 1,089 & 6,73 & 6,17 & 1,13 & 1,01 & 1,1413 & 05 & 07 \\
\hline 1,14 & 0,91 & 1,0374 & 40,36 & 38,90495 & 1,03 & 0,95 & 0,9785 & 22,44 & 22,93306 \\
\hline 0,98 & 0,92 & 0,9016 & 7,71 & 8,551464 & 0,96 & 1,01 & 0,9696 & 8 & 8,250825 \\
\hline \multirow{2}{*}{\multicolumn{5}{|c|}{ Média dos palitos $\mathbf{2 2 , 7 3 9 1 3}$}} & \multicolumn{5}{|c|}{ Média dos palitos $\mathbf{2 3 , 3 1 8 4 2}$} \\
\hline & & & & & \multicolumn{5}{|c|}{ Laser Er,Cr:YSGG 2W e Clearfil S 3 - dente 6} \\
\hline \multicolumn{5}{|c|}{ Laser Er,Cr:YSGG $2 \mathrm{~W}$ e Clearfil $\mathrm{S}^{3}$ - dente 5} & Lado 1 & Lado 2 & Área & $\mathrm{N}$ & $\mathrm{MPa}$ \\
\hline \multirow[t]{2}{*}{ Lado 1} & \multirow[t]{2}{*}{ Lado 2} & Área & \multirow[t]{2}{*}{$\mathrm{N}$} & $\mathrm{MPa}$ & 1,02 & 1,01 & 2 & 22,38 & \\
\hline & & & & & 1,05 & 1,06 & 1,113 & 22,91 & 20,58401 \\
\hline $\begin{array}{l}0,91 \\
102\end{array}$ & 0,86 & & 95 & & 1,02 & 1,16 & 1,1832 & 5,97 & 5,045639 \\
\hline 1,03 & 1,14 & 1,17 & $\frac{12}{1499}$ & & 1,07 & 1,07 & 1,1449 & 30,21 & 26,38658 \\
\hline 1,06 & 0,94 & 0,9964 & $\frac{14,99}{78}$ & \multirow{2}{*}{8,746356} & 1,07 & 1,04 & 1,1128 & 13,96 & 12,54493 \\
\hline \multirow{3}{*}{0,98} & 0,91 & 0,8918 & 7,8 & & 1,18 & 1,02 & 1,2036 & 35,5 & 485 \\
\hline & & \multirow{2}{*}{\multicolumn{3}{|c|}{ Média dos palitos 12,31996}} & 0,93 & 1,02 & 0,9486 & 0,5 & 093 \\
\hline & & & & & 1,18 & 1,02 & 1,2036 & 0,5 & 0,41542 \\
\hline \multirow{2}{*}{\multicolumn{5}{|c|}{ Laser Er,Cr:YSGG 4W e Single Bond - dente 1}} & 1,05 & 1,03 & 1,0815 & 11,6 & 10,72584 \\
\hline & & & & & \multicolumn{5}{|c|}{ Média dos palitos 14,16092} \\
\hline Lado 1 & Lado 2 & Área & $\mathrm{N}$ & $\mathrm{MPa}$ & \multicolumn{5}{|c|}{ Laser Er,Cr:YSGG 4W e Single Bond - dente 2} \\
\hline 1 & 0,98 & 0,98 & 17,36 & 17,71429 & \multirow{2}{*}{ Lado 1} & \multirow{2}{*}{ Lado 2} & \multirow{2}{*}{ Área } & \multirow{2}{*}{$\mathrm{N}$} & \multirow{2}{*}{$\mathrm{MPa}$} \\
\hline 1 & 1,02 & 1,02 & 1,47 & 1,441176 & & & & & \\
\hline 1 & 1,02 & 1,02 & 29,61 & 29,02941 & 1,02 & 1 & 1,02 & 32,64 & 32 \\
\hline 0,95 & 1 & 0,95 & 22,5 & 23,68421 & 1 & 1 & 1 & 23,28 & 23,28 \\
\hline 1 & 0,91 & 0,91 & 27,58 & 30,30769 & 1,01 & 1,03 & 1,0403 & 0,77 & 0,740171 \\
\hline 0,95 & 0,93 & 0,8835 & 15,91 & 18,00792 & 0,8 & 0,8 & 0,64 & 11,23 & 17,54688 \\
\hline 1,02 & 1,01 & 1,0302 & 43,15 & 41,88507 & 0,97 & 0,94 & 0,9118 & 79,7 & 87,40952 \\
\hline 0,99 & 0,92 & 0,9108 & 17,42 & 19,12604 & 1,01 & 0,92 & 0,9292 & 50,9 & 54,7783 \\
\hline \multirow{2}{*}{\multicolumn{5}{|c|}{ Média dos palitos 22,64948}} & 0,99 & 0,93 & 0,9207 & 5,61 & 6,09319 \\
\hline & & & & & \multicolumn{5}{|c|}{ Média dos palitos $\mathbf{3 1 , 6 9 2 5 8}$} \\
\hline
\end{tabular}




\begin{tabular}{|c|c|c|c|c|c|c|c|c|c|}
\hline \multicolumn{5}{|c|}{ Laser Er,Cr:YSGG 4W e Single Bond - dente 3} & \multicolumn{5}{|c|}{ Laser Er,Cr:YSGG 4W e Single Bond - dente 4} \\
\hline Lado 1 & Lado 2 & Área & $\mathrm{N}$ & $\mathrm{MPa}$ & Lado 1 & Lado 2 & Área & $\mathrm{N}$ & $\mathrm{MPa}$ \\
\hline 1,01 & 0,98 & 0,9898 & 21,45 & 21,67104 & 0,99 & 0,96 & 0,9504 & 23,06 & 24,26347 \\
\hline 1 & 0,9 & 0,9 & 16,86 & 18,73333 & 0,92 & 1 & 0,92 & 20,79 & 22,59783 \\
\hline 1,01 & 1,04 & 1,0504 & 30,63 & 29,16032 & 0,97 & 1,02 & 0,9894 & 25,48 & 25,75298 \\
\hline 1,05 & 0,91 & 0,9555 & 27,99 & 29,29356 & 1 & 1,06 & 1,06 & 24,2 & 22,83019 \\
\hline 0,99 & 0,91 & 0,9009 & 0,3 & 0,333 & 0,99 & 1,05 & 1,0395 & 19,42 & 18,68206 \\
\hline 1,05 & 0,93 & 0,9765 & 23,97 & 24,54685 & 1,02 & 0,99 & 1,0098 & 8,43 & 8,348188 \\
\hline 1,03 & 0,91 & 0,9373 & 113,4 & 120,9858 & 0,95 & 1 & 0,95 & 51,68 & 54,4 \\
\hline \multicolumn{5}{|c|}{ Média dos palitos 19,40524} & 1,02 & 0,98 & 0,9996 & 17,83 & 17,83713 \\
\hline \multicolumn{5}{|c|}{ Laser Er,Cr:YSGG 4W e Single Bond - dente 5} & \multicolumn{5}{|c|}{ Média dos palitos $\mathbf{2 4 , 3 3 8 9 8}$} \\
\hline Lado 1 & Lado 2 & Área & $\mathrm{N}$ & $\mathrm{MPa}$ & \multicolumn{5}{|c|}{ Laser Er,Cr:YSGG 4W e Single Bond - dente 6} \\
\hline 0,84 & 0,8 & 0,672 & 19,96 & 29,70238 & Lado 1 & Lado 2 & Área & $\mathrm{N}$ & $\mathrm{MPa}$ \\
\hline 0,81 & 0,96 & 0,7776 & 42,58 & 54,7 & & & & & \\
\hline 1,14 & 0,92 & 1,0488 & 24,66 & & 1,02 & 1 & 1,02 & 40,43 & 39,63725 \\
\hline 1,08 & 0,96 & 1,0368 & 5,54 & 5,343364 & 0,95 & 1,02 & 0,969 & 32,93 & 33,98349 \\
\hline 0,97 & 0,92 & 0,8924 & 5,54 & 6,207978 & 1,02 & 1,06 & 1,0812 & 21,92 & 20,27377 \\
\hline 0,97 & 1 & 0,97 & 11,01 & 11,35052 & 1 & 1,1 & 1,1 & 24,98 & 22,70909 \\
\hline 1,12 & 1,06 & 1,1872 & 29,28 & 24,66307 & 1,04 & 1,02 & 1,0608 & 50,12 & 47,24736 \\
\hline 0,97 & 1,04 & 1,0088 & 31,46 & 557 & 1,01 & 1,02 & 1,0302 & 35,91 & 34,85731 \\
\hline 0,96 & 0,98 & 0,9408 & 31,46 & 33,43963 & 1,04 & 1,09 & 1,1336 & 34,42 & 30,36344 \\
\hline \multicolumn{5}{|c|}{ Média dos palitos 24,46259} & 1 & 1,08 & 1,08 & 39,38 & 36,46296 \\
\hline \multicolumn{5}{|c|}{ Laser Er,Cr:YSGG 4 W e Clearfil SE - dente 1} & \multicolumn{5}{|c|}{ Média dos palitos 33,19184} \\
\hline Lado 1 & Lado 2 & Área & $\mathrm{N}$ & $\mathrm{MPa}$ & \multicolumn{5}{|c|}{ Laser Er,Cr:YSGG 4W e Clearfil SE - dente 2} \\
\hline & & & & & \multirow{2}{*}{ Lado 1} & \multirow{2}{*}{ Lado 2} & \multirow{2}{*}{ Área } & \multirow[t]{2}{*}{$N$} & \multirow{2}{*}{$\mathrm{MPa}$} \\
\hline 1,01 & 1,02 & 1,0302 & 13,92 & 13,51194 & & & & & \\
\hline 1,03 & 0,92 & 0,9476 & 26,38 & 27,83875 & 0,94 & 0,96 & 0,9024 & 44,34 & 49,13564 \\
\hline 1,08 & 1,03 & 1,1124 & 16,2 & 14,56311 & 0,99 & 1,07 & 1,0593 & 40,67 & 38,39328 \\
\hline 1,02 & 0,98 & 0,9996 & 12,86 & 12,86515 & 0,98 & 0,99 & 0,9702 & 33,69 & 34,7248 \\
\hline 1,02 & 0,94 & 0,9588 & 9,83 & 10,2524 & 0,97 & 0,98 & 0,9506 & 41,52 & 43,67768 \\
\hline 1,03 & 0,92 & 0,9476 & 13,73 & 14,48924 & 0,99 & 0,99 & 0,9801 & 8,37 & 8,539945 \\
\hline 1,06 & 1,02 & 1,0812 & 8,53 & 7,889382 & 1 & 0,95 & 0,95 & 23,66 & 24,90526 \\
\hline 0,98 & 1,06 & 1,0388 & 15,3 & 14,72853 & 1,02 & 1,09 & 1,1118 & 14,35 & 12,907 \\
\hline 1,05 & 0,98 & 1,029 & 10,34 & 10,04859 & \multirow{2}{*}{\multicolumn{5}{|c|}{ Média dos palitos 30,32623}} \\
\hline & & Médi & palito & 14,02079 & & & & & \\
\hline
\end{tabular}




\begin{tabular}{|c|c|c|c|c|c|c|c|c|c|}
\hline \multicolumn{5}{|c|}{ Laser Er,Cr:YSGG 4W e Clearfil SE - dente 3} & \multicolumn{5}{|c|}{ Laser Er,Cr:YSGG 4W e Clearfil SE - dente 4} \\
\hline Lado 1 & Lado 2 & Área & $\mathrm{N}$ & $\mathrm{MPa}$ & Lado 1 & Lado 2 & Área & $\mathrm{N}$ & $\mathrm{MPa}$ \\
\hline 1,04 & 1,06 & 1,1024 & 18,15 & 16,46408 & 0,96 & 0,99 & 0,9504 & 24,91 & 26,21002 \\
\hline 1 & 0,99 & 0,99 & 28,28 & 28,56566 & 0,96 & 0,98 & 0,9408 & 26,68 & 28,35884 \\
\hline 1,04 & 0,92 & 0,9568 & 11,72 & 12,24916 & 1,02 & 0,98 & 0,9996 & 57,66 & 57,68307 \\
\hline 0,94 & 1,14 & 1,0716 & 27,56 & 25,71855 & 0,98 & 0,96 & 0,9408 & 29,65 & 31,51573 \\
\hline 1,17 & 1,07 & 1,2519 & 35,36 & 28,24507 & 0,95 & 1,01 & 0,9595 & 13,3 & 13,86139 \\
\hline 1,06 & 0,91 & 0,9646 & 25,58 & 26,51876 & 0,95 & 0,95 & 0,9025 & 33,01 & 36,57618 \\
\hline 1,01 & 0,91 & 0,9191 & 10,43 & 11,34806 & 1,04 & 0,99 & 1,0296 & 23,57 & 22,89239 \\
\hline 1,03 & 1,13 & 1,1639 & 26,11 & 22,4332 & 1,08 & 0,97 & 1,0476 & 36,27 & 34,62199 \\
\hline 1,08 & 1,1 & 1,188 & 10,2 & 8,585859 & 1 & 0,98 & 0,98 & 27,29 & 27,84694 \\
\hline 0,89 & 1,08 & 0,9612 & 22,59 & 23,50187 & \multirow{2}{*}{\multicolumn{5}{|c|}{ Média dos palitos $\mathbf{3 1 , 0 6 2 9 5}$}} \\
\hline \multicolumn{5}{|c|}{ Média dos palitos 20,36303} & & & & & \\
\hline \multicolumn{5}{|c|}{ Laser Er,Cr:YSGG 4W e Clearfil SE - dente 5} & \multicolumn{5}{|c|}{ Laser Er,Cr:YSGG 4W e Clearfil SE - dente 6} \\
\hline Lado 1 & Lado 2 & Área & $\mathrm{N}$ & $\mathrm{MPa}$ & Lado 1 & Lado 2 & Área & $\mathrm{N}$ & $\mathrm{MPa}$ \\
\hline 1,16 & 1,14 & 1,3224 & 2,99 & 2,261041 & 0,96 & 1,03 & 0,9888 & 53,66 & 54,2678 \\
\hline 1,13 & 1 & 1,13 & 13,03 & 11,53097 & 1,1 & 0,97 & 1,067 & 34,19 & 32,04311 \\
\hline 1,14 & 0,9 & 1,026 & 33,11 & 32,27096 & 1,09 & 1,01 & 1,1009 & 56,91 & 51,69407 \\
\hline 1,1 & 1,02 & 1,122 & 41,4 & 36,8984 & 1,01 & 0,91 & 0,9191 & 80,91 & 88,03177 \\
\hline 0,89 & 1 & 0,89 & 30,5 & 34,26966 & 0,9 & 1,04 & 0,936 & 44,78 & 47,84188 \\
\hline 1 & 1,14 & 1,14 & 24,4 & 21,40351 & 1,01 & 0,99 & 0,9999 & 18,87 & 18,87189 \\
\hline 1,03 & 1,14 & 1,1742 & 58,98 & 50,22994 & 0,98 & 1,02 & 0,9996 & 24,71 & 24,71989 \\
\hline 1,11 & 1,16 & 1,2876 & 43,1 & 33,47313 & 0,97 & 1,11 & 1,0767 & 38,34 & 35,6088 \\
\hline 1,12 & 1,1 & 1,232 & 54,9 & 44,56169 & 1,05 & 1,04 & 1,092 & 37,85 & 34,66117 \\
\hline \multicolumn{5}{|c|}{ Média dos palitos 29,65548} & \multicolumn{5}{|c|}{ Média dos palitos $\mathbf{4 0 , 1 8 0 8 8}$} \\
\hline \multicolumn{5}{|c|}{ Laser Er,Cr:YSGG 4W e Clearfil S 3 - dente 1} & \multicolumn{5}{|c|}{ Laser Er,Cr:YSGG 4W e Clearfil $\mathrm{S}^{3}$ - dente 2} \\
\hline Lado 1 & Lado 2 & Área & $\mathrm{N}$ & $\mathrm{MPa}$ & Lado 1 & Lado 2 & Área & $\mathrm{N}$ & $\mathrm{MPa}$ \\
\hline 0,93 & 0,88 & 0,8184 & 5,18 & 6,329423 & 0,96 & 1,01 & 0,9696 & 0 & 0 \\
\hline 0,93 & 0,88 & 0,8184 & 5,18 & 9,508427 & 1 & 1,04 & 1,04 & 15,48 & 14,88462 \\
\hline 0,8 & 0,89 & 0,712 & 6,77 & 0,169599 & 0,94 & 1,06 & 0,9964 & 4,57 & 4,586511 \\
\hline 1,18 & 0,99 & 1,0384 & 0 & 0 & 0,98 & 1,06 & 1,0388 & 4,57 & 4,399307 \\
\hline 1,06 & 0,89 & 0,9434 & 0,16 & 14,86184 & 1,08 & 0,94 & 1,0152 & 2,38 & 2,344366 \\
\hline 0,92 & 1,07 & 0,9844 & 14,63 & 7,779791 & 1,05 & 1,08 & 1,134 & 12,52 & 11,04056 \\
\hline 0,92 & 1,08 & 0,9936 & 7,73 & 0 & 0,97 & 0,93 & 0,9021 & 0 & 0 \\
\hline 0,96 & 1,01 & 0,9696 & 0 & 0 & 1,03 & 1,08 & 1,1124 & 2,34 & 2,10356 \\
\hline 1,18 & 0,99 & 1,1682 & 0 & 0,459431 & \multirow{3}{*}{\multicolumn{5}{|c|}{ Média dos palitos 4,919865 }} \\
\hline 1,12 & 1,03 & 1,1536 & 0,53 & 9,508427 & & & & & \\
\hline & & Médi & 1. & 4,345391 & & & & & \\
\hline
\end{tabular}




\begin{tabular}{|c|c|c|c|c|c|c|c|c|c|}
\hline \multicolumn{5}{|c|}{ Laser Er,Cr:YSGG 4W e Clearfil $S^{3}$ - dente 3} & \multicolumn{5}{|c|}{ Laser Er,Cr:YSGG 4W e Clearfil S ${ }^{3}$ - dente 4} \\
\hline Lado 1 & Lado 2 & Área & $\mathrm{N}$ & $\mathrm{MPa}$ & Lado 1 & Lado 2 & Área & $\mathrm{N}$ & $\mathrm{MPa}$ \\
\hline 0,88 & 1 & 0,88 & 6,81 & 7,738636 & 1 & 0,97 & 0,97 & 22,13 & 22,81443 \\
\hline 1,26 & 1 & 1,26 & 22,15 & 17,57937 & 1,15 & 1,02 & 1,173 & 12,56 & 10,70759 \\
\hline 1,15 & 1,1 & 1,265 & 26,95 & 21,30435 & 1,12 & 1,01 & 1,1312 & 0 & 0 \\
\hline 0,92 & 0,97 & 0,8924 & 9,53 & 10,67907 & 0,98 & 0,99 & 0,9702 & 8,65 & 8,915687 \\
\hline 1,02 & 1,04 & 1,0608 & 29,83 & 28,1 & 1,05 & 1 & 1,05 & 35,32 & 381 \\
\hline 1,04 & 0,96 & 0,9984 & 26,77 & 26 & 1,03 & 1,01 & 1,0 & 13,73 & 12 \\
\hline 0,96 & 0,98 & 0,9408 & 34,78 & 36,96854 & 0,97 & 0,96 & 0,9312 & 10,09 & 548 \\
\hline 0,93 & 0,93 & 0,8649 & 14,68 & 16,97306 & 1,03 & 1,18 & 1,2154 & 11,96 & 9,840382 \\
\hline \multicolumn{5}{|c|}{ Média dnc nalitoc $\mathbf{2 0 . 7 7 2 0 3}$} & 1 & 0,94 & 0,94 & 10,87 & 11,56383 \\
\hline \multirow{2}{*}{\multicolumn{5}{|c|}{ Laser Er,Cr:YSGG 4W e Clearfil $\mathrm{S}^{3}$ - dente 5}} & 0,96 & 0,98 & 0,9408 & 3,12 & 3,316327 \\
\hline & & & & & 0,97 & 0,99 & 0,9603 & 6,21 & 6,466729 \\
\hline Lado 1 & Lado 2 & Área & $\mathrm{N}$ & $\mathrm{MPa}$ & \multicolumn{5}{|c|}{ Média doc nalitoc 11.93606 } \\
\hline & & & & & \multirow{2}{*}{\multicolumn{5}{|c|}{ Laser Er,Cr:YSGG 4W e Clearfil S ${ }^{3}$ - dente 6}} \\
\hline 0,99 & 0,99 & 0,9801 & 32,89 & 33,5578 & & & & & \\
\hline 1 & 1,06 & 1,06 & 9,31 & 8,783019 & \multirow[t]{2}{*}{ Lado 1} & \multirow[t]{2}{*}{ Lado 2} & \multirow[t]{2}{*}{ Área } & \multirow[t]{2}{*}{1} & \multirow[t]{2}{*}{$\mathrm{MPa}$} \\
\hline 1,01 & 0,98 & 0,9898 & 27,58 & $27, \varepsilon$ & & & & & \\
\hline 1,1 & 1,1 & 1,21 & 9,18 & 7,586777 & 0,96 & 0,96 & 0,9216 & 40,6 & 44,05382 \\
\hline 1,05 & 0,97 & 1,0185 & 35,18 & 34,54099 & 1,05 & 1,03 & 1,0815 & 64,75 & 59,87055 \\
\hline 1,11 & 0,99 & 1,0989 & 26,23 & 23,86932 & 0,96 & 1,07 & 1,0272 & 17,48 & 17,01713 \\
\hline 1 & 1,01 & 1,01 & 45,44 & 44,9901 & 0,96 & 1,08 & 1,0368 & 17,01 & 16,40625 \\
\hline 1 & 0,98 & 0,98 & 43,65 & 44,54082 & 0,95 & 0,96 & 0,912 & 24,36 & 26,71053 \\
\hline 1 & 1,02 & 1,02 & 43,38 & 42,52941 & 1,07 & 0,97 & 1,0379 & 16,09 & 15,50246 \\
\hline 1 & 1,07 & 1,07 & 0 & 0 & 0,95 & 0,96 & 0,912 & 2,35 & 2,576754 \\
\hline \multicolumn{5}{|c|}{ Média dos palitos $\mathbf{2 6 , 8 2 6 2 5}$} & \multicolumn{5}{|c|}{ Média dos palitos 26,01964} \\
\hline
\end{tabular}


APÊNDICE B - DADOS OBTIDOS COM O TESTE DE MICROTAÇÃO APÓS 90 DIAS

\begin{tabular}{|c|c|c|c|c|c|c|c|c|c|}
\hline \multicolumn{5}{|c|}{ controle e Single Bond-dente 1} & \multicolumn{5}{|c|}{ controle e Single Bond - dente 2} \\
\hline Lado 1 & Lado 2 & Área & $\mathrm{N}$ & $\mathrm{MPa}$ & Lado 1 & Lado 2 & Área & $\mathrm{N}$ & $\mathrm{MPa}$ \\
\hline 1,06 & 1,04 & 1,1024 & 0,15 & 0,136067 & 0,84 & 1,03 & 0,8652 & 34,21 & 39,53999 \\
\hline 1,04 & 0,94 & 0,9776 & 0 & 0 & 1,15 & 1,12 & 1,288 & 22,12 & 17,17391 \\
\hline 0,93 & 1,05 & 0,9765 & 36,72 & 37,60369 & 1,17 & 1,19 & 1,3923 & 66,82 & 47,99253 \\
\hline 1,08 & 0,88 & 0,9504 & 40 & 42,08754 & 1,06 & 1,11 & 1,1766 & 63,41 & 53,89257 \\
\hline 1,18 & 1,07 & 1,2626 & 43,73 & 34,63488 & 1,15 & 1,15 & 1,3225 & 8,72 & 6,593573 \\
\hline 1,12 & 1,01 & 1,1312 & 40,82 & 36,08557 & 1,18 & 1,11 & 1,3098 & 52,08 & 39,7618 \\
\hline 1,05 & 1,09 & 1,1445 & 73,37 & 64,1066 & 0,96 & 1,16 & 1,1136 & 52,08 & 46,76724 \\
\hline 0,89 & 1,07 & 0,9523 & 35,53 & 37,30967 & 0,77 & 1,07 & 0,8239 & 36,71 & 44,55638 \\
\hline 1,07 & 1,08 & 1,1556 & 44,04 & 38,11007 & 0,95 & 0,79 & 0,7505 & 0,15 & 0,199867 \\
\hline \multicolumn{5}{|c|}{ Média dos palitos 32,23045} & \multicolumn{5}{|c|}{ Média dos palitos 32,94198} \\
\hline \multicolumn{5}{|c|}{ controle e Single Bond - dente 3} & \multicolumn{5}{|c|}{ controle e Single Bond - dente 4} \\
\hline Lado 1 & Lado 2 & Área & $\mathrm{N}$ & $\mathrm{MPa}$ & Lado 1 & Lado 2 & Área & $\mathrm{N}$ & $\mathrm{MPa}$ \\
\hline 0,9 & 1,04 & 0,936 & 15,74786 & 15 & 1,08 & 1,08 & 1,1664 & 30,35 & 26,02023 \\
\hline 0,97 & 1,11 & 1,0767 & 28,44804 & 28,44804 & 1,03 & 1,07 & 1,1021 & 17,58 & 15,95137 \\
\hline 0,94 & 0,95 & 0,893 & 45,48712 & 45,48712 & 1,13 & 1,03 & 1,1639 & 26,97 & 23,17209 \\
\hline 0,93 & 1,14 & 1,0602 & 2,4618 & 2,4618 & 1,08 & 1,1 & 1,188 & 28,47 & 23,96465 \\
\hline 0,99 & 1,03 & 1,0197 & 17,38747 & $\frac{17,38747}{1150206}$ & 1,01 & 0,98 & 0,9898 & 33,3 & 33,64316 \\
\hline 1,08 & 0,9 & 0,972 & $\frac{11,50206}{3067507}$ & 1 & 0,01 & 1,03 & 0,0103 & 23,97 & 23,04143 \\
\hline $\begin{array}{r}1,1 \\
0,98\end{array}$ & \begin{tabular}{|l|}
1,01 \\
1,07
\end{tabular} & $\frac{1}{6}$ & & & 1,08 & 1,12 & 1,2096 & 19,79 & 16,36078 \\
\hline 0,94 & 1,03 & 0,9682 & 32,04916 & 32,04916 & 1,28 & 1,05 & 1,344 & 43,05 & 32,03125 \\
\hline 0,97 & 0,95 & 0,9215 & 29,52794 & 29,52794 & 1 & 1,01 & 1,01 & 33,84 & 33,50495 \\
\hline 0,97 & 0,96 & 0,9312 & 46,77835 & 46,77835 & \multirow{2}{*}{\multicolumn{5}{|c|}{ Média dos palitos $\mathbf{2 5 , 2 9 8 8 8}$}} \\
\hline \multicolumn{5}{|c|}{ Média dos palitos 26,60725} & & & & & \\
\hline \multicolumn{5}{|c|}{ controle e Single Bond - dente 5} & \multicolumn{5}{|c|}{ controle e Single Bond - dente 6} \\
\hline Lado 1 & Lado 2 & Área & $\mathrm{N}$ & $\mathrm{MPa}$ & Lado 1 & Lado 2 & Área & $\mathrm{N}$ & $\mathrm{MPa}$ \\
\hline 1,14 & 1,01 & 1,1514 & 57,02 & 49,52232 & 1 & 0,96 & 0,96 & 59,52 & 62 \\
\hline 1,15 & 0,93 & 1,0695 & 35,64 & 33,32398 & 1,21 & 0,97 & 1,1737 & 27,38 & 23,32794 \\
\hline 1,14 & 1 & 1,14 & 27,26 & 23,91228 & 1,03 & 1,05 & 1,0815 & 21,8 & 20,15719 \\
\hline 0,9 & 1,02 & 0,918 & 32,5 & 35,40305 & 1,13 & 0,99 & 1,1187 & 37,38 & 33,41378 \\
\hline 0,92 & 1 & 0,92 & 52,08 & 56,6087 & 1,06 & 1,05 & 1,113 & 3,34 & 3,000898 \\
\hline \multirow{2}{*}{\multicolumn{5}{|c|}{ Média dos palitos 39,75407}} & 1,03 & 1 & 1,03 & 59,95 & 58,20388 \\
\hline & & & & & \multicolumn{5}{|c|}{ Média dos palitos 33,35062} \\
\hline
\end{tabular}




\begin{tabular}{|c|c|c|c|c|}
\hline Lado 1 & Lado 2 & Área & $\mathrm{N}$ & $\mathrm{MPa}$ \\
\hline 0,99 & 0,99 & 0,9801 & 28,12 & 28,69095 \\
\hline 1,03 & 1,13 & 1,1639 & 42,79 & 36,76433 \\
\hline 0,99 & 0,99 & 0,9801 & 15,6 & 15,91674 \\
\hline 1,03 & 1,06 & 1,0918 & 39,83 & 36,48104 \\
\hline 1,04 & 1,03 & 1,0712 & 8,95 & 8,355116 \\
\hline
\end{tabular}

controle e Clearfil SE - dente 3

\begin{tabular}{|r|r|r|r|l|}
\hline Lado 1 & Lado 2 & Área & $\mathrm{N}$ & $\mathrm{MPa}$ \\
\hline 1,04 & 1,01 & 1,0504 & 41,61 & 39,61348 \\
\hline 1,09 & 1,02 & 1,1118 & 12,43 & 11,18007 \\
\hline 1,02 & 0,98 & 0,9996 & 44,31 & 44,32773 \\
\hline 1,04 & 1,08 & 1,1232 & 3,14 & 2,795584 \\
\hline 1,07 & 1 & 1,07 & 40,86 & 38,18692 \\
\hline 0,96 & 1,01 & 0,9696 & 46,82 & 48,28795 \\
\hline 0,99 & 1,06 & 1,0494 & 5,54 & 5,279207 \\
\hline 1,04 & 0,94 & 0,9776 & 23,87 & 24,41694 \\
\hline 1,04 & 0,98 & 1,0192 & 20,28 & 19,89796 \\
\hline 0,97 & 0,95 & 0,9215 & 38,56 & 41,84482 \\
\hline 0,99 & 1,1 & 1,089 & 6,12 & 5,619835 \\
\hline 0,98 & 1,06 & 1,0388 & 28,39 & 27,32961 \\
\hline \multicolumn{5}{|c|}{ Média dos palitos 25,73168 } \\
\hline
\end{tabular}

controle e Clearfil SE - dente 5

\begin{tabular}{|r|r|r|r|l|}
\hline Lado 1 & Lado 2 & \multicolumn{1}{l|}{ Área } & N & $\mathrm{MPa}$ \\
& & & & \\
\hline 1,06 & 0,99 & 1,0494 & 20,43 & 19,46827 \\
\hline 1 & 1,01 & 1,01 & 0,28 & 0,277228 \\
\hline 0,99 & 1,09 & 1,0791 & 29,11 & 26,97618 \\
\hline 0,94 & 1,09 & 1,0246 & 18,71 & 18,26078 \\
\hline 1,05 & 1,06 & 1,113 & 23,77 & 21,35669 \\
\hline 0,95 & 1,04 & 0,988 & 68,25 & $\mathbf{6 9 , 0 7 8 9 5}$ \\
\hline 1,09 & 1,04 & 1,1336 & 4,64 & 4,093155 \\
\hline 0,95 & 1 & 0,95 & 4,28 & 4,505263 \\
\hline 1,04 & 0,99 & 1,0296 & 35,66 & 34,63481 \\
\hline 0,99 & 1,03 & 1,0197 & 9,72 & 9,532215 \\
\hline 0,96 & 0,99 & 0,9504 & 1,9 & 1,999158 \\
\hline \multicolumn{5}{|c}{ Média dos palitos 19,10752 } \\
\hline
\end{tabular}

controle e Clearfil SE - dente 2

\begin{tabular}{|r|r|r|r|l|}
\hline Lado 1 & Lado 2 & \multicolumn{1}{l|}{ Área } & N & MPa \\
\hline 1,02 & 1,01 & 1,0302 & 38,72 & 37,58493 \\
\hline 1,02 & 0,96 & 0,9792 & 22,04 & 22,50817 \\
\hline 1,02 & 1,06 & 1,0812 & 7,82 & 7,232704 \\
\hline 0,95 & 1 & 0,95 & 19,77 & 20,81053 \\
\hline 1,1 & 0,96 & 1,056 & 1,3 & 1,231061 \\
\hline 1,11 & 1,03 & 1,1433 & 6,39 & 5,589084 \\
\hline 1,03 & 1,02 & 1,0506 & 18,98 & 18,06587 \\
\hline 1,02 & 1 & 1,02 & 17,54 & 17,19608 \\
\hline 1,01 & 0,99 & 0,9999 & 7,86 & 7,860786 \\
\hline 1,02 & 1,04 & 1,0608 & 2,79 & 2,63009 \\
\hline 1,01 & 1,07 & 1,0807 & 24,78 & 22,92958 \\
\hline 0,95 & 0,95 & 0,9025 & 32,56 & 36,07756 \\
\hline \multicolumn{5}{|c|}{ Média dos palitos 16,64304} \\
\hline controle e Clearfil SE - dente 4 \\
\hline Lado 1 & Lado 2 & Área & $\mathrm{N}$ & $\mathrm{MPa}$ \\
\hline \multicolumn{5}{|c|}{} \\
\hline 0,99 & 0,99 & 0,9801 & 56,05 & 57,18804 \\
\hline 0,99 & 1,05 & 1,0395 & 12,85 & 12,36171 \\
\hline 1,08 & 1,03 & 1,1124 & 38,25 & 34,38511 \\
\hline 1,02 & 1,06 & 1,0812 & 22,32 & 20,64373 \\
\hline 0,85 & 1 & 0,85 & 1,75 & 2,058824 \\
\hline 0,95 & 1,06 & 1,007 & 1,97 & 1,956306 \\
\hline 1 & 0,97 & 0,97 & 11,88 & 12,24742 \\
\hline 1,01 & 1 & 1,01 & 7,9 & 7,821782 \\
\hline 0,96 & 1 & 0,96 & 25,06 & 26,10417 \\
\hline 0,99 & 1,02 & 1,0098 & 5,19 & 5,139632 \\
\hline \multicolumn{5}{|c|}{ Média dos palitos 17,99067} \\
\hline
\end{tabular}

controle e Clearfil SE - dente 6

\begin{tabular}{|r|r|r|r|r|}
\hline Lado 1 & Lado 2 & Área & $\mathrm{N}$ & $\mathrm{MPa}$ \\
\hline 1 & 1,03 & 1,03 & 0 & 0 \\
\hline 1,03 & 0,96 & 0,9888 & 0 & 0 \\
\hline 1,05 & 0,96 & 1,008 & 0 & 0 \\
\hline 0,97 & 1,04 & 1,0088 & 0,42 & 0,416336 \\
\hline 0,94 & 1,04 & 0,9776 & 0 & 0 \\
\hline 0,93 & 0,97 & 0,9021 & 1,5 & 1,662787 \\
\hline 1,05 & 1,05 & 1,1025 & 0,73 & 0,662132 \\
\hline \multicolumn{7}{|c|}{ Média dos palitos $\mathbf{0 , 3 9 1 6 0 8}$} \\
\hline
\end{tabular}




\begin{tabular}{|c|c|c|c|c|c|c|c|c|c|}
\hline \multicolumn{5}{|c|}{ controle e Clearfil $S^{3}$ - dente 1} & \multicolumn{5}{|c|}{ controle e Clearfil $\mathrm{S}^{3}$ - dente 2} \\
\hline Lado 1 & Lado 2 & Área & $\mathrm{N}$ & $\mathrm{MPa}$ & Lado 1 & Lado 2 & Área & $\mathrm{N}$ & $\mathrm{MPa}$ \\
\hline 0,83 & 1,07 & 0,8881 & 37,5 & 42,22497 & 0,97 & 1,02 & 0,9894 & 31,96 & 32,30241 \\
\hline 0,93 & 0,87 & 0,8091 & 21,14 & 26,1278 & 1,02 & 0,98 & 0,9996 & 32,31 & 32,32293 \\
\hline 0,96 & 1,06 & 1,0176 & 23,77 & 23,35888 & 0,95 & 0,98 & 0,931 & 64,48 & 69,25886 \\
\hline 0,95 & 1,23 & 1,1685 & 42,76 & 36,59392 & 0,94 & 0,98 & 0,9212 & 23,93 & 25,97699 \\
\hline 1,07 & 0,88 & 0,9416 & 11,81 & 12,54248 & 0,96 & 0,97 & 0,9312 & 12,24 & 13,14433 \\
\hline 1 & 0,96 & 0,96 & 43,93 & 45,76042 & 1,01 & 1,03 & 1,0403 & 40,78 & 39,20023 \\
\hline \multicolumn{5}{|c|}{ Média dos palitos $\mathbf{3 1 , 1 0 1 4 1}$} & 0,97 & 1,01 & 0,9797 & 50,23 & 51,2708 \\
\hline \multicolumn{5}{|c|}{ controle e Clearfil $S^{3}$ - dente 3} & \multicolumn{5}{|c|}{ Média dos palitos 37,63951 } \\
\hline Lado 1 & Lado 2 & Área & $\mathrm{N}$ & $\mathrm{MPa}$ & \multicolumn{5}{|c|}{ controle e Clearfil S $S^{3}$ - dente 4} \\
\hline 0,98 & 0,93 & 0,9114 & 50,85 & 55,79329 & \multirow{2}{*}{ Lado 1} & \multirow{2}{*}{ Lado 2} & \multirow{2}{*}{ Área } & \multirow{2}{*}{$\mathrm{N}$} & \multirow{2}{*}{$\mathrm{MPa}$} \\
\hline 1,03 & 0,96 & 0,9888 & 43,6 & 44,09385 & & & & & \\
\hline 1,03 & 0,95 & 0,9785 & 34,77 & 35,53398 & 1 & 0,99 & 0,99 & 34,51 & 34,85859 \\
\hline \multicolumn{5}{|c|}{ Média dos palitos 45,14037} & 1,04 & 1,2 & 1,248 & 58,23 & 46,65865 \\
\hline \multicolumn{5}{|c|}{ controle e Clearfil $S^{3}$ - dente 5} & \multicolumn{5}{|c|}{ Média dos palitos 40,75862} \\
\hline Lado 1 & Lado 2 & Área & $\mathrm{N}$ & $\mathrm{MPa}$ & \multicolumn{5}{|c|}{ controle e Clearfil S $S^{3}$ - dente 6} \\
\hline 0,98 & 0,93 & 0,9114 & 37,42 & 41,05771 & \multirow[t]{2}{*}{ Lado 1} & \multirow[t]{2}{*}{ Lado 2} & \multirow[t]{2}{*}{ Área } & \multirow[t]{2}{*}{$\mathrm{N}$} & \multirow[t]{2}{*}{$\mathrm{MPa}$} \\
\hline 1,09 & 0,99 & 1,0791 & 35,3 & 32,71245 & & & & & \\
\hline 0,99 & 0,97 & 0,9603 & 34,59 & 36,01999 & 0,88 & 0,96 & 0,8448 & 17,09 & 20,22964 \\
\hline 0,98 & 0,95 & 0,931 & 19,65 & 21,10634 & 0,91 & 0,95 & 0,8645 & 48,46 & 56,05552 \\
\hline 0,97 & 0,94 & 0,9118 & 40,93 & 44,88923 & 1,02 & 1,07 & 1,0914 & 57,21 & 52,41891 \\
\hline 1,05 & 0,96 & 1,008 & 22,08 & 21,90476 & 0,89 & 1,12 & 0,9968 & 14,55 & 14,59671 \\
\hline 0,94 & 1,04 & 0,9776 & 4,96 & 5,07365 & 0,89 & 0,94 & 0,8366 & 36,9 & 44,1071 \\
\hline \multicolumn{5}{|c|}{ Média dos palitos 28,9663} & 0,97 & 0,91 & 0,8827 & 19,54 & 22,13663 \\
\hline \multirow{2}{*}{\multicolumn{5}{|c|}{ Laser Er,Cr:YSGG 2W e Single Bond - dente 1}} & 0,96 & 1,03 & 0,9888 & 2,75 & 2,781149 \\
\hline & & & & & \multicolumn{5}{|c|}{ Média dos palitos 30,33224} \\
\hline Lado 1 & Lado 2 & Área & $\mathrm{N}$ & $\mathrm{MPa}$ & \multicolumn{5}{|c|}{ Laser Er,Cr:YSGG 2W e Single Bond - dente 2} \\
\hline 0,91 & 0,8 & 0,728 & 6,3 & 8,653846 & \multirow[t]{2}{*}{ Lado 1} & \multirow[t]{2}{*}{ Lado 2} & \multirow[t]{2}{*}{ Área } & $\mathrm{N}$ & $\mathrm{MPa}$ \\
\hline 1 & 0,99 & 0,99 & 31,87 & 32,19192 & & & & & \\
\hline 0,94 & 0,99 & 0,9306 & 13,49 & 14,49602 & 0,99 & 0,87 & 0,8613 & 1,15 & 1,335191 \\
\hline 1 & 1,08 & 1,08 & 33,14 & 30,68519 & 1,05 & 1,25 & 1,3125 & 0 & 0 \\
\hline 0,99 & 1,04 & 1,0296 & 14,08 & 13,67521 & 1,18 & 1 & 1,18 & 19,25 & 16,31356 \\
\hline 0,98 & 1,04 & 1,0192 & 6,14 & 6,024333 & & & Média & dos palito & s 5,882917 \\
\hline & & Média & os palitc & s 17,62109 & & & & & \\
\hline
\end{tabular}




\begin{tabular}{|c|c|c|c|c|c|c|c|c|c|}
\hline \multicolumn{5}{|c|}{ Laser Er,Cr:YSGG 2W e Single Bond - dente 3} & \multicolumn{5}{|c|}{ Laser Er,Cr:YSGG 2W e Single Bond - dente 4} \\
\hline Lado 1 & Lado 2 & Área & $\mathrm{N}$ & $\mathrm{MPa}$ & Lado 1 & Lado 2 & Área & $\mathrm{N}$ & $\mathrm{MPa}$ \\
\hline 1,08 & 0,97 & 1,0476 & 20,09 & 19,17717 & 1,11 & 1,09 & 1,2099 & 13,12 & 10,84387 \\
\hline 1,09 & 1,07 & 1,1663 & 9,69 & 8,308325 & 1,04 & 1,2 & 1,248 & 34,16 & 27,37179 \\
\hline 0,93 & 1,04 & 0,9672 & 0 & 0 & 1,05 & 0,93 & 0,9765 & 32,1 & 32,8725 \\
\hline 0,92 & 1,07 & 0,9844 & 4,19 & 4,2564 & 0,85 & 1,06 & 0,901 & 21,32 & 23,6626 \\
\hline 1,11 & 1,09 & 1,2099 & 13,39 & 11,06703 & 0,98 & 0,93 & 0,9114 & 10,94 & 12,00351 \\
\hline \multirow{2}{*}{\multicolumn{5}{|c|}{ Média dos palitos $\mathbf{8 , 5 6 1 7 8 5}$}} & \multicolumn{5}{|c|}{ Média dos palitos $\mathbf{2 1 . 3 5 0 8 6}$} \\
\hline & & & & & \multirow{2}{*}{\multicolumn{5}{|c|}{ Laser Er,Cr:YSGG 2W e Single Bond - dente 6}} \\
\hline \multicolumn{5}{|c|}{ Laser Er,Cr:YSGG 2W e Single Bond - dente 5} & & & & & \\
\hline Lado 1 & Lado 2 & Área & $\mathrm{N}$ & $\mathrm{MPa}$ & & & & & \\
\hline & & & & & 1,06 & 0,94 & 0,9964 & 0 & 0 \\
\hline 0,95 & 0,93 & 0,8835 & 28,71 & 32,49576 & 0,96 & 0,96 & 0,9216 & 3,42 & 3,710938 \\
\hline 1,03 & 0,99 & 1,0197 & 16,62 & 16,29891 & 0,96 & 0,96 & 0,9216 & 9,11 & 9,884983 \\
\hline 1,02 & 1,02 & 1,0404 & 4,97 & 4,777009 & 0,99 & 0,95 & 0,9 & 19,36 & 348 \\
\hline 1,09 & 0,99 & 1,0791 & 15,31 & & 0,96 & 0,96 & 0,9216 & 0,56 & 0,607639 \\
\hline 0,96 & 1,01 & 0,9696 & 15,9 & 16,39851 & \multicolumn{5}{|c|}{ Média dos palitos 6,957671} \\
\hline \multicolumn{5}{|c|}{ Média dos palitos $\mathbf{1 6 , 8 3 1 5 9}$} & \multicolumn{5}{|c|}{ Laser Er,Cr:YSGG 2W e Clearfil SE - dente 2} \\
\hline \multicolumn{5}{|c|}{ Laser Er,Cr:YSGG $2 \mathrm{~W}$ e Clearfil SE - dente 1} & Lado 1 & Lado 2 & Área & $\mathrm{N}$ & $\mathrm{MPa}$ \\
\hline Lado 1 & Lado 2 & Área & $\mathrm{N}$ & $\mathrm{MF}$ & 0,98 & 1,06 & 1,0388 & 0 & 0 \\
\hline & & & & & 1,04 & 0,95 & 0,988 & 10,24 & 10,36437 \\
\hline 0,96 & 1,02 & 0 & 59 & & 0,99 & 1,05 & 1,0395 & 8,71 & 8,379028 \\
\hline 0,95 & 0,91 & 0,8645 & 37,06 & 42, & 1,03 & 0,98 & 1,0094 & 10,12 & 10,02576 \\
\hline 1,06 & 1,05 & 1,113 & 46,19 & 41,50045 & 1,04 & 0,99 & 1,0296 & 0,99 & 0,961538 \\
\hline 1,12 & 1,02 & 1,1424 & 1,87 & 1,63 & 0,95 & 0,88 & 0,836 & 10,93 & 13,07416 \\
\hline 1,11 & 0,96 & 1,0656 & 8,12 & & 1,09 & 0,95 & 1,0355 & 0,34 & 0,328344 \\
\hline 0,93 & 1,04 & 0,9672 & 5,23 & 5,407361 & 0,95 & 1,09 & 1,0355 & 0,59 & 0,569773 \\
\hline \multirow{2}{*}{\multicolumn{5}{|c|}{ Média dos palitos 17,64428}} & 1,03 & 1,01 & 1,0403 & 1,24 & 1,191964 \\
\hline & & & & & 0,97 & 0,88 & 0,8536 & 0,76 & 0,89035 \\
\hline \multicolumn{5}{|c|}{ Laser Er,Cr:YSGG 2W e Clearfil SE - dente 3} & \multicolumn{5}{|c|}{ Média dos palitos $\mathbf{4 , 5 7 8 5 2 9}$} \\
\hline Lado 1 & Lado 2 & Área & $\mathrm{N}$ & $\mathrm{MPa}$ & \multicolumn{5}{|c|}{ Laser Er,Cr:YSGG 2W e Clearfil SE - dente 4} \\
\hline 0,95 & 0,91 & 0,8645 & 7,94 & 9,1845 & \multirow[t]{2}{*}{ Lado 1} & \multirow[t]{2}{*}{ Lado 2} & \multirow[t]{2}{*}{ Área } & \multirow[t]{2}{*}{$\mathrm{N}$} & \multirow[t]{2}{*}{$\mathrm{MPa}$} \\
\hline 0,94 & 0,97 & 0,9118 & 0,6 & 0,658039 & & & & & \\
\hline 1,02 & 1,05 & 1,071 & 41,61 & 38,85154 & 1,04 & 1,02 & 1,0608 & 0 & 0 \\
\hline 0,94 & 1,03 & 0,9682 & 23,96 & 24,74695 & 1,09 & 1,08 & 1,1772 & 11,66 & 9,904859 \\
\hline 1,07 & 0,99 & 1,0593 & 35,5 & 33,5127 & 1,13 & 0,96 & 1,0848 & 0,6 & 0,553097 \\
\hline 0,99 & 0,97 & 0,9603 & 8,27 & 8,611892 & 1,14 & 1,03 & 1,1742 & 0 & 0 \\
\hline 1,03 & 1,07 & 1,1021 & 21,07 & 19,11805 & 1,03 & 1,03 & 1,0609 & 0,63 & 0,59384 \\
\hline \multirow{2}{*}{\multicolumn{5}{|c|}{ Média dos palitos 19,24052}} & 1,01 & 0,96 & 0,9696 & 0 & \\
\hline & & & & & \multicolumn{5}{|c|}{ Média dos palitos $\mathbf{1 , 8 4 1 9 6 5}$} \\
\hline
\end{tabular}




\begin{tabular}{|c|c|c|c|c|}
\hline \multicolumn{5}{|c|}{ Laser Er,Cr:YSGG 2W e Clearfil SE - dente 5} \\
\hline Lado 1 & Lado 2 & Área & $\mathrm{N}$ & $\mathrm{MPa}$ \\
\hline 0,98 & 1,08 & 1,0584 & 10,16 & 9,599395 \\
\hline 1,07 & 0,95 & 1,0165 & 1,22 & 1,200197 \\
\hline 1,25 & 0,93 & 1,1625 & 21,14 & 18,18495 \\
\hline 1,03 & 0,98 & 1,0094 & 0,75 & 0,743016 \\
\hline 1,27 & 0,96 & 1,2192 & 10,24 & 8,39895 \\
\hline \multicolumn{5}{|c|}{ Média dos palitos 7,625301 } \\
\hline \multicolumn{5}{|c|}{ Laser Er,Cr:YSGG 2W e Clearfil S ${ }^{3}$ - dente 1} \\
\hline Lado 1 & Lado 2 & Área & $\mathrm{N}$ & $\mathrm{MPa}$ \\
\hline 1,03 & 0,9 & 0,927 & 1,59 & 1,71521 \\
\hline 0,99 & 0,88 & 1,1655 & 8,13 & 9,331956 \\
\hline 1,03 & 0,9 & 0,927 & 4,89 & 5,275081 \\
\hline 0,99 & 1,13 & 1,1187 & 1,15 & 1,027979 \\
\hline 1,1 & 1,08 & 1,188 & 41,58 & 35 \\
\hline 0,98 & 1,09 & 1,0682 & 0,88 & 0,823816 \\
\hline 1,03 & 0,93 & 0,9579 & 0 & 0 \\
\hline
\end{tabular}

Laser Er,Cr:YSGG 2W e Clearfil SE - dente 6

\begin{tabular}{|r|r|r|r|l|}
\hline Lado 1 & Lado 2 & Área & $\mathrm{N}$ & $\mathrm{MPa}$ \\
\hline 0,97 & 1,1 & 1,067 & 23,25 & 21,79007 \\
\hline 1,04 & 0,88 & 0,9152 & 22,85 & 24,96722 \\
\hline 1,04 & 1,03 & 1,0712 & 22,34 & 20,85512 \\
\hline 1,1 & 1 & 1,1 & 10,9 & 9,909091 \\
\hline 1,05 & 1,11 & 1,1655 & 15,22 & 13,05877 \\
\hline \multicolumn{5}{|c|}{ Média dos palitos 18,11605 } \\
\hline \multicolumn{5}{c}{} \\
\hline
\end{tabular}

Laser Er,Cr:YSGG 2W e Clearfil $\mathrm{S}^{3}-$ dente 2

\begin{tabular}{|r|r|r|r|l|}
\hline Lado 1 & Lado 2 & Área & \multicolumn{1}{l|}{$\mathrm{M}$} & $\mathrm{MPa}$ \\
\hline 0,95 & 1,02 & 0,969 & 16,19 & 16,70795 \\
\hline 0,98 & 1,03 & 1,0094 & 12,3 & 12,18546 \\
\hline 1,08 & 0,9 & 0,972 & 18,2 & 18,72428 \\
\hline 0,99 & 0,89 & 0,8811 & 55,28 & 62,73976 \\
\hline 1,05 & 1,03 & 1,0815 & 6,91 & 6,389274 \\
\hline 1,03 & 0,99 & 1,0197 & 14,12 & 13,84721 \\
\hline 1,02 & 0,93 & 0,9486 & 14,39 & 15,16972 \\
\hline \multicolumn{5}{|c}{ Média dos palitos 20,82338 } \\
\hline
\end{tabular}

Laser Er,Cr:YSGG $2 \mathrm{~W}$ e Clearfil $\mathrm{S}^{3}$ - dente 3

\begin{tabular}{|r|r|r|r|r|}
\hline Lado 1 & Lado 2 & Área & $\mathrm{N}$ & \multicolumn{1}{l|}{$\mathrm{MPa}$} \\
\hline 0,92 & 0,99 & 0,9108 & 0 & 0 \\
\hline 1,08 & 0,92 & 0,9936 & 6,63 & 6,672705 \\
\hline 0,91 & 0,99 & 0,9009 & 0,32 & 0,3552 \\
\hline 0,97 & 1,13 & 1,0961 & 21,18 & 19,32305 \\
\hline 0,92 & 0,99 & 0,9108 & 4,57 & 5,017567 \\
\hline 0,91 & 0,91 & 0,8281 & 31,4 & 37,91813 \\
\hline 0,91 & 0,91 & 0,8281 & 0 & 0 \\
\hline 0,97 & 1,09 & 1,0573 & 0 & 0 \\
\hline 1,09 & 0,99 & 1,0791 & 20,75 & 19,22899 \\
\hline \multicolumn{5}{|c|}{ Média dos palitos 9,835071 } \\
\hline
\end{tabular}

Laser Er,Cr:YSGG 4W e Single Bond - dente 1

\begin{tabular}{|r|r|r|r|l|}
\hline Lado 1 & Lado 2 & Área & N & MPa \\
\hline 1,05 & 1 & 1,05 & 22,33 & 21,26667 \\
\hline 1,04 & 1 & 1,04 & 26,82 & 25,78846 \\
\hline 0,96 & 0,95 & 0,912 & 8,19 & 8,980263 \\
\hline 0,96 & 0,92 & 0,8832 & 27,01 & 30,58197 \\
\hline 0,94 & 1,05 & 0,987 & 0,14 & 0,141844 \\
\hline \multicolumn{7}{|c|}{ Média dos palitos 17,35184 } \\
\hline
\end{tabular}

Laser Er,Cr:YSGG 2W e Clearfil S 3 - dente 4

\begin{tabular}{|r|r|r|r|r|}
\hline \multicolumn{1}{|l|}{ Lado 1 } & \multicolumn{1}{|l|}{ Lado 2 } & Área & $\mathrm{N}$ & $\mathrm{MPa}$ \\
\hline 0,97 & 0,95 & 0,9215 & 0 & 0 \\
\hline 0,99 & 0,94 & 0,9306 & 0 & 0 \\
\hline 1,09 & 0,98 & 1,0682 & 0 & 0 \\
\hline 0,98 & 1 & 0,98 & 0 & 0 \\
\hline \multicolumn{5}{|c|}{ Média dos palitos 0 } \\
\hline
\end{tabular}

Laser Er,Cr:YSGG 2W e Clearfil $S^{3}-$ dente 6

\begin{tabular}{|r|r|r|r|r||}
\hline Lado 1 & Lado 2 & Área & N & MPa \\
\hline 1,03 & 1,01 & 1,0403 & 29,34 & 28,2034 \\
\hline 1 & 0,89 & 0,89 & 3,79 & 4,258427 \\
\hline 0,89 & 1 & 0,89 & 24,34 & 27,34831 \\
\hline 1,15 & 0,91 & 1,0465 & 14,01 & 13,38748 \\
\hline 0,91 & 1,03 & 0,9373 & 17,85 & 19,04406 \\
\hline \multicolumn{5}{|c|}{ Média dos palitos 18,44834 } \\
\hline
\end{tabular}




\begin{tabular}{|c|c|c|c|c|c|c|c|c|c|}
\hline \multicolumn{5}{|c|}{ Laser Er,Cr:YSGG 4W e Single Bond - dente 3} & \multicolumn{5}{|c|}{ Laser Er,Cr:YSGG 4W e Single Bond - dente 2} \\
\hline Lado 1 & Lado 2 & Área & $\mathrm{N}$ & $\mathrm{MPa}$ & Lado 1 & Lado 2 & Área & $\mathrm{N}$ & $\mathrm{MPa}$ \\
\hline 0,91 & 0,97 & 0,8827 & 22,1 & 25,03682 & 0,92 & 0,92 & 0,8464 & 11,83 & 13,97684 \\
\hline 0,9 & 1,05 & 0,945 & 0 & 0 & 0,99 & 0,98 & 0,9702 & 15,36 & 15,83179 \\
\hline 0,93 & 1,05 & 0,9765 & 3,74 & 3,830005 & 1,06 & 0,97 & 1,0282 & 27,18 & 26,43455 \\
\hline 1,03 & 1,25 & 1,2875 & 0 & 0 & 0,99 & 0,98 & 0,9702 & 0 & 0 \\
\hline 0,91 & 0,97 & 0,8924 & 22,1 & 25,03682 & 1,06 & 1,06 & 1,1236 & 0 & 0 \\
\hline \multicolumn{5}{|c|}{ Média dos palitos 7,216706 } & \multicolumn{5}{|c|}{ Média dos palitos $\mathbf{1 1 , 2 4 8 6 4}$} \\
\hline \multicolumn{5}{|c|}{ Laser Er,Cr:YSGG 4W e Single Bond - dente 5} & \multicolumn{5}{|c|}{ Laser Er,Cr:YSGG 4W e Single Bond - dente 6} \\
\hline Lado 1 & Lado 2 & Área & $\mathrm{N}$ & $\mathrm{MPa}$ & Lado 1 & Lado 2 & Área & $\mathrm{N}$ & $\mathrm{MPa}$ \\
\hline 0,9 & 0,97 & 0,873 & 31 & 35 , & 0,95 & 1,1 & 1,045 & 8,18 & 7751 \\
\hline 0,9 & 0,88 & 0,792 & 27,44 & 34,64646 & 1 & 0,93 & 0,93 & 41,1 & 44,19355 \\
\hline 1,04 & 1,15 & 1,196 & 8,51 & 7,115385 & 1,08 & 1,02 & 1,1016 & 18,51 & 283 \\
\hline \multicolumn{5}{|c|}{ Média dos palitos $\mathbf{2 5 , 7 5 7 2}$} & 1,04 & 1,03 & 1,0712 & 12,16 & 11,35176 \\
\hline \multicolumn{5}{|c|}{ Laser Er,Cr:YSGG 4W e Clearfil SE - dente 1} & \multicolumn{5}{|c|}{ Média dos palitos 20,04397 } \\
\hline Lado 1 & Lado 2 & Área & $\mathrm{N}$ & $\mathrm{MPa}$ & \multicolumn{5}{|c|}{ Laser Er,Cr:YSGG 4W e Clearfil SE - dente 2} \\
\hline & & & & & Lado 1 & Lado 2 & Área & $\mathrm{N}$ & $\mathrm{MPa}$ \\
\hline 1,06 & 1,02 & 1,0812 & 0,21 & 0,194229 & & & & & \\
\hline 0,94 & 0,97 & 0,9118 & 0 & 0 & 1,05 & 0,93 & 0,9765 & 11,24 & 11,5105 \\
\hline 0,97 & 1,06 & 1,0282 & 1,88 & 1,828438 & 0,94 & 0,96 & 0,9024 & 33,72 & 37,36702 \\
\hline 1,07 & 0,94 & 1,0058 & 3,51 & 3,489759 & 1 & 0,95 & 0,95 & 3 & 3,157895 \\
\hline 0,96 & 0,93 & 0,8928 & 10,44 & 11,69355 & 0,91 & 0,93 & 0,8463 & 2,1 & 2,48139 \\
\hline \multicolumn{5}{|c|}{ Média dos palitos $\mathbf{3 , 4 4 1 1 9 5}$} & \multicolumn{5}{|c|}{ Média dos palitos 13,6292} \\
\hline \multicolumn{5}{|c|}{ Laser Er,Cr:YSGG 4W e Clearfil SE - dente 3} & \multicolumn{5}{|c|}{ Laser Er,Cr:YSGG 4W e Clearfil SE - dente 4} \\
\hline Lado 1 & Lado 2 & Área & $\mathrm{N}$ & $\mathrm{MPa}$ & Lado 1 & Lado 2 & Área & $\mathrm{N}$ & $\mathrm{MPa}$ \\
\hline 0,89 & 0,86 & 0,7654 & 5,91 & 7,721453 & 0,97 & 1,06 & 1,0282 & 8,03 & 7,809765 \\
\hline 0,87 & 0,96 & 0,8352 & 11,08 & 13,26628 & 0,94 & 0,95 & 0,893 & 8,03 & 8,992161 \\
\hline 1,08 & 0,89 & 0,9612 & 14,04 & 14,60674 & 0,91 & 0,99 & 0,9009 & 17,43 & 19,34732 \\
\hline 1,06 & 1,13 & 1,1978 & 27,36 & 22,84188 & 0,97 & 0,98 & 0,9506 & 13,41 & 14,10688 \\
\hline 1,02 & 0,99 & 1,0098 & 18,93 & 18,74629 & 1,04 & 0,97 & 1,0088 & 29,95 & 29,68874 \\
\hline \multicolumn{5}{|c|}{ Média dos palitos $\mathbf{1 5 , 4 3 6 5 3}$} & \multicolumn{5}{|c|}{ Média dos palitos $\mathbf{1 5 , 9 8 8 9 7}$} \\
\hline
\end{tabular}




\begin{tabular}{|c|c|c|c|c|c|c|c|c|c|}
\hline \multicolumn{5}{|c|}{ Laser Er,Cr:YSGG 4W e Clearfil SE - dente 5} & \multicolumn{5}{|c|}{ Laser Er,Cr:YSGG 4W e Clearfil $\mathrm{S}^{3}$ - dente 2} \\
\hline Lado 1 & Lado 2 & Área & $\mathrm{N}$ & $\mathrm{MPa}$ & Lado 1 & Lado 2 & Área & $\mathrm{N}$ & $\mathrm{MPa}$ \\
\hline 0,93 & 0,99 & 0,9207 & 0 & 0 & 0,91 & 0,96 & 0,8736 & 22,93 & 26,24771 \\
\hline 0,96 & 0,92 & 0,8832 & 20,77 & 23,51676 & 0,98 & 0,96 & 0,9408 & 11,11 & 11,8091 \\
\hline 0,97 & 0,91 & 0,8827 & 41,26 & 46,74295 & 0,96 & 0,98 & 0,9408 & 0,34 & 0,361395 \\
\hline 0,99 & 0,97 & 0,9603 & 20,72 & 21,57659 & 0,9 & 0,96 & 0,864 & 0 & 0 \\
\hline \multirow[t]{2}{*}{1,05} & 0,97 & 1,0185 & 28,58 & 28,06087 & 1,02 & 0,93 & 0,9486 & 19,99 & 21,07316 \\
\hline & \multicolumn{4}{|c|}{ Média dos palitos 23,97943} & \multicolumn{5}{|c|}{ Média dos palitos $\mathbf{1 1 , 8 9 8 2 7}$} \\
\hline \multicolumn{5}{|c|}{ Laser Er,Cr:YSGG 4W e Clearfil $S^{3}$ - dente 1} & \multicolumn{5}{|c|}{ Laser Er,Cr:YSGG 4W e Clearfil $S^{3}$ - dente 4} \\
\hline Lado 1 & Lado 2 & Área & $\mathrm{N}$ & $\mathrm{MPa}$ & Lado 1 & Lado 2 & Área & $\mathrm{N}$ & $\mathrm{MPa}$ \\
\hline 1,06 & 1,01 & 1,0706 & 1,99 & 1,858771 & 0,96 & 0,99 & 0,9504 & 4,99 & 5,250421 \\
\hline 0,97 & 1,1 & 1,067 & 4,75 & 4,451734 & 0,96 & 0,94 & 0,9024 & 11,1 & 12,30053 \\
\hline 0,91 & 1,16 & 1,0556 & 0 & 0 & 1,01 & 0,99 & 0,9999 & 14,53 & 14,53145 \\
\hline 0,89 & 1,04 & 0,9256 & 0,4 & 0,432152 & 0,96 & 1 & 0,96 & 4,02 & 4,1875 \\
\hline \multirow[t]{2}{*}{1,04} & 0,95 & 0,988 & 0,42 & 0,425101 & \multicolumn{5}{|c|}{ Média dos palitos 9,067476} \\
\hline & \multicolumn{4}{|c|}{ Média dos palitos 1,433552 } & \multirow{2}{*}{\multicolumn{5}{|c|}{ Laser Er,Cr:YSGG 4W e Clearfil S ${ }^{3}$ - dente 6}} \\
\hline \multirow{2}{*}{\multicolumn{5}{|c|}{ Laser Er,Cr:YSGG 4W e Clearfil $\mathrm{S}^{3}$ - dente 3}} & & & & & \\
\hline & & & & & Lado 1 & Lado 2 & Área & $\mathrm{N}$ & $\mathrm{MPa}$ \\
\hline Lado 1 & Lado 2 & Área & $\mathrm{N}$ & $\mathrm{MPa}$ & 1,01 & 0,93 & 0,9393 & 10,74 & 11,43405 \\
\hline 0,96 & 0,96 & 0,9216 & 1 & 1,085069 & 0,96 & 0,97 & 0,9312 & 23,99 & 25,76246 \\
\hline 0,94 & 1 & 0,94 & 0,57 & 0,606383 & 1,02 & 0,94 & 0,9588 & 16,21 & 16,90655 \\
\hline 0,98 & 0,96 & 0,9408 & 17,05 & 18,12287 & \multicolumn{5}{|c|}{ Média dos palitos 18,03435} \\
\hline 0,93 & 0,98 & 0,9114 & 14,1 & 15,4707 & & & & & \\
\hline 0,97 & 1,03 & 0,9991 & 1,62 & 1,621459 & & & & & \\
\hline \multicolumn{5}{|c|}{ Média dos palitos 7,381298 } & & & & & \\
\hline \multicolumn{5}{|c|}{ Laser Er,Cr:YSGG 4 W e Clearfil $\mathrm{S}^{3}$ - dente 5} & & & & & \\
\hline Lado 1 & Lado 2 & Área & $\mathrm{N}$ & $\mathrm{MPa}$ & & & & & \\
\hline 1,03 & 0,98 & 1,0094 & 7,97 & 7,89578 & & & & & \\
\hline 0,94 & 1,04 & 0,9776 & 3,97 & 4,060966 & & & & & \\
\hline 0,98 & 0,97 & 0,9506 & 15,23 & 16,02146 & & & & & \\
\hline 0,96 & 0,98 & 0,9408 & 7,3 & 7,759354 & & & & & \\
\hline 1,05 & 0,97 & 1,0185 & 7,69 & 7,550319 & & & & & \\
\hline \multicolumn{5}{|c|}{ Média dos palitos 8,657576} & & & & & \\
\hline
\end{tabular}


Anexo - Parecer do Comitê de Ética em Pesquisa 


\author{
Universidade de Sāo Paulo \\ Faculdade de Odontologia \\ Comitê de Ética em Pesquisa
}

\title{
PARECER DE APROVAÇĀO \\ FR 234107 \\ Protocolo 233/2008
}

O grupo de trabalho indicado pelo Comitẽ de Ética em Pesquisa APROVOU o protocolo de pesquisa "Avaliaçāo longitudinal da adesão de dentina irradiada pelo laser de Er; Cr: YSGG", de responsabilidade do(a) Pesquisador(a) Juliana Elston Goldman, sob orientação do(a) do(a) Prof.(a) Dr.(a.) Ana Cecilia Comêa Aranha.

Tendo em vista a legislação vigente, devem ser encaminhados a este Comitê relatórios anuais referentes ao andamento da pesquisa e ao término cópia do trabalho em "cd". Qualquer emenda do projeto original deve ser apresentada a este CEP para apreciaçăo, de forma clara e sucinta, identificando a parte do protocolo a ser modificada e suas justificativas.

São Paulo, 02 de julho de 2009.

Prof. Dr. Joâo Gualberto de Cerqueira Lúz

Coordenador do CEP-FOUSP 